المهارات الحياتية وعلاقتها بصراع الأدوار فى الأسرة لدى عينة من الزوجات العاملات

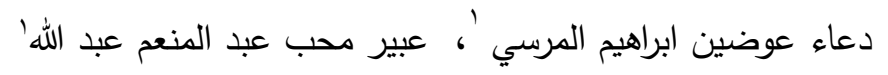

الوقت وتحمل المسئولية والإجمالى ) لصالح المستوى التعليمى

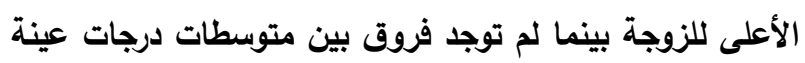

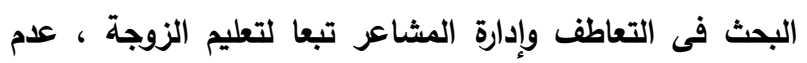

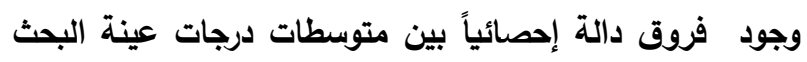

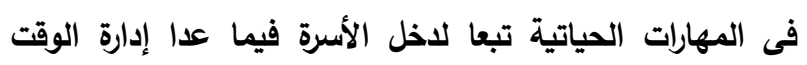

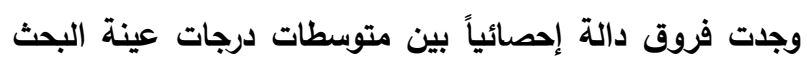

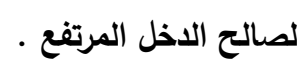

كما توصلت النتائج الى وجود فروق دالة إحصائياً بين

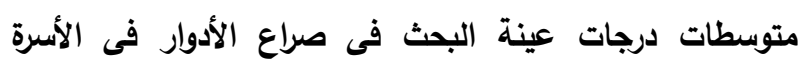

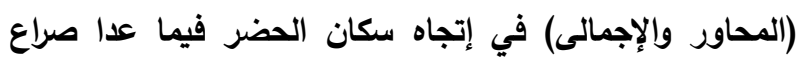

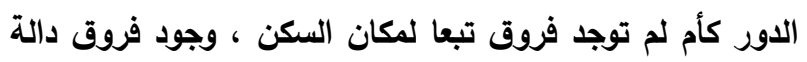

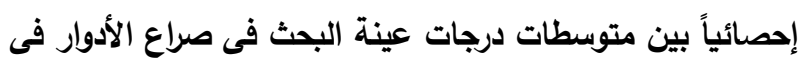

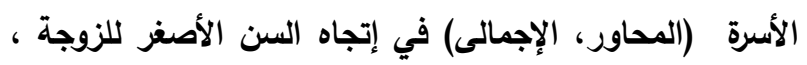

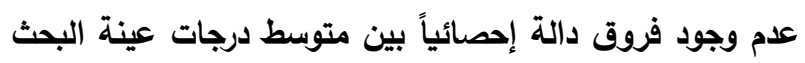

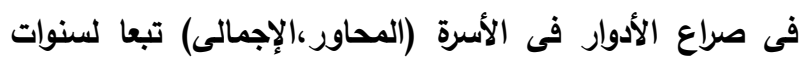

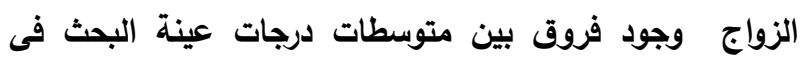
صراع الأدوار فى الأسرة (المحاور، الإجمالى) في إتجاه الأبناء

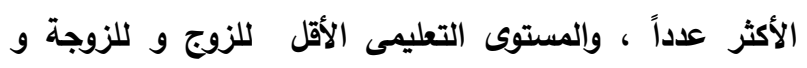

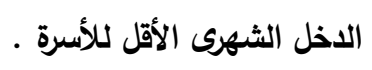
يوصى البحث: زيادة تفعيل دور مكاتب الإششاد والتوجيه

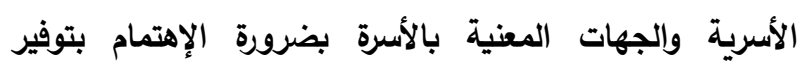

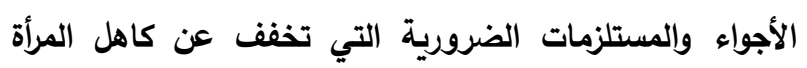

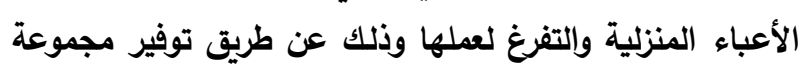
الذذمات الإجتماعية مثل دور حضانة ورياض الألئل الأطفال،

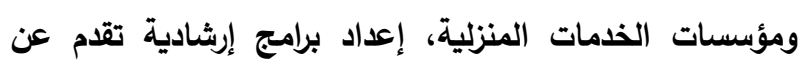
طريق وسائل الإعلام المختلفة وخاصة الإعلام المرئى لتوعية التئية

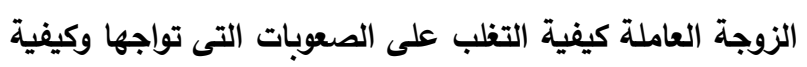

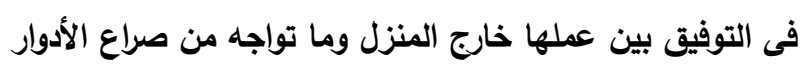

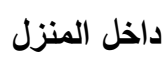

$$
\text { الملخص العربى }
$$

هاف البحث التعرف على علاقة المهارات الحياتية (إدارة

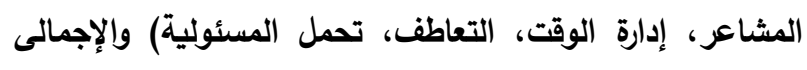

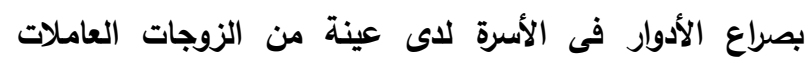

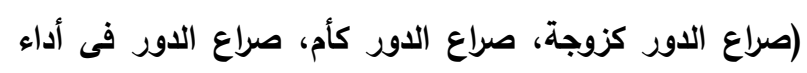
الأعمال المنزلية ) والإجمالى. وتم تطبيق أدوات البحث المتمثلة في إستمارة البيانات الأولية، وإستبياني المهارات الحياتية ، صراع الأدوار فى الأسرة

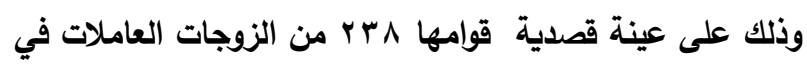

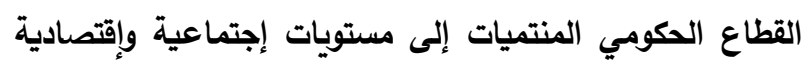

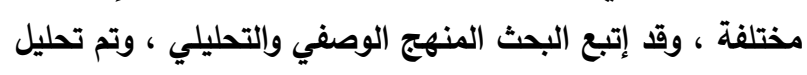
البيانات وإجراء المعالجات الإحصائية المناسبة بإستخدام برنامج البهائ

(Spss)

وتوصلت النتائج إلى وجود علاقة إرتباطية سالبة دالة

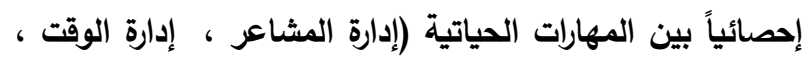

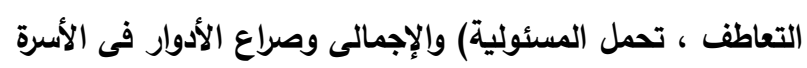

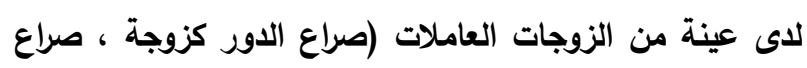

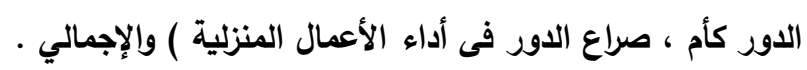

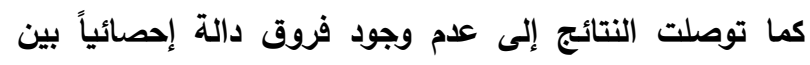
متوسطات درجات عينة البحث فى المهارات الحياتية المحاور

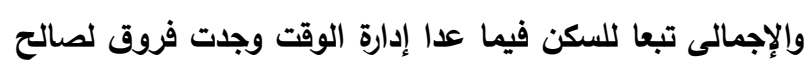

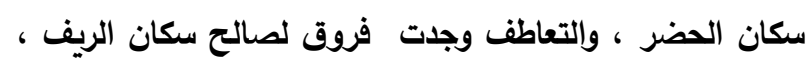

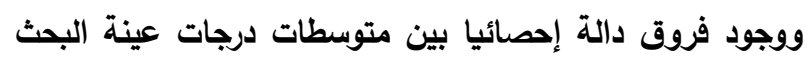

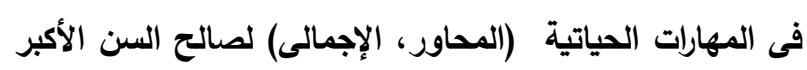

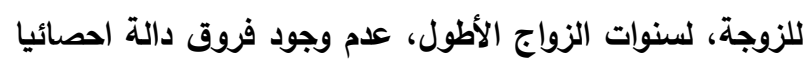

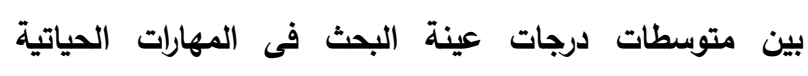

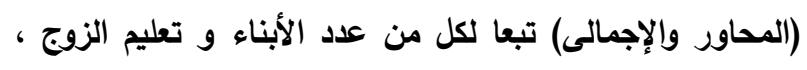
ووجود فروق بين متوسطات درجات عينة البحث فى مهارة (إدارة 
الحقيقية للحياة على أساس أنها تعبر عن الكفاءة فى الحصول على المعلومات وكيفية إستخدمها والإستفادة منها

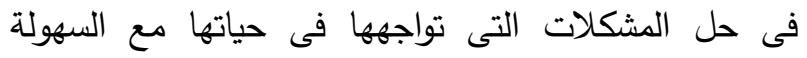
واليسر فى أداء الأعمال بدرجة من الإتقان فى أقل وقت

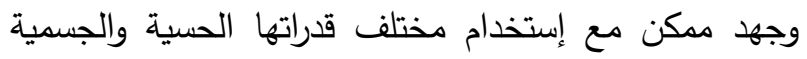
والعقلية فى إنجاز أى عمل تقوم به (مهدية رضضان ،

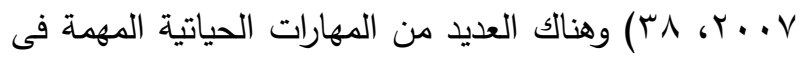
حياة الأسرة عامة والمرأة خاصة وإن فقدان هذه المهارات تؤدى إلى إضعاف عجلة التتمية كون المرأة العنصر الهام

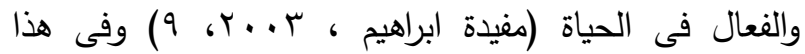

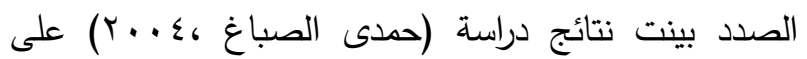
حاجة المرأة العاملة لتتمية قدرتها ومهاراتها الثخصية والمهنية والمجتمعية حيث أنها تقوم بأدوار متعددة تحتاج إلى الموازنة

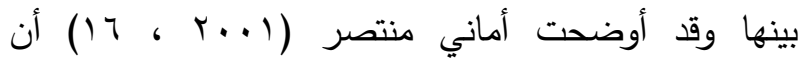
المهارات الحياتية هى المعلومات والمعارف والقيم التى

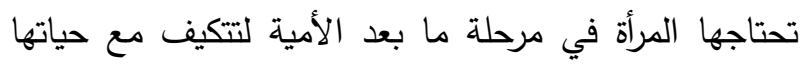
اليومية وتزاولها في ظل متغيرات العصر وتعاونها على العى العيات Brown مواجهة المواقف والتحديات التى تواجه الأسرة ويرى (139, 2004) أن المهارات الحياتية تتميز بالكفاءة الثخصية فى مواجهة مشكلات الحياة وذكر محمود منسى ، خديجة

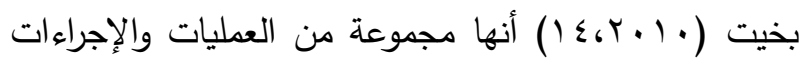
التى من خلالها يستطيع الزوجين مواجهة وحل مشكلات

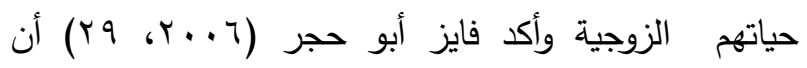
المهارات الحياتية مستمرة بإستمرار الحياة وتسهم بشكل فعال فى إكساب الزوجين مجموعة من المهارات الأساسية التى تمكنها من التفاعل والتعامل مع صعوبات الحياة الزوجية وتعزيز الإيجابيات بما يكفل لهم القدرة على حل المشكلات وإتخاذ القرارات وقد صنفت UNICEF

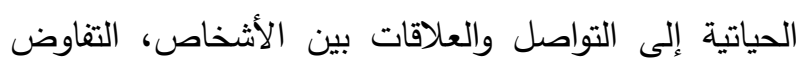

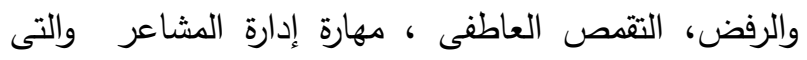

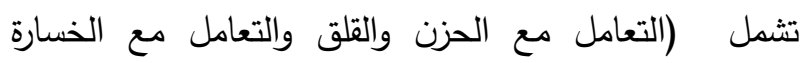
والإساءة والصدمة المؤلمة ) وقد أوضحت منال الحتة ولتعل
الكلمات الافتتاحية :- المهارات الحياتية - صراع الأدوار

فى الأسرة - المرأة العاملة

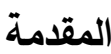

تعد المرأة عنصراً أساسياً فى المجتمع فهى فى الأساس

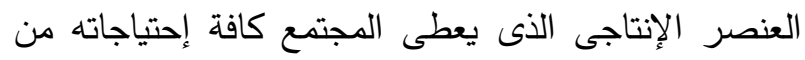
الموارد البشرية، فالمرأة هى التى تعتىى بشؤون أبنائها وترعاهم وتغرس القيم وتربيهم التربية الصالحة حتى يكونوا

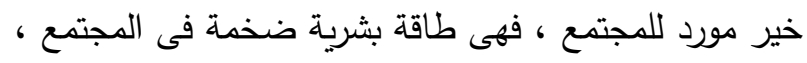
فتعبئة قواها ومساهتها الفعالة فى مختلف جوانب التتمية سوف يساعد على دفع عجلة التقدم بالمجتمع (أريج الثماسى

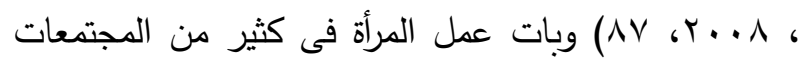
ضرورة ملحة فرضتها العديد من التغيرات المجتمعية منها على سبيل المثال التغيرات الإقتصادية التى تمثلت فى إرتناع

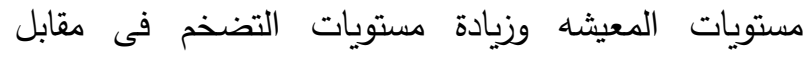
إنخفاض القيمة الحقيقية للإجور فى العديد من الدول بحيث

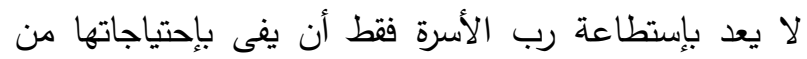

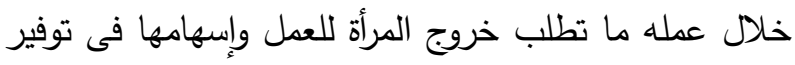

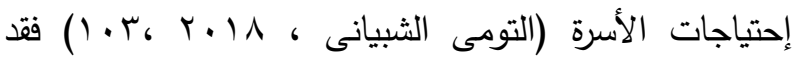
أضاف عمل المرأة قوة إقتصادية أخرى لكثير من الأسر الترائ

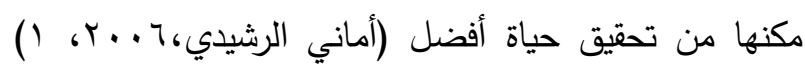
حيث تقوم المرأة العاملة بمجموعة من الأدوار المتعددة والمتمثلة فى دورها الأكبر فى الأسرة من خلال عمليات الإنجاب والتتشئة الإجتماعية وتوفير سبل الرعاية والحماية لأطفالها ودورها كمسئولة فى تدبير شئون المنزل ، وكذلك الإن

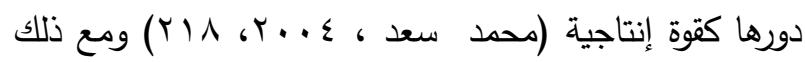

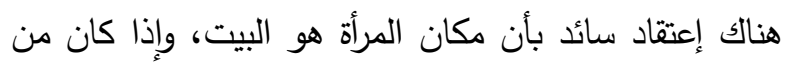

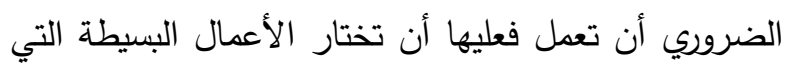

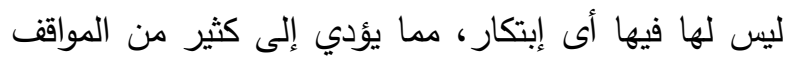

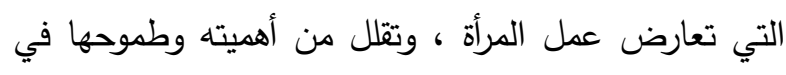

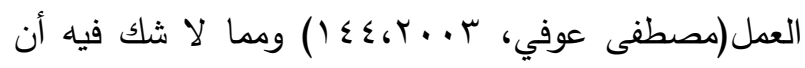
مهاراتها هى الوسيلة المباشرة للتفاعل بسهوله مع المواقف لأن 
قدرة ربة الأسرة على الموازنة السليمة بين مواردها المتاحة والدخل المالى مع تحديد أولوية الحاجات التى يراد إشباعها

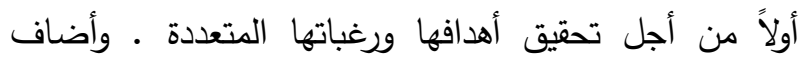

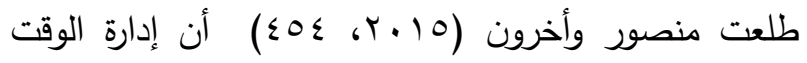
تظهر قدرة المرأة على التخطيط والتظيم والإلتزام بالوقت لإنجاز مهام وأهداف محددة ذات قيمة حقيقية للمرأة العاملة

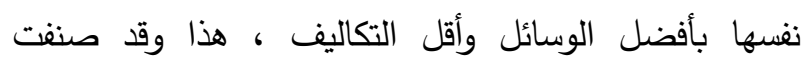
(2007,6)World Health Organization ثمانى مهارات ، اتخاذ القرار، الإتصال ، الوعى بالذات ، التفكير الإبداعى ، العلاقات الثخصية ، التفكير الناقد ، حل هل

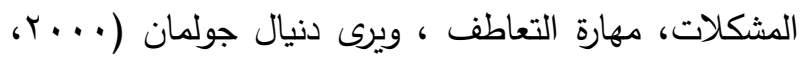

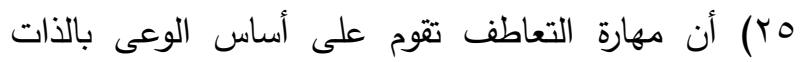
وتعنى قراءة مشاعر الآخرين والتعرف عليها والإستجابة لها

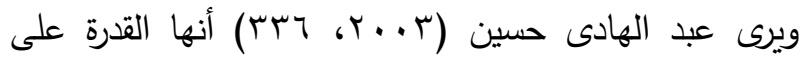
التماثل مع إهتمامات شخص آخر أو الشعور بشعوره وأوضح

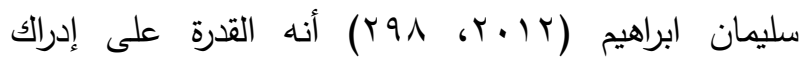
إنفعالات الآخرين والتوحد معهم وفهم مشاعرهم وإنفعالاتهم

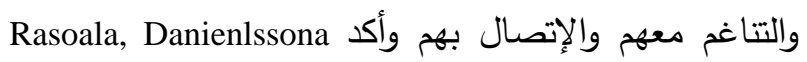
andTomas تمكن الفرد من فهم إنفعالات ومشاعر الآخرين بهدف تقديم المساعدة لهم ويرى Grant (2014,338) بأنه القدرة على تبنى لهن وجهة نظر الآخرين بغرض فهم إنفعالاتهم ومشاعرهم وترى

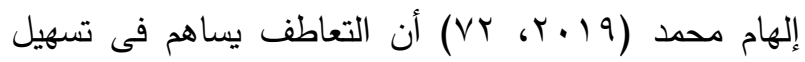
التواصل والتعاون والإحترام ووجود التراحم بين الأفراد وبعضهم ويساعد الأفراد على إقامة والأستمرار فى العلاقات ولات وتئرد الإجتماعية المتبادلة مع الأخرين وقد توصلت نتائج دراسة

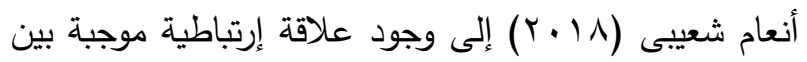
المهارات الحياتية للزوجين فى أزمة منتصف العمر (مهارة

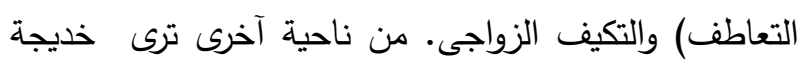

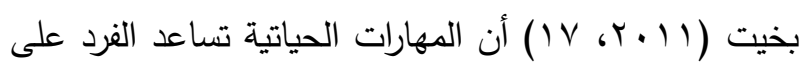
إدارة حياته وعلى التكيف مع ذاته والتعايش مع المتغيرات

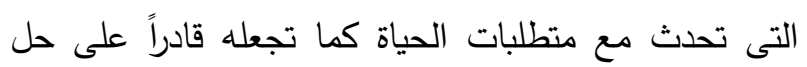

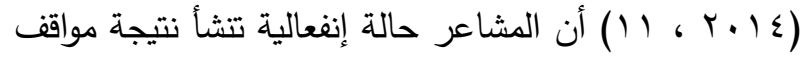
وتعكس إستجابة وردود أفعال معينة وتؤثر على أداء الفرد

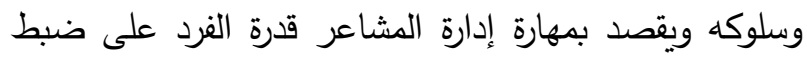
وتوجيه إنفعالاته ومشاعره تجاه الأخرين (لطيفة النعيمى

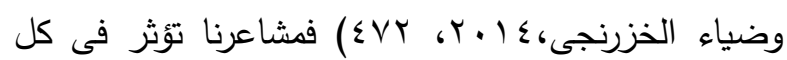

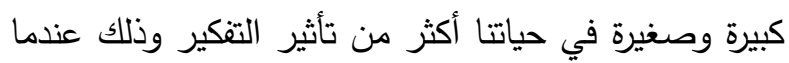

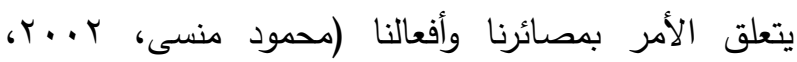
؟7 با) والأفراد الذين يدركون مشاعرهم وعواطفهم بصورة

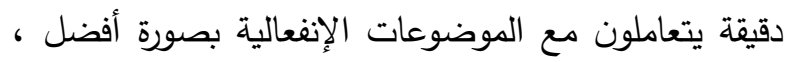

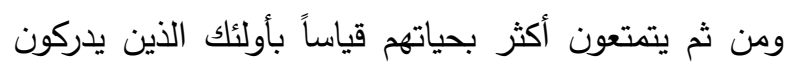

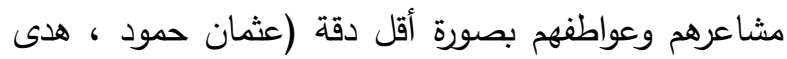

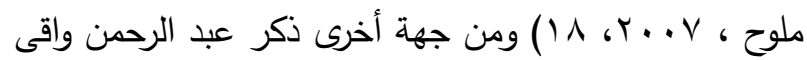

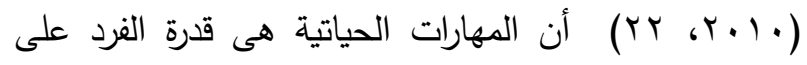
التعامل بإيجابية مع مشكلاته الحياتية الثخصية والإجتماعية وتشمل، مهارات الإتصال الإجتماعى وحسن إستخدام الموارد

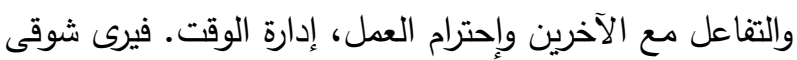

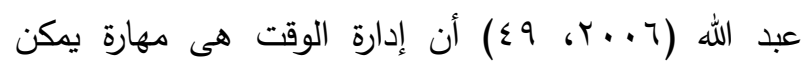
تعلمها وتتميتها مع الوقت، فهى تتظم وقت الثخص بين جميع الأنشطة التى في حياته فتجعل وقتاً لعمله ووقتاً للأنشطة الإجتماعية ووقتاً للعائلة وأوضح أيمن يوسف التف

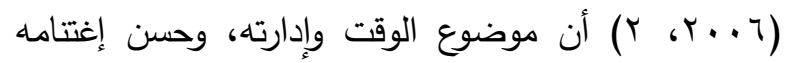
يعتبر من الموضوعات المهمه في الإدارة بشكل عام وإدارة الأسرة على نحو الخصوص، وتعد إدارته من أهم الأعمال الواجب التعامل معها بكفاءة وفعالية، حيث تعتبر مؤشراً أساسياً لقياس مدى فعالية الفرد في تتظيمه للوقت وإستثماره وتوظيفه وتوزيعه بفعاليه على المهام المختلفه، ومحاوله تقليل الضائع منه هدراً لتحقيق أهدافه . وأوضحت وجيدة حماد

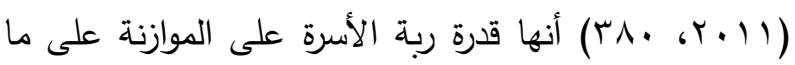
لديها من وقت متاح وبين الأعمال والمسئوليات التى تقوم بها خلال اليوم وتوزيعه على الأنشطة حسب أهميتها والتغلب على مضيعات الوقت وذلك من أجل الإستقادة القصوى به .

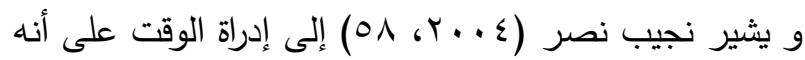




$$
\text { مجلة الإسكندرية للتبادل العلمى - (مجلد إع العدد () يناير - مارس (Y.r }
$$

هى أعمال نسائية قط لا يجوز للزوج مساعدة زوجته فى

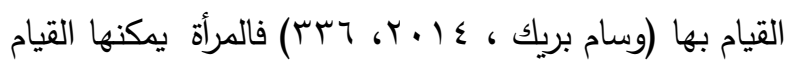
بأكثر من دور إذ أنها قد تقوم بدور الزوجة ، الأم بكفاءة إلى الى جانب القيام بدورها كامرأة عاملة لكن هذا يتوقف على طبيعة المرأة والدعم الذي تتلقاه من الأسر و الزوجه، والأهل لتستطيع الموازنة بين دورها كأم ودورها كأمرأة عاملة لكن في بعض الحالات لا تستطيع المرأة تحقيق هذا التوازن في

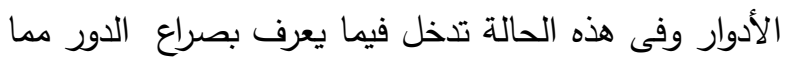
يعرضها لضغوطات يمكن أن تؤدي بها إلى الفشل في أداء

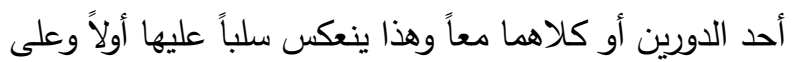

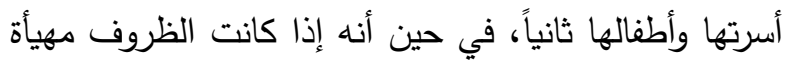

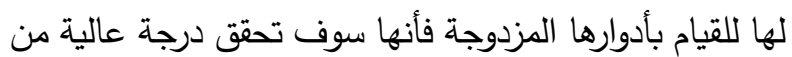
الرضا النفسي مما ينعكس بشكل إيجابي عليها وعلى أسرتها

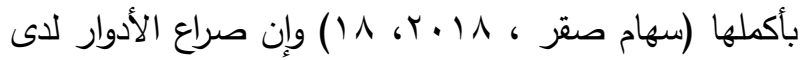
الزوجة العاملة هو الصراع الذى يظهر بحكم التوقعات المختلفة المتباينة التى تتنظر منها تأديتها لدور الزوجة لرونة وقيامها بدور الأم ، إلى جانب كونها عاملة بمؤسسة ومن ثم تختلف التوقعات وتتعدد المطالب مع قد ينتابها من شعور بالعجز بعدم القدرة على القيام بجميع هذه المطالب وتلبية

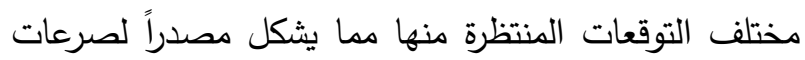
داخلية تعيشها المرأة على مستوى شخصي وأخرى على مستوى العلاقات مع الأفراد والمجتمع مما يؤدى إلى حدوث نوع من التعارض بين الأدوار التى تقوم بها (عائشة بو بكر

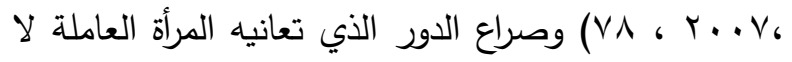
ينبع من إثتراكها في القيام بنوعين من العمل في وقت واحد داخل المنزل وخارجه ، ولكنه ينبع من تتاقض القيم الخاصة بالعمل فهى مطالبة بأن تعمل بإخلاص وإلتزام كالرجل تماماً ، في الوقت نفسه تطالب بإعطاء الأولوية الكاملة لأسرتها

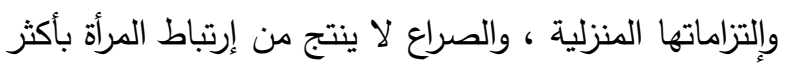
من نسق إجتماعي ، وإنما هو صراع أولويات أي أن المرأة تعانى من صراع متعدد الجوانب ناتج من العوامل الإجتماعية والثقافية بين المفاهيم الموروثة التقليدية والمفاهيم الحديثة التي
المشكلات وتحمل المسئولية، وأوضح أسامة حسين(T . . ؟، 1) أن المهارات الحياتية هى القدرة على الإختيار وتحمل

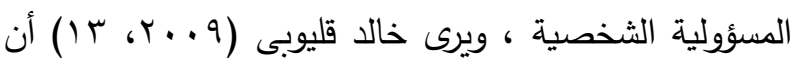
تحمل المسئولية من الصفات التى يجب أن يتحلى بها كل

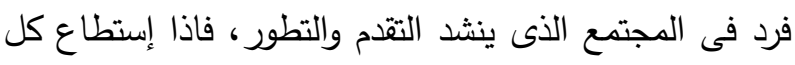
فرد أن يتحمل المسئولية إرتقى المجتمع، ويشيرجميل

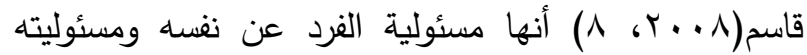
تجاه أسرته وأصدقائه وتجاه دينه ووطنه من خلال فهمه لدوره فى تحقيق أهدافه وإهتمامه بالآخرين من خلال علاقته الإيجابية ومشاركته فى حل مشكلات المجتمع وتحقيق

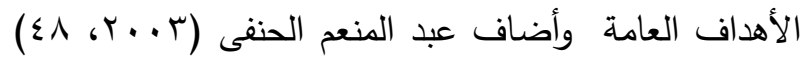
أننا فى حاجة ماسة إلى ربة الأسرة المسئولة عن جميع أفراد أسرتها بكل ما يمر بها من ضغوطات وعقبات وذلك لأن الأسرة تعيش تحت ضغوط متطلبات الحياة المعيشية وهى دائما بحاجة إلى إصدار قرارات مصيرية سواء تخص الأسرة

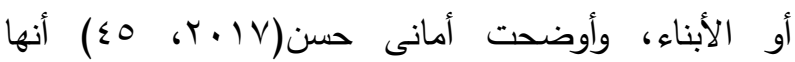
الإستجابات النابعة من المرأة المتزوجة والدالة على حرصها على أسرتها، وعلى تماسكها وإستقرارها وتحقيق أهدافها، وتدعيم تقدمها في شتى النواحي ، وتفهمها المشكلات التي تعترض أسرتها في حاضرها ومستقبلها ، والمغزى الإجتماعي لأفعالها وقراراتها بحيث يدفعها ذلك إلى بذل قصارى جهدها في كل ما يوكل إليها من أعمال. ومما لا شك فيه أن الإنسان لم يولد فى هذا الكون عبثاً وإنما لكل فرد منا دوراً يؤديه أو وظيفة محددة يقوم بها، وكلما تطورت الحياة وتعقدت كلما زادت الأدوار وإختلفت ، فظروف الحياة تفرض على الفرد لكى يتكيف ويتوازن مع تلك الحياة

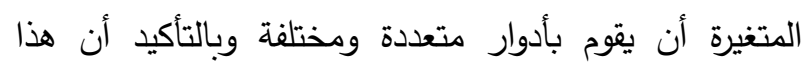
التعدد والإختلاف سينتج عنه صراعات متعددة ومنها ما يسمى بصراع الأدوار ، وهذا الصراع يتجلى أكثر عند المرأة

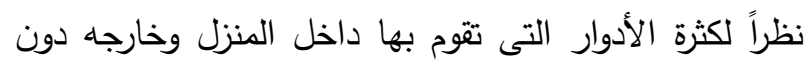
مساعدة من أحد خاصة فى مجتمعاتتا الثرقية التى مازالت

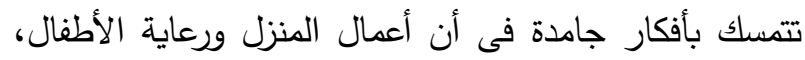


علاقة إيجابية بين نمطى الصراع بين الأسرة والعمل ، كما

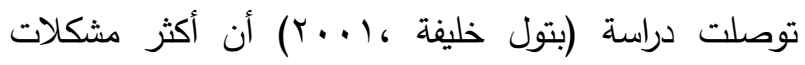
صراع الدور لدى المرأة العاملة وغير العاملة هى الأعمال المنزلية والتى تثمل إدارة المنزل ، والجهد البدنى والنفسى

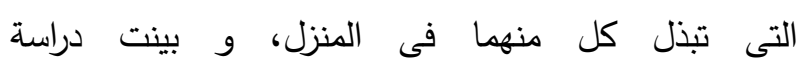
(Cinamon,2004)

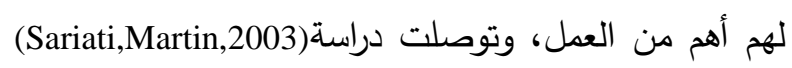

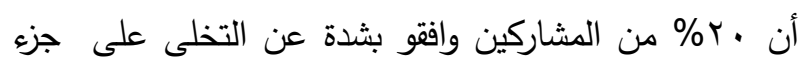
من دخلهم مقابل الحصول على بعض الوقت الذى يمكن أن

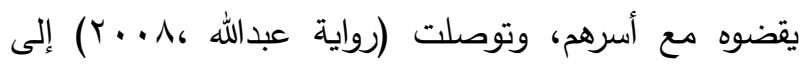
وجودعلاقة إرتباطية موجبة دالة إحصائيا بين صراع الدور

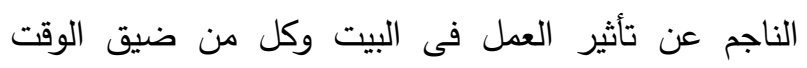
والجهد والتعب ووجود علاقة إرتباطية سالبة بين صراع الأدوار والرضا عن العلاقة الزوجية كما توصلت نتائج دراسة (shallom , 2013) على التوافق الزواجى وتوصلت نتائج دراسة (رحاب حسن

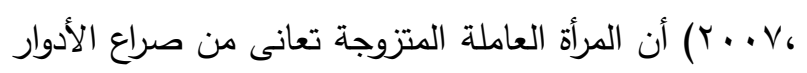
التى تقوم بها كأم وزوجة وعاملة وهذا ينعكس على إستقرارها

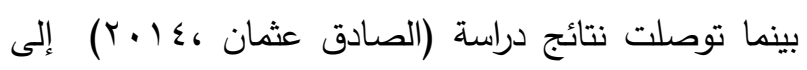
إمكانية توفيق المرأة بين عملها خارج المنزل والأعباء الأسرية دانية بشكل عام و أن العاملات يجدن تشجيع من أزواجهن

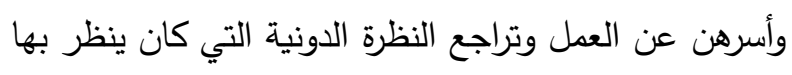
المجتمع إلى المرأة العاملة و أصبحت الأدوار التقليدية داخل

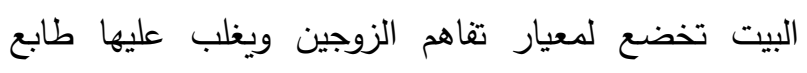
الحوار لا الأمر وتوصلت نتائج دراسة (2014, Kumari) إلى لئ أن هناك مجموعة عمرية مختلفة من النساء العاملات يعانين من مختلف المشاكل والتحديات، وعدم القدرة على الموازنة

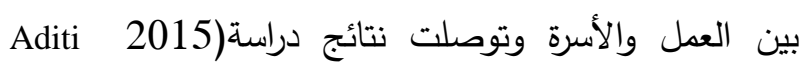
(Aeran, Ravindra Kumar العائلي لعمل المرأة يساهم في إنجازها لواجباتها على أكمل وجه في كل من ميدان العمل والحياة العائلية. وقد أظهرت نتائج دراسة (Kodagoda , Thilakshi,2010) ان فئ المشكلات
تعلي قدر المرأة بإعتبارها مؤهلة للعمل كالرجل ، هذا

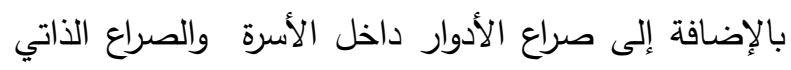
بين عاطفة الأمومة والإنجاب وبين واجبات العمل ومتطلبات

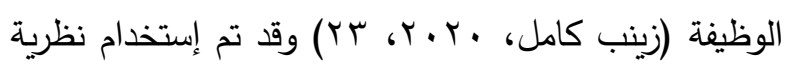
الدور الإجتماعي في العلاقات الأسرية بإعتبار أنها تهتم

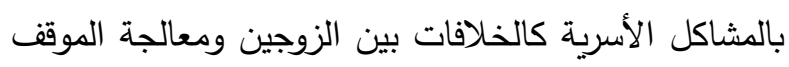
الإجتماعي الذي يعيش فيه ، كما أن لكل من الزوجين أدوارًا

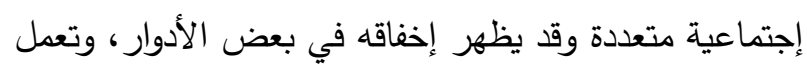

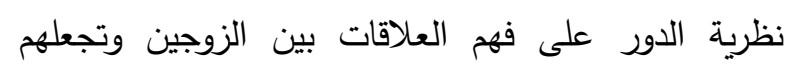
يشعرون بذاتهم مما يجعلهم يخرجون من سلبيتهم وعزلتهم، وبالتالي تحويل صراع الأدوار إلى تعاون بين الزوج والزوجة (Abdel\& et all 2003,39) ولقد أرجع البعض إهتماماتهم بصراع الدور لدى المرأة نتيجة لحدوث تغيرات جذرية في

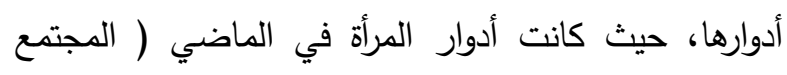
التقليدي) واضحة ومحددة ، أما اليوم فأصبحت تقوم بالعديد

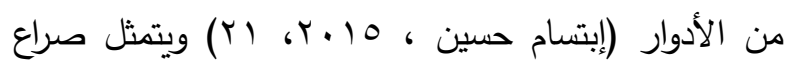
الأدوار للمرأة العاملة في العصر الحديث في كثرة الأعباء التي تقع على عاتق الزوجة داخل المنزل وخارجه ويزداد هذا الصراع في حالة الأم العاملة التي يقع على على عاتقها تربية الأطفال ومتابعة تحصيلهم الدراسي ، وتلبية إحتياجات الزوج والقيام بالعلاقات الإجتماعية مع الأهل والأصدقاء بالإضافة الإنة

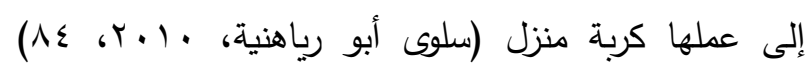
وتعاني المرأة العاملة من صراع بين دورها كعاملة لها لهال مسؤوليات في واقع عملها، ودورها كربة بيت مسؤولة عن من المهام المنزلي..، كزوجة ومربية أطفال، وهو ما يتطلب منها

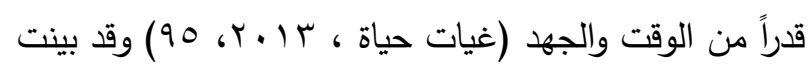

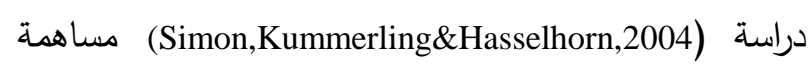
كل من ضيق الوقت والجهد بثكل متساوى فى ظهور صراع الأدوار وتوصلت نتائج دراسة (Cinamon and Rich,2004) أن العاملات تعانى من تأثير العمل على متطلبات الأسرة وأنهن يعانين من إرهاق عاطفى يؤثر في علاقتهن بأزواجهن وكثفت نتائج,HuangHammer \& Perrin) (2004 عن وجود 


$$
\text { مجلة الإسكندرية للتبادل العلمى - (مجلد \& العدد ( ) يناير - مارس اY.r }
$$

سن الزوجة ، مدة الحياة الزوجية، عدد الأبناء، المستوى

التعليمى للزوجين، متوسط الدخل الثهرى للأسرة) ؟

- هل تختلف نسبة مشاركة متغيرات المستوى الإجتماعى والإقتصادى فى تفسير نسبة التباين على المتغير التابع

$$
\text { (صراع الأدوار فى الأسرة ) ؟ }
$$

\section{الاهداف البحثية}

يهدف البحث الحالى التعرف على العلاقة بين المهارات الحياتية وصراع الأدوار فى الأسرة للى عينة من الزوجات

$$
\text { العاملات من خلال التعرف على: }
$$

1- مستوى كل من المهارات الحياتية (إدارة المشاعر، إدارة الوقت، التعاطف، تحمل المسئولية) الإجمالى وصراع الأدوار فى الأسرة (صراع الدور كزوجة، صراع الدور

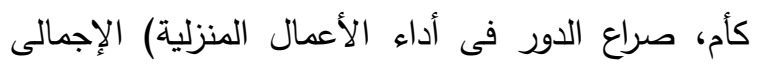

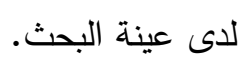

r- تحديد الفروق بين متوسطات درجات عينة البحث فى

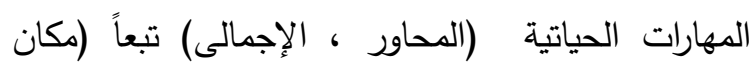

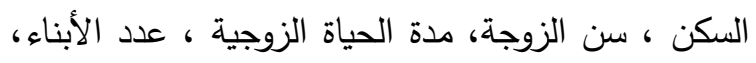

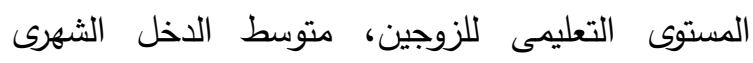

$$
\text { لنأسرة) }
$$

r- تحديد الفروق بين المتوسطات درجات عينة البحث فى في

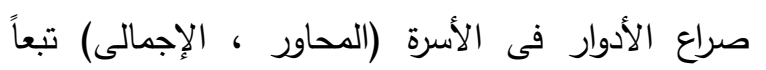

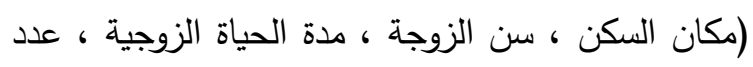

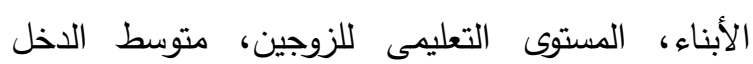

$$
\text { الثهرى للأسرة) }
$$

ع- تحديد نسبة مشاركة متغيرات المستوى الإجتماعى لفرة والإقتصادى فى تنسير نسبة التباين على المتغير التابع

$$
\text { (صراع الأدوار فى الأسرة). }
$$

التى تواجه هؤلاء النساء العاملات عدم القدرة على الموازنة بين العمل والواجبات المنزلية وتوصلت نتائج دراسة (Cynthia j , Patel,2006) بكثير من صراع الدور فى الأسرة والعمل من النساء غير

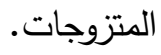

فى ضوء ما سبق ترى الباحثتان أن عمل المرأة إرتبط

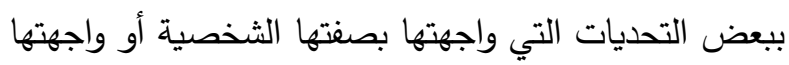
هي وأسرتها (الزوج والأبناء) وذلك لتعدد أدوارها في الحياة كإمرأة أو أم وزوجة عليها واجبات ينبغي عليها أن تؤديها، وبلا شك أن عملها خارج المنزل يزيد من أعبائها الأساسية ورجها وهي الإسهام في إدارة المنزل ورعاية وتربية الأبناء والإهتمام بزوجها فالنساء لا تزال يقع علي عاتقها أن تفعل الكثير من الأعمال المنزلية والرعاية الأسرية إلى جانب مسئولياتها في لئي العمل، والوقت الذي تقضيه المرأة في الأعمال المنزلية فالزوجة هي المحرك الأساسي للأسر وقد جاءت مشكلة البحث للإجابة على التساؤل التالى ما العلاقة بين المهارات الحياتية (إدارة المشاعر، إدارة الوقت، التعاطف، تحمل

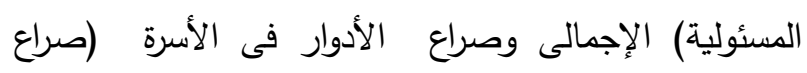
الدور كزوجة، صراع الدور كأم، صراع الدور فى أداء الأعمال المنزلية ) الإجمالى لاى عزوه، عينة من الزوجات العاملات والذى ينبثق منه الأسئلة الفرعية التالية: - ما مستوى كل من المهارات الحياتية بمحاورها وصراع

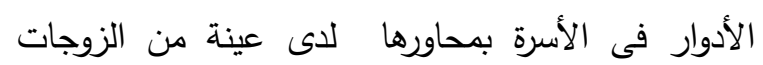

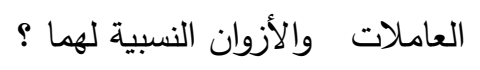

- ما الفروق بين متوسطات درجات عينة البحث فى

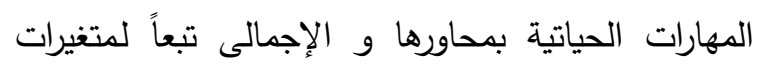
الدراسة (مكان السكن ، سن الزوجة ، مدة الحياة الزوجية

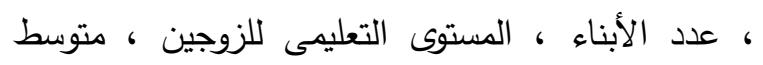
الدخل الثهرى للأسرة) ؟ - ما الفروق بين متوسطات درجات عينة البحث فى صراع

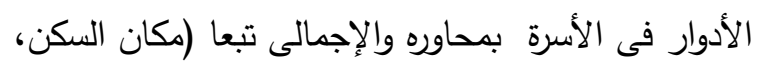


سن الزوجة ، مدة الحياة الزوجية، عدد الأبناء، الدستوى

التعليمى للزوجين، متوسط الدخل الثهرى للأسرة).

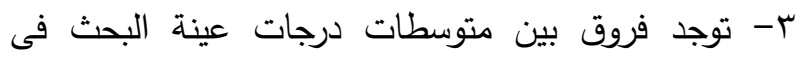

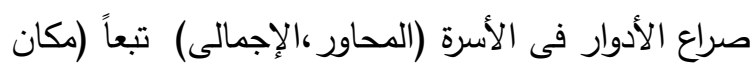

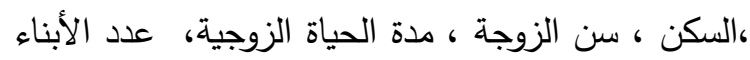

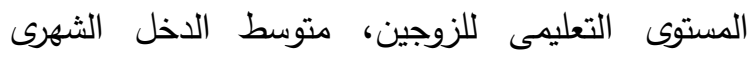

$$
\text { لكلأسرة). }
$$

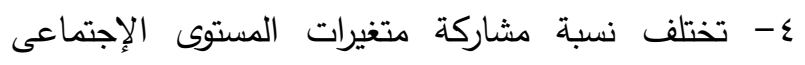

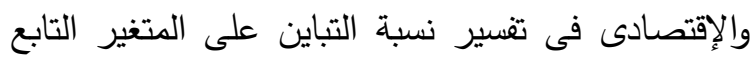

$$
\text { (صراع الأدوار فى الأسرة). }
$$

أولاً: المصطلحات العلمية والمفاهيم المرأة العاملة:- تلك المرأة تلك التى تخرج من البيت إلى العمل فى أحدى مؤسسات الدولة سواء كانت حكومية أو خاصة فى فترة محددة من النهار (أمنة بركات ، ع ـ...ب،

والمقصود بالزوجة العاملة فى البحث:- هى المرأة المتزوجة

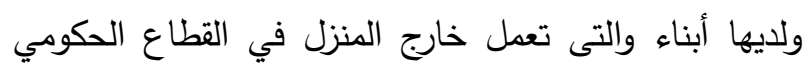
وتتقاضى أجر مقابل ما تقوم به من عمل.

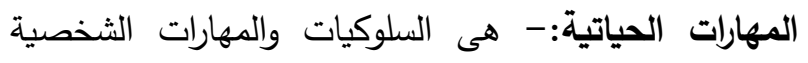
والإجتماعية اللازمة للأفراد للتعامل بثقة وإقتدار مع أنفههم

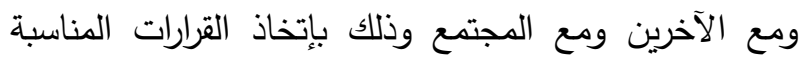
والصحيحة وتحمل المسئوليات الثخصية والإجتماعية وفهم النفس والغير وتكوين علاقات إيجابية مع الآخرين وتفادى حدوث الأزمات والقدرة على التنكير الإبتكاري (أنعام شعيبي

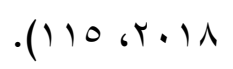

وتعرف إجرائيا على أنها:- قدرة الزوجة العاملة على القيام

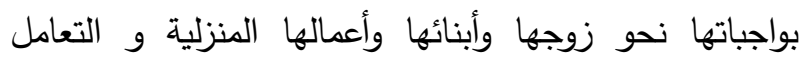

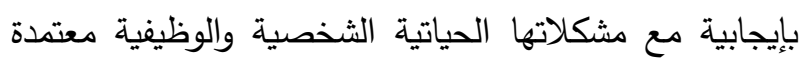

\section{الاهمية البحثية}

1- ترجع أهمية الدراسة إلي أن قضية الصراع بين العمل

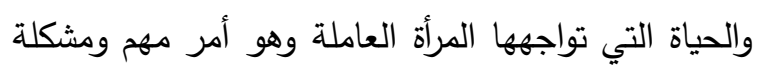

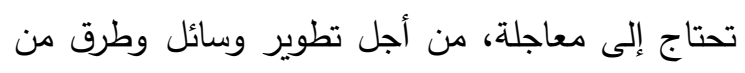

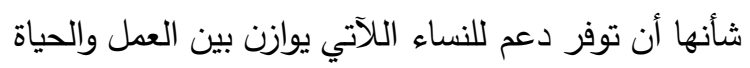
الأسرية .

r- أصبحت هناك حاجة ماسة إلى ضرورة إمتلاك الزوجة

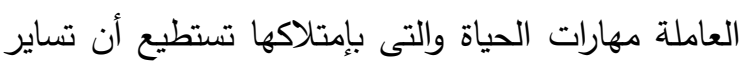

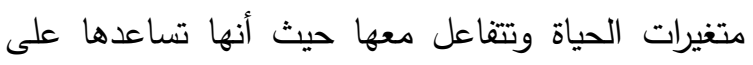
التعامل الناجح مع صراع الأدوار داخل أسرتها. ץ- تمكننا نتائج هذه الدراسة من مراعاة واجبات ومسئوليات

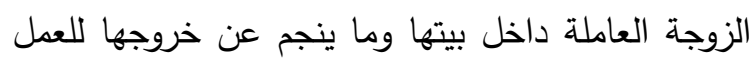
من آثار سلبية على نفسها وعلى أسرتها حيث يولد الكثير من الضغوط النفسية.

ع- تحسين وتوعية الأفراد المحيطين بالزوجة العاملة (الزوج

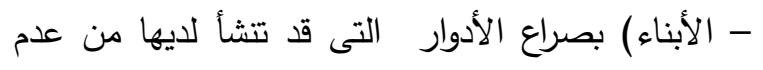

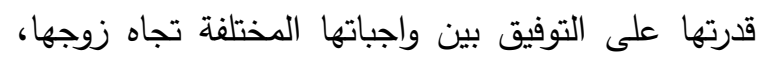

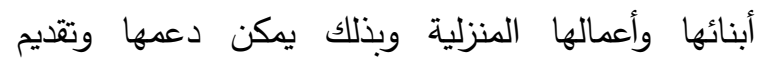
المساعدات لها للتخفيف من حدة صراع الأدوار لديها.

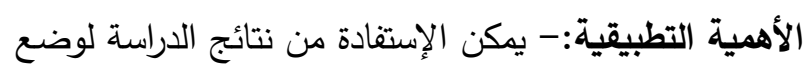
خطط وسياسات تتموية للمرأة العاملة تسهل عليها القيام بأدوارها الأسرية ويقلل من حجم صراع أدوراها فى الأسرة .

\section{الفروض البحثية}

1 - توجد علاقة إرتباطية دالة إحصائياً بين المهارات الحياتية

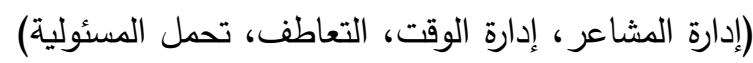

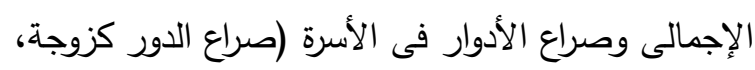

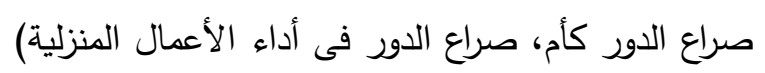

$$
\text { الإجمالى لاى عينة من الزوجات العاملات. }
$$

r- توجد فروق بين متوسطات درجات عينة البحث فى

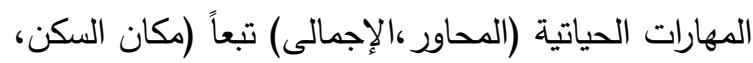




$$
\text { مجلة الإسكندرية للتبادل العلمى - (مجلد إع العدد () يناير - مارس (Y.r }
$$

جانب كونها زوجة وأم ودورها كربة منزل ما يخلق صراع يتمثل فى صراع الدور كزوجة وكأم وأداء الأعمال المنزلية صراع فى دورها كزوجة: الصراع الناتج من شعور الزوجة بالتقصير تجاه زوجها وإحساسها بعدم قدرتها على القيام بواجباتها تجاه (الزوج ) على أكمل وجه مع عدم تحمل الزوج المسئولية وعدم مراعاته للأعباء التى تقع على كاهلها و مطالبتها بإلتزاماتها وواجباتها دون النظر إلى ظروفها المحيطة وهذا يخلق جو للعديد

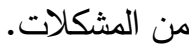

صراع فى دورها كأم: هو الصراع الناتج من الصعوبات التى التى

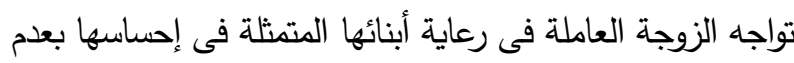

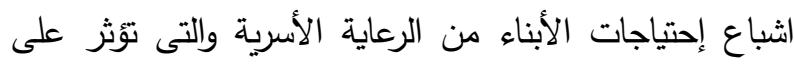

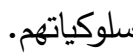
صراع فى أداء الأعمال المنزلية: هو الصراع الناتج من الصعوبات التى تواجه الزوجة العاملة فى إدارة شئون المنزل اليومية والمتمثلة فى تعدد المسئوليات المتعلقة بالأعمال الدنزلية دون مساعدة أفراد الأسرة لها مما يزيد العبئ عليها. ثانياً: منهج البحث :-إتبع هذا البحث المنهج الوصفى التحليلى. ثالثا: حدود البحث: تمثلت حدود البحث فى الآتى

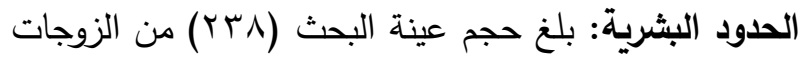
العاملات فى القطاع الحكومى وقد تم إختيار العينة بطريقة غرضية ومن مستويات إقتصادية، وإجتماعية مختلفة. الحدود المكانية: تم إختيار العينة من أسر مقيمة بدينتى أجا والمنصورة بمحافظة الدقهلية. الحدود الزمنية: تم التطبيق الميدانى لأدوات البحث فى صورتها

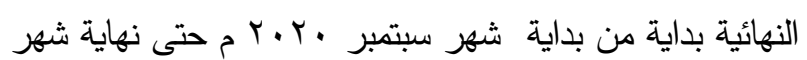

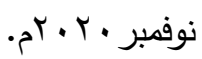
رابعاً: إعاد وبناء أدوات البحث وتقنينها :- إشتملت الأدوات المستخدمة فى ضوء الأهداف البحثية على ما يلى: إستمارة البيانات العامة: تم إعداد استمارة البيانات العامة بهدف الحصول على بعض المعلومات التى تفيد البحث عن
بذلك على ما تملكه من مهارات( إدارة المشاعر وإدارة الوقت والتعاطف و تحمل المسئولية ). مهارة إدارة المشاعر:- قدرة الزوجة العاملة على إدراك

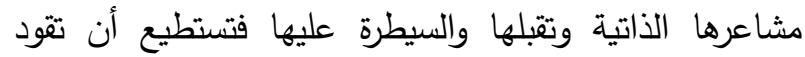

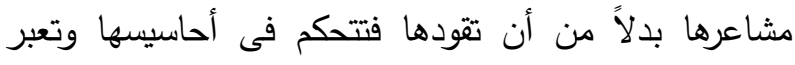
عنها بحكمة وتتصرف بشكل مناسب بالإضافة إلى إستخدام تلك المشاعر بطرق متزنة فتستطيع التعامل مع حالات التقق والضيق والسيطرة وضبط الإندفاعات وتكون لديها القدرة على

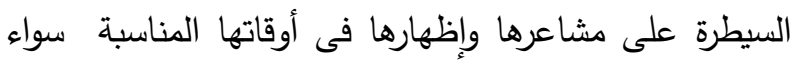

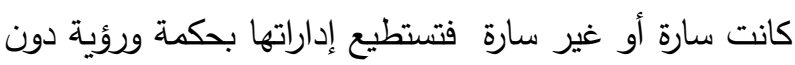

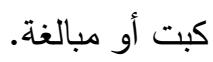
مهارة إدارة الوقت:- - قدرة الزوجة العاملة على الإستخدام

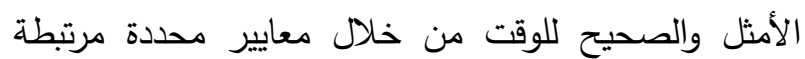

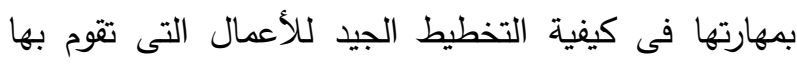

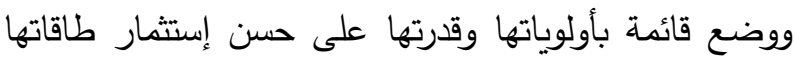
وإمكانياتها المتاحة. مهارة التعاطف:- قدرة الزوجة العاملة على إدراك أحاسيس

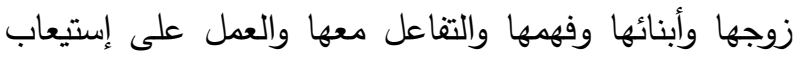
المواقف التى يعيشونها سواء أكانت مغرحة أو محزنة . مهارة تحمل المسئولية:- مهارة إدتلاك الزوجة العادية العادلة للقدرات والسلوكيات التى تساعدها على الوفاء بالوجبات والإلتزمات التى توكل إليها تجاه زوجها وأبنائها وما تقوم به التهاه

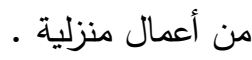
صراع الأدوار للمرأة العاملة: هو تلك التصورات والتوقعات المتعارضة التي تنتظر من المرأة العاملة تجاه أدائها لأدوارها

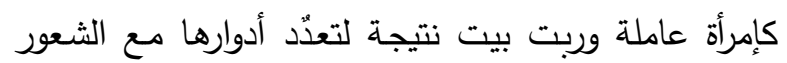

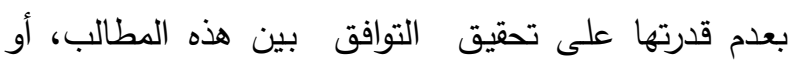
إستجابة لمختلف التوقُعات في وقت واحد (سمير بن موسى لهى

$$
\text { . ( IOV ، T. } 10
$$

وتعرف صراع الأدوار فى الأسرة إجرائياً: هو معاناة الزوجة

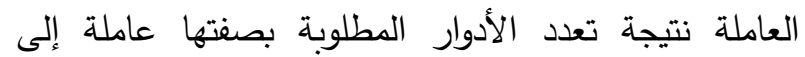




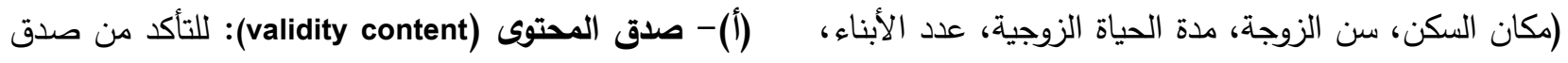

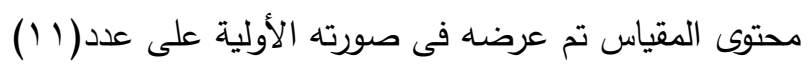

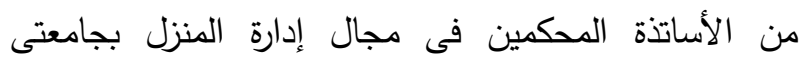

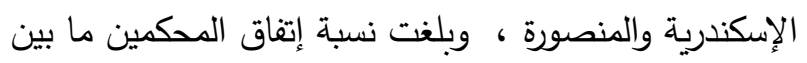

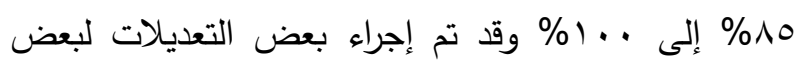

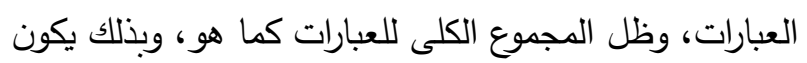
قد خضع لصدق المحتوى. المستوى التعليمى للزوجين، متوسط الدخل الثهرى للأسرة).

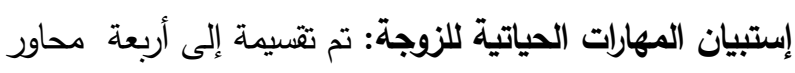
(إدارة المشاعر ، إدارة الوقت، التعاطف، تحمل المسئولية).

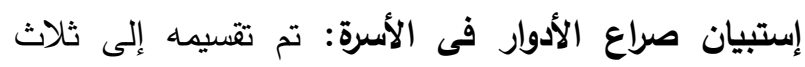

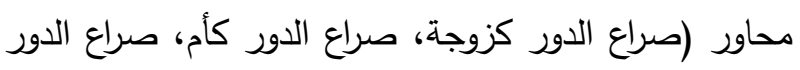
فى أداء الأعمال المنزلية). تقنين الإستبيان: أولاً: حساب صدق الاستبيان: (ب)- صدق الإتساق الداخلى:

جدول ا ـ معاملات الإرتباط بين كل عبارة والدرجة الكلية لإستبيانى المهارات الحياتية وصراع الأدوار فى الأسرة ن= (· (r)

\begin{tabular}{|c|c|c|c|c|c|c|c|}
\hline \multicolumn{3}{|c|}{ صراع الأدوار فى الأسرة } & \multicolumn{4}{|c|}{ المهارات الحياتية } & \multirow[b]{2}{*}{ b } \\
\hline صراع الأورال فلى أدزاء & صراع الاوركأم & صزاع الاور & المسئولية & التعاطف & إدارة الوقت & المشاعر & \\
\hline$* *, 011$ & $* * \cdot, \pi \tau \varepsilon$ & $*,, \varepsilon \leqslant r$ & $* *, 710$ & $* *,, \vee 00$ & $* *,, \vee \vee 1$ & $* * ., 07 \mathrm{~V}$ & 1 \\
\hline$* *, \vee \vee 70$ & $*,, \leq 00$ & $*, \leq 70$ & **, , Tr. & $* *, 00 r$ & $* *,, \vee 90$ & $* *, \wedge \wedge \leq$ & r \\
\hline **, or. & $* *, T \wedge \vee$ & $* *, \leq q$. & $* *, \Delta r V$ & **, OYT & 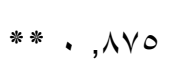 & $* *,, \vee \wedge \uparrow$ & $r$ \\
\hline$* *,, 7 \leq \Lambda$ & **, שr, & $* *, V r r$ & ** , r r r & $* \cdot, \varepsilon \cdot V$ & $* *, T \cdot V$ & $* *, 010$ & $\varepsilon$ \\
\hline * • r & $*,, \leq 71$ & ס ס דו, , & $* *,, \vee \wedge q$ & *** & $*, \quad, \leq 0 \leq$ & ***, & 0 \\
\hline$* *,, \vee 00$ & س & $* * \cdot, 07 \mathrm{~V}$ & $* *,, V Y V$ & $* *, 0.0$ & $* *, \vee \vee 71$ & $*, \leqslant 19$ & 7 \\
\hline$* *, 0 \leq 1$ & $* *, 07 r$ & $* *,, \vee 9 \vee$ & $* *,, \Lambda \cdot r$ & $* *, T \wedge r$ & $* *, \leqslant \wedge 0$ & $* *,, V \cdot T$ & $v$ \\
\hline$* *, \vee \backslash 11$ & $* *,, \vee \circ 9$ & $* * \cdot, \wedge \cdot 7$ & $* *,, \diamond \wedge \varepsilon$ & $* *, \vee V T V$ & $* *, \quad, T \leq r$ & $* *,, \leqslant \wedge \uparrow$ & $\wedge$ \\
\hline$* *, \quad \vee \vee 0$ & $* *$, , tor & סטדו, • ש & $* *, 79 r$ & $* *$, Nor & $* *, \quad, v \leq \vee$ & **, , , ז & 9 \\
\hline$* *,, \vee \ldots$ & $* *, \wedge \leq 1$ & ** , , VRr & $* *,, O \wedge r$ & $* *, T \vee \wedge$ & $* *, 07 r$ & $* *, v \cdot V$ & 1. \\
\hline *** & $* *, \wedge \wedge)$ & $* *, 09$ & $* *,, \leqslant \diamond \uparrow$ & $* *, \leq q$. & $* *, \quad, \vee r$. & $* *, 797$ & 11 \\
\hline$* *,, V \backslash V$ & $* *, 090$ & * * . & $*,, \leq 1 \leq$ & $*$, , 0 Or & $* *,, \vee \backslash \vee$ & **, orv & Ir \\
\hline$* *, 790$ & & & & & $* *$, , Tr & & ir \\
\hline$* *, 0.7$ & & & & & $* *, 09 r$ & & $1 \leq$ \\
\hline
\end{tabular}


كانت دالة عند مستوى (1 . , ) مما يدل على تجانس محاور

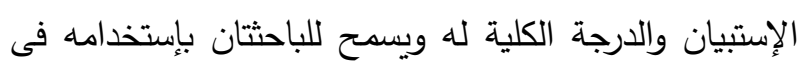

بحثهما

ثانياً: حساب ثبات الإستبيان Reliability:

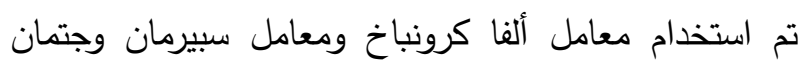

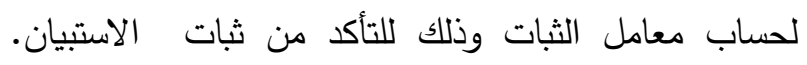
يتضح من جدول (r) أن قيم معاملات ثبات ألفا ومعاملات

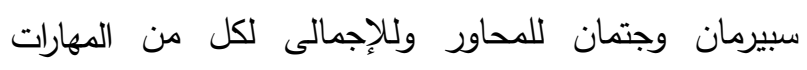

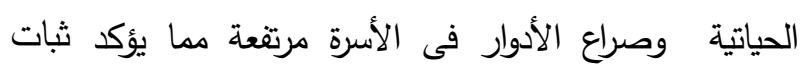
الإستبيان وصلاحيته للتطبيق

جدول r. قيم معامل الثبات لإستبيانى المهارات الحياتية

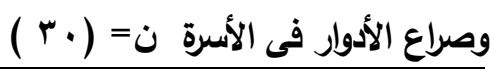
المقياس المحاور العبارات ألفامل سبيرمان جتمان

\begin{tabular}{|c|c|c|c|c|c|}
\hline, 101 &, 107 &,$\wedge \vee Y$ & Ir & إدشاعر & \\
\hline , $९ ९ \leqslant$ &, 190 &, $9 \cdot r$ & $1 \varepsilon$ & الوقارة & المهارات \\
\hline , ^^० &,$\wedge \wedge 9$ & . & Ir & التعاطف & الحياتية \\
\hline , А円А &,$\wedge \leq Y$ & , ^०ะ & Ir & المسئولية & \\
\hline , 90r &, 909 & , 949 & 0. & الى & \\
\hline , А־т & , גדV & מדז, & Ir & جة & \\
\hline, $9 Y 1$ &, $9+9$ & , & Ir & كأم & صراع \\
\hline,$\wedge \vee \wedge$ &,$\wedge \wedge Y$ & 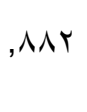 & $1 \leq$ & الأعي ادماء & الأسرة \\
\hline . &,$\wedge \vee \vee$ & , 949 & r & الإجمالى & \\
\hline
\end{tabular}

أولاً النتائج البثثية:- نتائج خصائص العينة: وصف المتغيرات المتعلقة بخصائص العينة يتضح من نتائج جدول

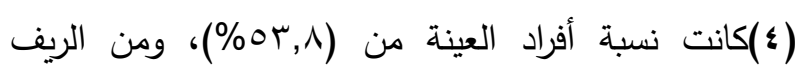

يتضح من نتائج جدول( (1) أن قيم معامل الإرتباط بين درجة

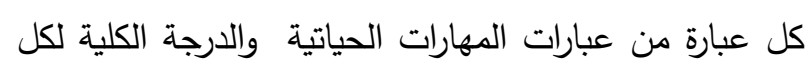

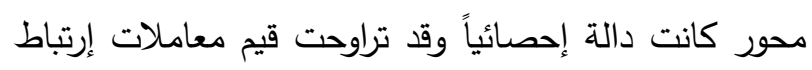

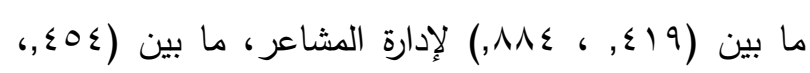

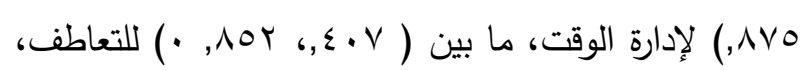

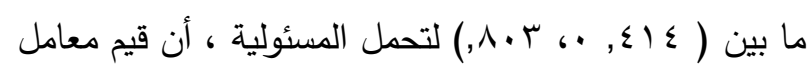

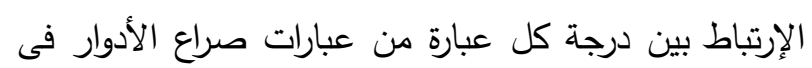
الأسرة والدرجة الكلية لكل محور كانت دالة دالة إحصائياً وقد

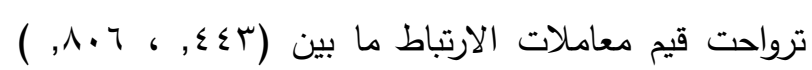

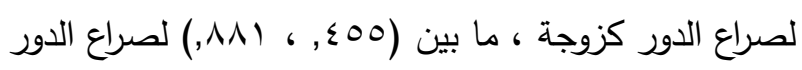

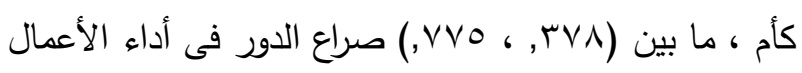
المنزلية ج) -الصدق البنائى: يتم فيه التأكد من صدق أداة البحث بإستخدام طريقة حساب معامل الإرتباط بين الدرجة الكلية للإستبيان والمحاور المكونة له.

جدول ץ. قيم معاملات الإرتباط بين الارجة الكلية لكل محور والدرجة الكلية لإستبيانى المهارات الحياتية وصراع الأدوار

\begin{tabular}{|c|c|c|c|c|}
\hline مستوي & الإرتباط & عبارات & المقياس & \\
\hline$\cdot, \cdot 1$ & $* *, \vee \vee Y$ & ir & المشاعر & \\
\hline$\cdot, \cdot 1$ & $* *, \wedge \leqslant r$ & $1 \leq$ & إدارة الوقت & الدهارات \\
\hline$\cdot, .1$ & $* *, \vee \vee \varepsilon$ & ir & التعاطف & الحياتية \\
\hline$\cdot, \cdot 1$ & $* *, \vee>0$ & ir & المسئولية & \\
\hline$\cdot, \cdot 1$ & $* *, V \leq T$ & ir & كراع الدور & \\
\hline$\cdot, \cdot 1$ & $* *, \wedge \cdot q$ & ir & صراع كأم & الأدوار \\
\hline$\cdot, \cdot 1$ & **;, Аᄉ & $1 \varepsilon$ & فراع الأدماء & الأسىرة \\
\hline
\end{tabular}

تضح من نتائج جدول (ץ) أن معاملات الإرتباط لمحاور الدهارات الحياتية لزوجة، ومحاور صراع الأدوار فى الأسرة 
(Y,Y

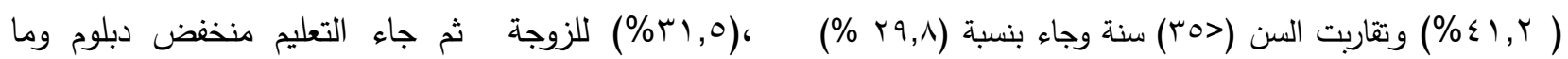

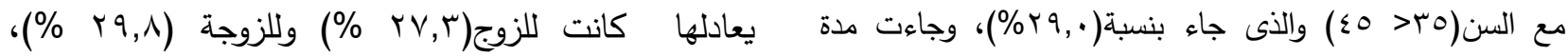

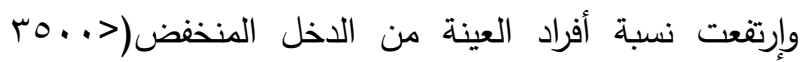

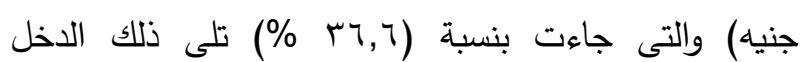

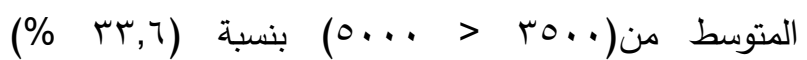
وإنخفضت عينة ذوات الدخل المرتفع ( (... جنيه فأكثر) التى جاءت بنسبة(१,^ و \% )

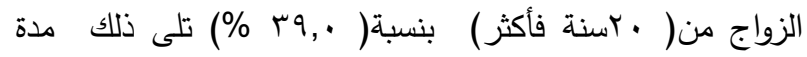

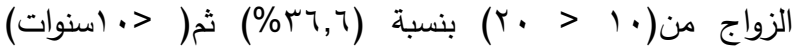

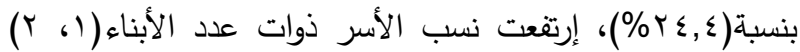
فرد وجاءت بنسبة(q,9 \% \%) تلى ذلك الأسر ذات عدد الأبناء

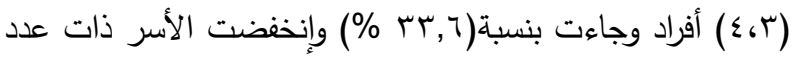

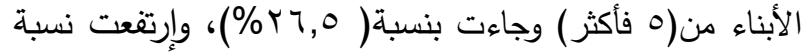
أفراد العينة من ذوى تعليم مرتفع جامعى، فوق الجامعى

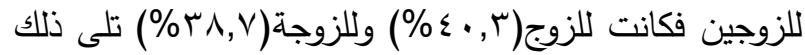

جدول ء. التوزيع النسبي للعينة وفقاً للخصائص الإجتماعية والإقتصادية

\begin{tabular}{|c|c|c|c|c|c|c|c|}
\hline$\%$ & العدد & الفئة & البيان & $\%$ & العدد & الفئة & البيان \\
\hline$r q, \wedge$ & v) & ro> & \multirow{4}{*}{ الزوجة } & $\varepsilon \neg, r$ & 11. & ريف & \multirow{4}{*}{ 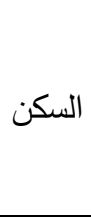 } \\
\hline rq,. & 79 & من & & or, ᄉ & IYA & 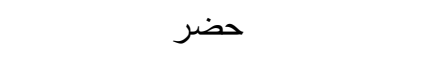 & \\
\hline$\varepsilon 1, r$ & 91 & من & & $1 \ldots$ & & & \\
\hline $1 \cdots$ & מוt & الإجمالى & & & rMA & الإ جمالي & \\
\hline$\%$ & العدد & الفئة & البيان & $\%$ & العدد & الفئة & البيان \\
\hline$r q, 9$ & 90 & $r-1$ & \multirow{4}{*}{ الأبناء } & $r \varepsilon, \varepsilon$ & $0 \wedge$ & > > اسنوات & \multirow{4}{*}{ الزواج } \\
\hline ד, זr & $\wedge$. & $\varepsilon-r$ & & T & $\wedge \vee$ & من • r r r r & \\
\hline$r \uparrow, 0$ & 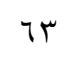 & م فأكثر & & rq,. & qr & 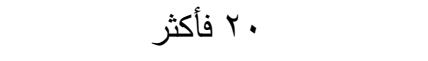 & \\
\hline $1 \cdots$ & tru & 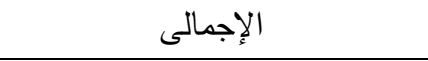 & & $1 \cdots$ & rth & الإجمالى & \\
\hline$\%$ & العدد & الفئة & البيان & $\%$ & العدد & الفئة & البيان \\
\hline$r V, r$ & 70 & تعليم منخفض دبلوم وما يعادلها & مستوي & $r ৭, \wedge$ & $v_{1}$ & تعليم منخفض دبلوم وما يعادلها & \multirow{4}{*}{ تعليمي } \\
\hline rr, & $\checkmark V$ & تعليم متوسط معاهد وما يعادلها & & M,o & vo & تعليم متوسط معاهد وما يعادلها & \\
\hline$\varepsilon \cdot, r$ & 97 & تعليم مرتفع جامعى، فوق الجامعى & & ऍ , , & $9 r$ & تعليم مرتفع جامعى، فوق الجامعى & \\
\hline \multirow[t]{6}{*}{$1 \ldots$} & rth & الإجمالى & & $1 \ldots$ & rra & الإجمالى & \\
\hline & & & & $\%$ & العدد & الفئة & البيان \\
\hline & & & & 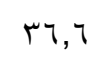 & $\wedge \vee$ & منخفض اقل من ... & \multirow{4}{*}{ للأسرة الاخل } \\
\hline & & & & ( t & $\wedge$ & متوسط من . .0ץ> ... .0 & \\
\hline & & & & $r q, \wedge$ & $v_{1}$ & مرتفع من . .0 جنيه & \\
\hline & & & & $1 \cdots$ & TrA & الإجمالى & \\
\hline
\end{tabular}


r - حساب المستويات إثتمل إستبيان المهارات الحياتية فى صورته النهائية على (•) عبارة خبرية وقد تم تقسيمه إلى إلى

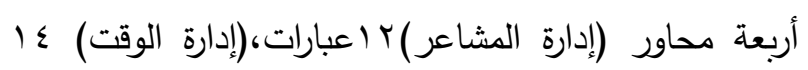

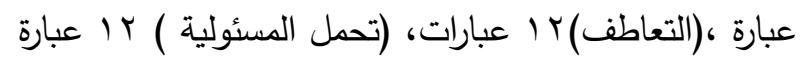
كما إثتمل إستبيان صراع الأدوار فى الأسرة فى صورته

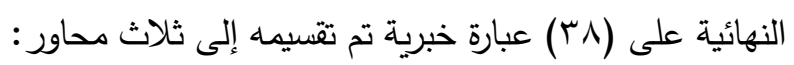

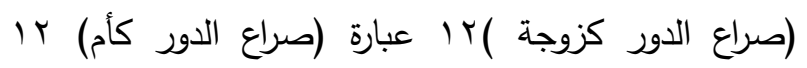

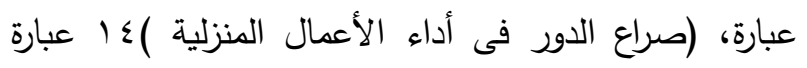
وحدت إستجابات الزوجات على هذه العبارات وفق إختيارات

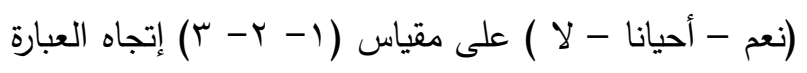
سالب وعلى مقياس (r- r- ( ) إذا كانت العبارات موجبة وبذلك أمكن تقسيم الإستبيانين إلى ثلاث مستويات وتم حساب المستويات عن طريق حساب المدى وطول الفئة

$$
\begin{aligned}
& \text { المدى= أكبر قيمة - أصغر قيمة }
\end{aligned}
$$

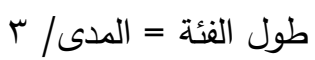$$
\text { كما موضتح بجدول (0) }
$$

نتائج وصف العينة فى ضوء الإستجابات على أدوات البحث: حساب الوزن النسبى و المستويات

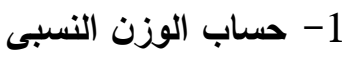
الوزن النسبى = التقدير الرقمى / إجمالى عدد العينة التقدير الرقمى = (ץ* تكرار نعم + ץ* تكرار إلى حدما

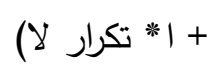

$$
\begin{aligned}
& \text { المستوى =( ن - () / ن (ن) عدد الإستجابات }
\end{aligned}
$$

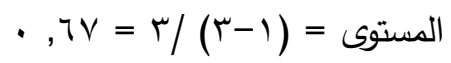

وللتعرف على درجة الموافقة لإستجابات أفراد العينة على

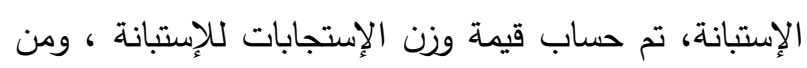
ثم تصبح الموافقة لدى أفراد العينة على العبارة والمحور إذا قل الوزن النسبى عن (VVT, ( ) ومتوسطة اذا إنحسر الوزن

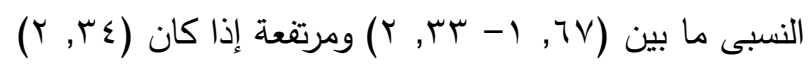
فأكثر.

\begin{tabular}{|c|c|c|c|c|c|c|c|c|}
\hline المرتفعى & المتوستوى & المنخفضوى المض & الفئةل & المدى & الكبرى & الصغرى القراء & محاور الاستبيان & الاستبيان \\
\hline TO: Y & $r V: r$. & $19: 1 r$ & $\checkmark$ & rt & ro & ir & إدارة المشاعر & \multirow{5}{*}{ المهارات } \\
\hline سז: ו & TY:TE & 10 & $\wedge$ & $r y$ & $\varepsilon$ & 10 & إدارة الوقت & \\
\hline ro: rA & $r V: r$. & $19: 1 r$ & v & rr & ro & ir & التعاطف & \\
\hline (4: & $r \wedge: r \mid$ & $r \cdot: I r$ & v & rr & Tr & ir & تحمل المسئولية & \\
\hline $1 T V: 111$ & $11 \cdot: \wedge \varepsilon$ & r: OV & $r y$ & $\wedge$ & IrV & ov & الاجمالى & \\
\hline ג & $r V: r$. & $19: 1 r$ & v & rt & ro & ir & كزوجة & \multirow{4}{*}{ الادوار فراعى } \\
\hline qז: די & $r \wedge: Y I$ & $r \cdot: l r$ & v & rr & די & ir & كأم & \\
\hline ת & TY & 10 & $\wedge$ & rt & $\varepsilon 1$ & 10 & فى أداء الأعمال المنزلية & \\
\hline $111: 19$ & ᄉᄉ : & $70: \leqslant r$ & rr & 71 & 111 & $\varepsilon r$ & الاجمالى & \\
\hline
\end{tabular}

جدول ه. القراءات الصغرى والكبرى والمدى وطول الفئة والمستويات للمهارات الحياتية وصراع الأدوار فى الأسرة 
المركز السادس تقاربت نسبة إستجابات أفراد العينة وجاءت غير دالة بوزن نسبى(ب.0) لديها القدرة على مواجهة صراعات

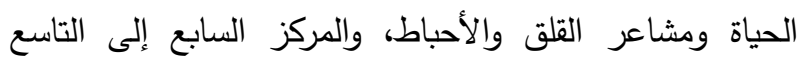

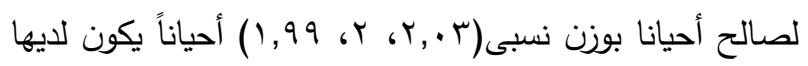
القدرة على السيطرة على نفسها بعد المواقف المزعجة ، ومواجهة

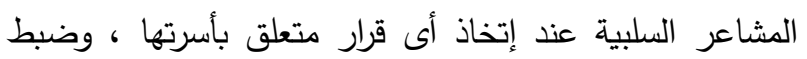

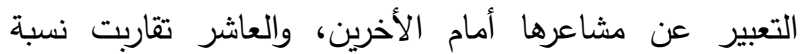

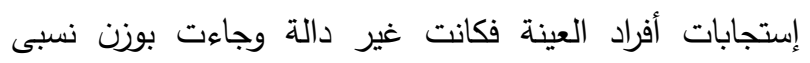

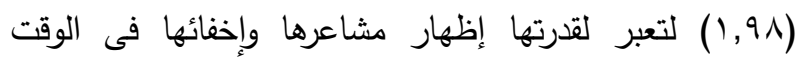
المناسب، فى المركز الحادى عشر، الثانى عشر لصالح أحياناً بوزن نسبى(1,9V، 1,97) تجدن سهولة في التعبير عن مشاعرها أمام الآخرين، تستطيع وضع حد فاصل بين تفكيرى

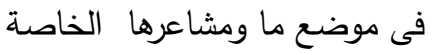

1-أولا وصف استجابات المهارات الحياتية إ- إدارة المشاعر يتضح من جدول (†) أن جميع العبارات التى تعبر عن (إدارة

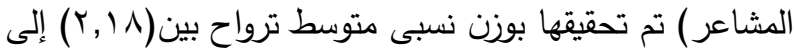
(1,97 (1,9 وكانت كا r دالة عند مستوى (0., ، 1. .,) ودرجة حرية r فيما عدا ثلاثثة عبارات تقاربت نسبة إستجابات أفراد العينة فكانت غير دالة جاءت العبارات كالتالى فى المركز الأول

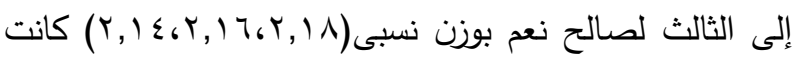
لمشاعرها الصادقة التى تساعدها فى النجاح فى حياتها، تحكمها فى مشاعرها يساعدها على إتخاذها للقرارات ، قدرتها الإنتقال من المشاعر السلبية للايجابية حسب الموقف ، فى المركز

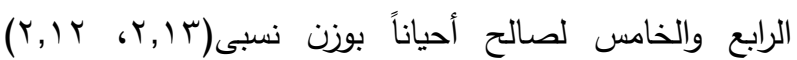
لقدرتها على إحتواء مشاعر التى تعوق أدائها للأعمال ولقدرتها

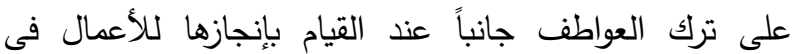

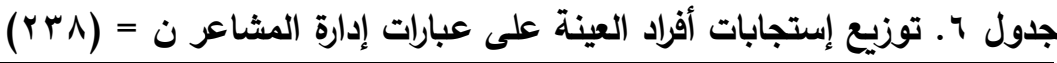

\begin{tabular}{|c|c|c|c|c|c|c|c|c|}
\hline كاY & الترتيب & 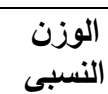 & $y$ & أحياناً & نعم & 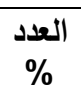 & العبارة & r \\
\hline$* 1 \cdot, \wedge 99$ & 2 & T.17 & $\begin{array}{l}7 \varepsilon \\
r Y, q .\end{array}$ & $\begin{array}{c}r \\
r q, \Lambda\end{array}$ & $\begin{array}{l}1 . r \\
\varepsilon r, r\end{array}$ & 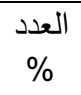 & تساعنى قدرتى على التحكم فى مشاعرى الترار السليمة & 1 \\
\hline$* * \backslash \wedge, r \wedge \vee$ & 0 & $r, I r$ & $\begin{array}{l}\text { or } \\
\text { r }, \lambda \text {. }\end{array}$ & $\begin{array}{l}1.7 \\
\varepsilon \leqslant, 0\end{array}$ & $\begin{array}{c}\Lambda . \\
r \mu, t\end{array}$ & 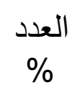 & أستطيع أنق أنحى عواطفى جانباً عندماً & r \\
\hline$* \vee, q \vee ०$ & 2 & $r, l \leq$ & $\begin{array}{c}0 q \\
r \leqslant, \wedge\end{array}$ & $\begin{array}{cl}\wedge V \\
r \Upsilon, 7\end{array}$ & $\begin{array}{l}9 r \\
r \Lambda, V\end{array}$ & 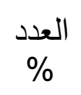 & أرى انى أستطيع الإنتقال من المشاعر & $r$ \\
\hline 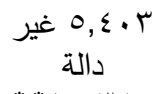 & r & $r, .0$ & $\begin{array}{l}V Y \\
r Y, \varepsilon\end{array}$ & $\begin{array}{l}90 \\
r 9,9\end{array}$ & $\begin{array}{c}T T \\
Y V, V .\end{array}$ & 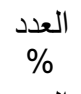 & لدى صعوبة فى مواجهة صراعات الحياة & $\varepsilon$ \\
\hline$* * 1, r, r \leq 0$ & 2 & 1,97 & $\begin{array}{l}V r \\
r \cdot, V .\end{array}$ & $\begin{array}{l}1 \cdot r \\
\varepsilon r, 9\end{array}$ & $\begin{array}{l}T r \\
r 7,0\end{array}$ & 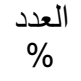 & 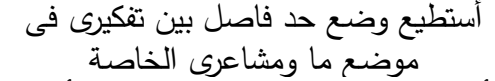 & 0 \\
\hline$* * 11,9 \cdot 1$ & $=$ & $1,9 \vee$ & 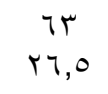 & $\begin{array}{l}1 \cdot \varepsilon \\
\varepsilon r, V\end{array}$ & $\begin{array}{l}\vee \backslash \\
r q, \wedge \text {. }\end{array}$ & 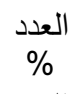 & أجد سهولة في التعبير عن مشاعري أمام & 7 \\
\hline l & $\dot{-}$ & 1,91 & $\begin{array}{l}V q \\
r, r .\end{array}$ & $\begin{array}{l}10 \\
r 0, V\end{array}$ & $\begin{array}{l}v \leq \\
r 1,1\end{array}$ & 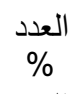 & أستطيع اظهار مشاعرى واخفاءها فى الوناسب & V \\
\hline$* * 11$, ror & - & $r, 1 \wedge$ & $\begin{array}{l}\text { ov } \\
r r, q .\end{array}$ & $\stackrel{\lambda r}{r \leq, 0}$ & $\begin{array}{l}99 \\
\leqslant 1,7\end{array}$ & 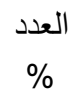 & مشاعري الصادقة تساعدني على آلعى النجاح & $\wedge$ \\
\hline$* * 17, T \leqslant V$ & $<$ & r & $\begin{array}{l}7 \varepsilon \\
r 7,9 .\end{array}$ & $\begin{array}{l}1.9 \\
\leqslant 0,1\end{array}$ & $\begin{array}{l}70 \\
r V, r\end{array}$ & 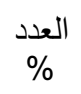 & لدى القدرةعلى مواجهة مشاعرى السلبية القرارات & 9 \\
\hline$* * 1 \leq$, or 9 & $\sigma$ & 1,99 & $\begin{array}{l}7 \varepsilon \\
Y 7,9\end{array}$ & $\begin{array}{l}1 \cdot v \\
\leqslant 0, .\end{array}$ & $\begin{array}{l}T V \\
Y \Lambda, Y \text {. }\end{array}$ & 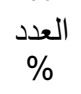 & أعبر عن مشاعرى مهما كانت أمام & 1. \\
\hline 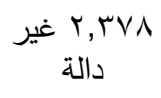 & $>$ & $r, \cdot r$ & $\begin{array}{l}V V \\
\text { Tr, }\end{array}$ & $\begin{aligned} q \cdot \\
r v, \Lambda\end{aligned}$ & $\begin{array}{l}\vee 1 \\
r q, \wedge\end{array}$ & & أجد صعوبة فى السيطرة على نفسى بعد & 11 \\
\hline$* q, \Sigma \wedge \vee$ & w & $r, I T$ & $\begin{array}{l}\text { ov } \\
r r, q .\end{array}$ & $\begin{array}{l}q r \\
r \Lambda, V\end{array}$ & $\begin{array}{c}\wedge q \\
r v, \varepsilon\end{array}$ & 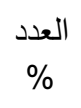 & أستطيع إحتواء مشاعر الإجهاد التى تعوق لاعمالى & IY \\
\hline
\end{tabular}




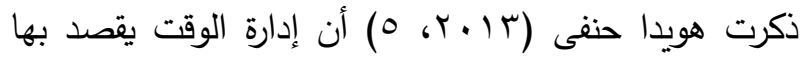
الإستخدم الرشيد للوقت من خلال تحديد الإحتياجات ووضع الأهداف والأولويات المطلوبة من خلال التخطيط والإلتزام والمتابعة وعمل جدول الأعمال بالإضاقة إلى تقدير المدة

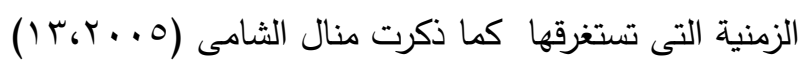

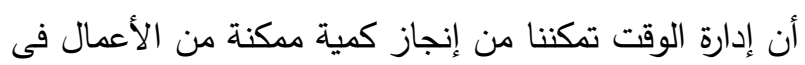

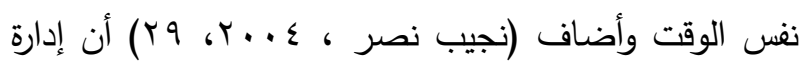

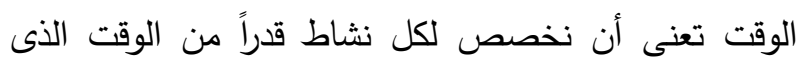

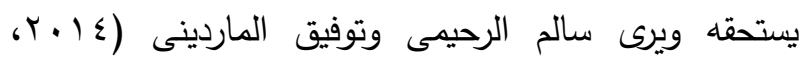

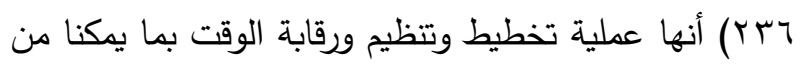
اختيار الثئ الصحيح المراد عمله والقيام بأعمال كثيرة فى

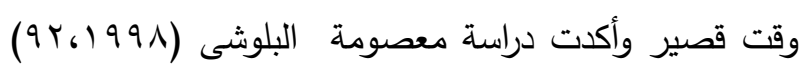
وجود فروق بين العاملة وغير العاملة فى القيام بأكثر من

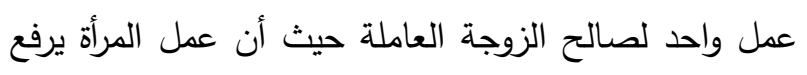

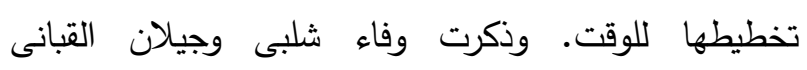

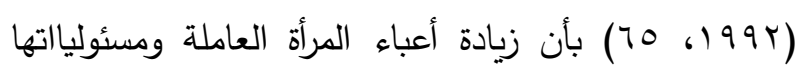
وضيق وقتها يجعلها تسعى دائما لما يساعدها فى أداء أعملها فى أقل وقت وبأقل جهذ ويعطى نتيجة جيدة وتوصلت نتائج دراسة (Hasegawa,Yuka,2010) أن الأمهات العاملات اللاتى إتجهن إلى تعديل توزيع الوقت إستغرقن وقت أقل فى

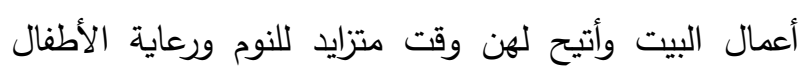
وشعرن بمزيد من الحيوية والطاقة نحو أسرهن وأن الأمهات العاملات اللاتى لم تتجهن إلى تعديل توزيع الوقت لم يكن

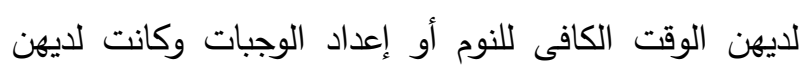
ضغوط متزايد نحو الوقت وكانت لديهن إحساس كبير بالتعب والإرهاق الزائد. r- إدارة الوقت :- يتضح من جدول (V) أن جميع العبارات التى تعبر عن (إدارة الوقت ) تم تحقيقها بوزن نسبى جاتح

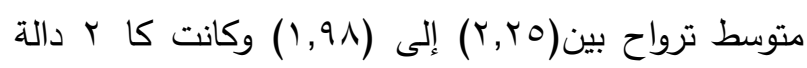
عند مستوى (0., ، 1., ) ودرجة حرية ب فيما عدا ثلاثة عبارات تقاربت نسبة إستجابات أفراد العينة فكانت غير دالة وقد جاءت العبارات كالتالى فى المركز الأول لصالح نعم بوزن نسبى (r,Yo) لتعبر ترتيب أعمالها حسب إحتياجات المنزل ومن فيه من أفراد الأسرة وجاءت فى المركز الثانى بـى

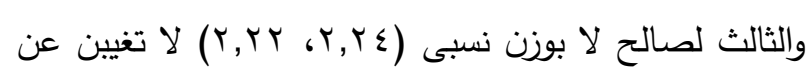

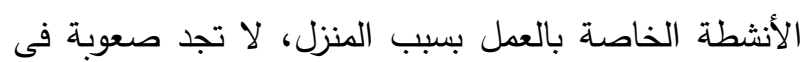

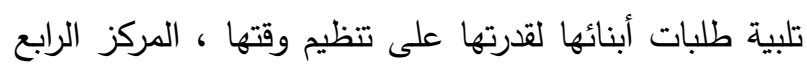
جاء لصالح نعم بوزن نسبى(Y,Y, (Y) ليعبر عن قدرتها تحديد الساعات للأعمال المختلفة والمركز الخامس لصالح أحياناً

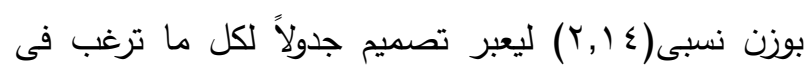

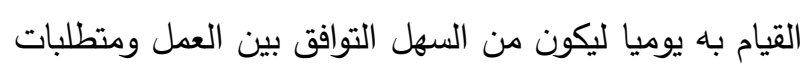

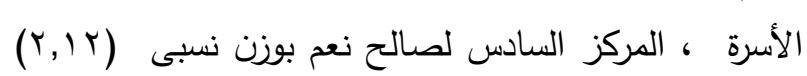
لايها القدرة على إستثمار وقتها بطريقة صحيحة ، المركز

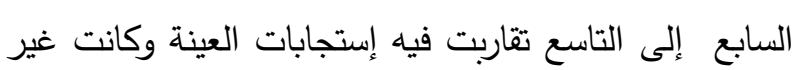

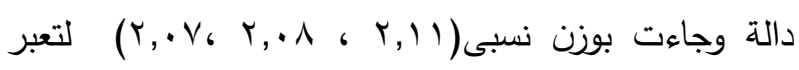
معرفة الوقت اللازم للقيام بكل عمل ، تحديد وقت للمشاركة فى الأنشطة المختلفة ،الحرص على إتباع الخطة الزمنية لكل ما تقوم به، جاء فى المركز العاشر إلى الرابع عشر لصالح

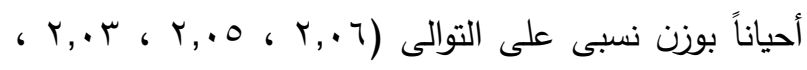

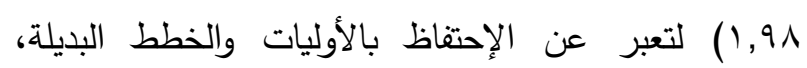

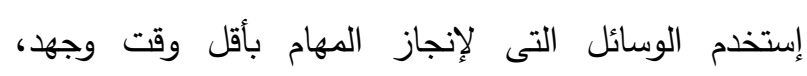
الحرص على بدء المهام وإنهائها فى أوقات محددة ، تحدد لإنداز

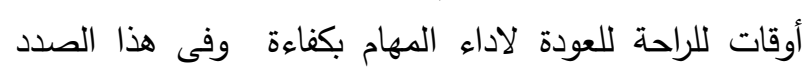




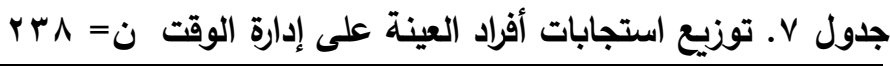

\begin{tabular}{|c|c|c|c|c|c|c|c|c|}
\hline كاr & ترتيب & الن الوزنى & $y$ & أحياناً & نعم & $\begin{array}{c}\text { العدد } \\
\%\end{array}$ & العبارة & r \\
\hline$* 1 \cdot, r / 9$ & 0 & $r, 1 \leq$ & $\begin{array}{l}0 . \\
r T, 0 \text {. }\end{array}$ & $\begin{array}{l}q r \\
r \wedge, V\end{array}$ & $\begin{array}{c}q . \\
r v, \wedge\end{array}$ & العدد & 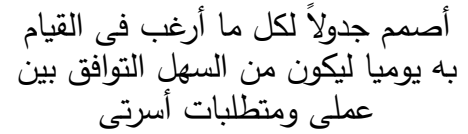 & 1 \\
\hline$* * r_{\odot}, \Sigma \vee$ & $\dot{-}$ & $r, \cdot T$ & $\begin{array}{l}0 \leqslant \\
r Y, V\end{array}$ & $\begin{array}{l}110 \\
\varepsilon \Lambda, r\end{array}$ & $\begin{array}{l}79 \\
r 9,\end{array}$ & 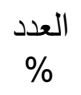 & أحتفظ بقائمة الأولوليات والخطط & r \\
\hline 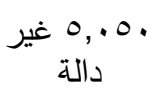 & $>$ & $r, 11$ & 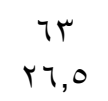 & $\begin{array}{c}\wedge V \\
r y, 7\end{array}$ & $\begin{array}{c}\Lambda \Lambda \\
r v,\end{array}$ & $\begin{array}{l}\text { العدد } \\
\text { \% }\end{array}$ & كل عمل بالضبط الأعمال اللى أقم لإنجاز & r \\
\hline 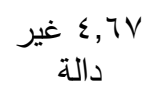 & $<$ & $r, \wedge$ & $\begin{array}{l}T \leq \\
r 7,9\end{array}$ & $\begin{array}{c}q . \\
r v, \wedge\end{array}$ & $\begin{array}{c}\wedge \varepsilon \\
r 0, r\end{array}$ & 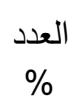 & أحدد وقتا للمشاركة فى الأنشطة لاقاربى وصديقاتى & $\varepsilon$ \\
\hline ***r, イ & $=$ & $r, .0$ & $\begin{array}{l}70 \\
T V, T\end{array}$ & $\begin{array}{l}\text { Ir. } \\
0 ., \varepsilon\end{array}$ & $\begin{array}{l}\text { or } \\
r, r\end{array}$ & 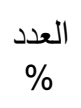 & يتداخل الوقت الذي أقضية في في الأسرة مع العمل & 0 \\
\hline 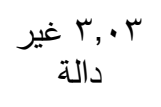 & $\sigma$ & $r, \cdot V$ & $\begin{array}{l}\text { TA, } \\
T H\end{array}$ & $\begin{array}{c}\wedge \wedge \\
\mathrm{r \nu}, \cdot\end{array}$ & $\begin{array}{c}\wedge r \\
r \varepsilon, q\end{array}$ & 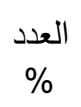 & أحرص على اتباع الخطة الزمنية & 7 \\
\hline$* * Y \leq, \Gamma \leq$ & - & r, ro & $\begin{array}{c}0 \leq \\
Y Y, V\end{array}$ & $\begin{array}{l}v \cdot \\
r q, \varepsilon\end{array}$ & $\begin{array}{l}11 \leqslant \\
\varepsilon \vee, 9\end{array}$ & 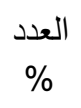 & أرتب الأعمال فى فترة ازدحامها حسب احتزل & V \\
\hline$* * \leqslant 0,+1$ & 2 & $r, \cdot r$ & $\begin{array}{l}\text { or } \\
\text { r }, 1\end{array}$ & $\begin{array}{l}\text { IrA } \\
\text { or,i }\end{array}$ & $\begin{array}{l}O \wedge \\
r \leq, \varepsilon\end{array}$ & 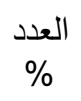 & أحرص على بدء مهامى وإنهائها فى المحد لها & $\wedge$ \\
\hline$* * \mid \vee, O \wedge$ & 2 & $r, r$, & $\begin{array}{l}1 \cdot 1 \\
\varepsilon 0, \varepsilon\end{array}$ & $\begin{array}{l}v \varepsilon \\
r 1,1\end{array}$ & $\begin{array}{l}0 T \\
Y T, 0\end{array}$ & 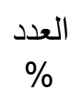 & 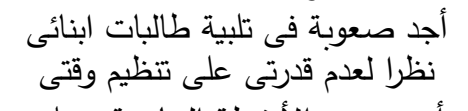 & 9 \\
\hline$* * \Upsilon 9, \wedge)$ & 2 & $r, r \varepsilon$ & $\begin{array}{l}119 \\
0 \cdot, \cdot\end{array}$ & $\begin{array}{l}O \wedge \\
r \varepsilon, \varepsilon\end{array}$ & $\begin{array}{l}71 \\
Y 0,7\end{array}$ & ا العدد & 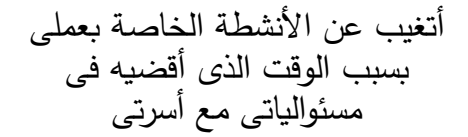 & 1. \\
\hline$*\rceil, \S)$ & $r$ & r,Ir & $\begin{array}{l}71 \\
Y 0,7\end{array}$ & $\begin{array}{c}\Lambda V \\
r T, 7\end{array}$ & $\begin{array}{c}q . \\
r v, \wedge .\end{array}$ & $\begin{array}{l}\text { العدد } \\
\text { \% }\end{array}$ & لاى القدرة على إستثمار وقتى بطريقة & 11 \\
\hline$* \wedge, \vee$. & 2 & $r, \cdot \varepsilon$ & $\begin{array}{l}7 \leq \\
Y 7,9\end{array}$ & $\begin{array}{l}1 \cdots \\
\varepsilon r,\end{array}$ & $\begin{array}{l}V \varepsilon \\
r 1,1\end{array}$ & 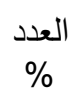 & 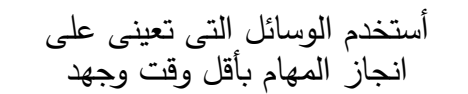 & Ir \\
\hline$* * 19,1 r$ & $w$ & 1,91 & $\begin{array}{l}T Y \\
Y V, V\end{array}$ & $\begin{array}{l}111 \\
\leq 7,7\end{array}$ & $\begin{array}{l}71 \\
Y 0,7\end{array}$ & $\begin{array}{l}\text { العدد } \\
\text { \% }\end{array}$ & أحدد أوقات للراحة لاعود للقيام بكهاءة & Tr \\
\hline$* * r_{\bullet}, r_{\bullet}$ & $w$ & $r, Y_{1}$ & $\begin{array}{l}71 \\
Y 7,1\end{array}$ & $\begin{array}{l}70 \\
r 7,9\end{array}$ & $\begin{array}{l}11 r \\
\varepsilon V, 1\end{array}$ & $\begin{array}{l}\text { العدد } \\
\text { \% }\end{array}$ & أحدد الساعات التى أريد قضائها فى الأعمال & $1 \varepsilon$ \\
\hline
\end{tabular}

عند حصول الثدائد لهم ، كما جاء المركز الرابع لصالح لا وبوزن نسبى(§,r) ليعبر لا تكون قاسية فى التعامل مع الآخرين بسب ضغوط العمل وجاءت باقى العبارات بوزن

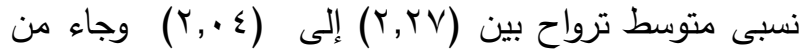

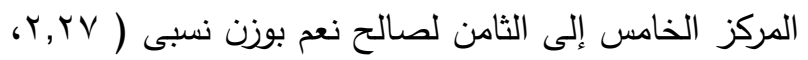

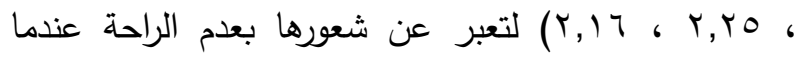
يكون الناس المحيطين بها متضايقين، الإهتمام بالأزمات r- التعاطف :- يتضح من جدول (^) أن جميع العبارات التى تعبر عن (التعاطف) كانت كاب دالة عند مستوى (0. ، · ,.) ودرجة حرية r وكان من المركز الأول إلى الثالث

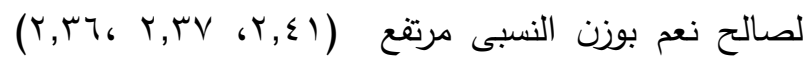
لتوضح عند تعرض الآخرين لمشكلة تحاول وضع نفسها مكأنهم حتى تستطيع تفهم مشاعرهم ، تتعاطف مع مشكلات الآخرين ومعانتهم بشكل فعال ، مساعدة أسرتها على الصمود 
التى يمر بها الزوج والعمل على مساعدته فى تجاوزها، عن الثعور بكل ما يشعر به أفراد أسرتها من مشاعر حزن

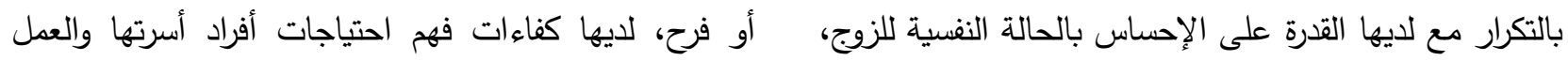
بإمكانها فهم مشاعر الأبناء وبما يحيط بهم من أحداث على تلبيتها، لديها القدرة على قراءة مشاعر أفراد أسرتها من بسهولة وجاء من المركز التاسع إلى الثانى عشر لصالح تعبيرات وجوههم، الإهتمام بمشاعر كل من حولها فى كل

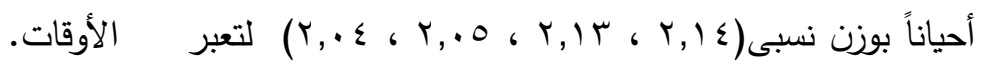

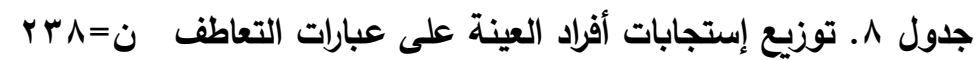

\begin{tabular}{|c|c|c|c|c|c|c|c|c|}
\hline كاץ & الترتيب & النسبى & ע & أحياناً & 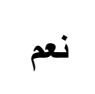 & \% & 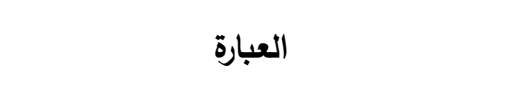 & b \\
\hline \multirow[t]{2}{*}{$* q, \vee r q$} & \multirow{2}{*}{$<$} & \multirow[t]{2}{*}{$r, 17$} & & $\wedge \vee$ & $9 \leq$ & & \multirow{2}{*}{ بإمكانى فهم مشاعر أبنائى وبما يحيط } & \multirow{2}{*}{1} \\
\hline & & & $r r, q$ & r & $r q, 0$ & $\%$ & & \\
\hline \multirow{2}{*}{$* * r r, 0, \varepsilon$} & \multirow{2}{*}{ r } & \multirow{2}{*}{ Y,YO } & $\varepsilon 9$ & 1) & $1 \cdot 1$ & 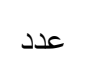 & \multirow{2}{*}{ وأهتم بالأزمات التى يمر بها زوجى في تجاوزها } & \multirow{2}{*}{ r } \\
\hline & & & $r \cdot, 0$ & $r \varepsilon$, & $\varepsilon 0, \varepsilon$ & $\%$ & & \\
\hline \multirow[t]{2}{*}{$* * \varepsilon 1, q \wedge r$} & \multirow{2}{*}{$w$} & \multirow[t]{2}{*}{$r, r \leq$} & & $\checkmark \cdot$ & $\varepsilon r$ & عدد & \multirow{2}{*}{ بسبب ضغوط العمل أصبحت قاسية فى الآخرين } & \multirow{2}{*}{ r } \\
\hline & & & or,o & $r q, \varepsilon$ & $1 \wedge, 1$ & $\%$ & & \\
\hline \multirow{2}{*}{$* * r, \wedge 91$} & \multirow{2}{*}{$=$} & \multirow{2}{*}{$r, .0$} & or & $|r|$ & 70 & عدد & \multirow{2}{*}{ لأى القدرة على قتراءة مشاعر أفراد } & \multirow[b]{2}{*}{$\varepsilon$} \\
\hline & & & 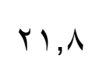 & $0 ., 1$ & $r v, r$ & $\%$ & & \\
\hline \multirow[t]{2}{*}{$* * \varepsilon 1, \wedge \cdot \vee$} & \multirow{2}{*}{2} & \multirow[t]{2}{*}{$r_{,} \cdot \varepsilon$} & 01 & Iry & 71 & 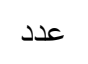 & \multirow{2}{*}{ أهتم بمشاعر كل من حولى فى كل } & \multirow{2}{*}{0} \\
\hline & & & $Y_{1, \varepsilon}$ & or, 9 . & $r_{0, T}$ & $\%$ & & \\
\hline \multirow[t]{2}{*}{$* * \eta \cdot, \varepsilon \mid r$} & \multirow{2}{*}{ - } & \multirow[t]{2}{*}{$r, \Sigma)$} & rV & $\wedge \vee$ & $1 r \varepsilon$ & 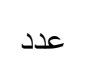 & \multirow{2}{*}{ أحاول وضع تعرض الآخرين لمشكئلة ما فإنني } & \multirow{2}{*}{7} \\
\hline & & & $11, r$ & r & or, 1 & $\%$ & & \\
\hline \multirow[t]{2}{*}{$* * r r, \neg 9 \vee$} & \multirow{2}{*}{$\therefore$} & $r, i r$ & $\varepsilon 9$ & 1.9 & $\wedge$. & 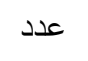 & لدى كفاءات فهم إحتياجات أفراد أسرتى & $y$ \\
\hline & & & $r \cdot, T$ & $\leqslant 0, \wedge$ & ד, ד & $\%$ & والعمل على تلبيتها & \\
\hline$* * 10, \vee r q$ & $\sigma$ & $r, 1 \leq$ & or & $1 \cdot 1$ & 10 & عدد & أستطيع الثعور بكل ما يشعر به افراد & $\Lambda$ \\
\hline & & & $r_{1, \Lambda}$ & $\varepsilon r, \varepsilon$ & $r_{0, v}$ & $\%$ & 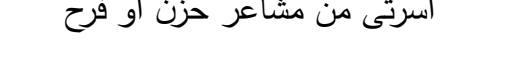 & $\Lambda$ \\
\hline$* * \Delta \wedge, \vee \leqslant \wedge$ & 2 & ז & $\varepsilon 9$ & $0 \leqslant$ & iro & 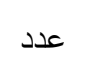 & أساعد أسرتى على الصمود عند حصول & 9 \\
\hline & & & $r \cdot, T$ & $r, Y$ & $07, V$ & $\%$ & & \\
\hline$* * \leqslant \wedge, .09$ & 2 & $r, r v$ & rᄉ & vo & iro & عدد & أتعاطف مع مشكلات الآخرين ومعانتهم & 1. \\
\hline & 2 & & 17 & M, & or,o & $\%$ & بشكل فعال & \\
\hline$* * \curlyvee \wedge, \Upsilon q \leq$ & $>$ & r, ro & 09 & 7) & 111 & عدد & لدى القدرة على الإحساس بالحالة النفسية & 11 \\
\hline & r & & $r \varepsilon, \wedge$ & Yo,T & $\varepsilon 9,7$ & $\%$ & لزَوجى & \\
\hline$* * Y 0, \wedge \leqslant q$ & 0 & $Y, Y V$ & $\varepsilon \wedge$ & $\vee \wedge$ & 114 & عدد & أشعر بعدم الراحة عندما يكون الناس & $I^{\prime}$ \\
\hline $10,10 \mathrm{~s}$ & 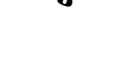 & 1, & $r \cdot, r$ & $r^{r, \Lambda}$ & $\varepsilon \vee, 1$ & $\%$ & المحيطين بى متضايقين & 11 \\
\hline
\end{tabular}


وإخلاص والعمل بدقة وتخطيط وجدية وإستعداده تحمل نتائج

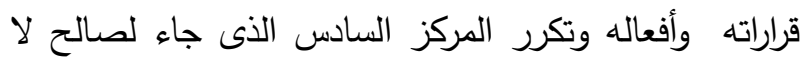
ليعبر عن ترك الأمور تسير فى الأسرة دون توجيه جاء

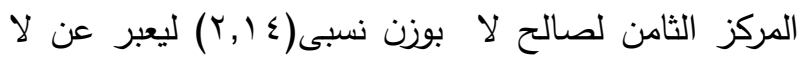

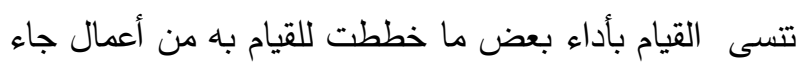

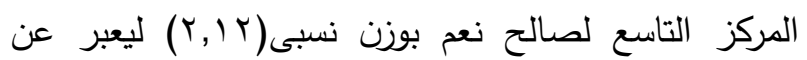
لديها القدرة على التفاعل بإيجابية مع متطلبات الحياة وتحدياتها وفى هذا الصدد ذكرت خديجة بخيت (......، • (1) أن تحمل المسئولية هى مجموعة من القدرات

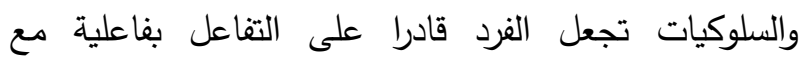
المتطلبات وتحدياتها وذلك عن طريق ما لاى الفرد من

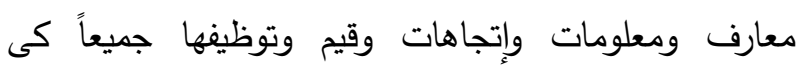

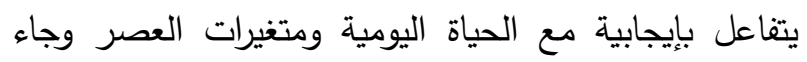
المركز العاشر والحادى عشر ليعبر عن تقارب إستجابات

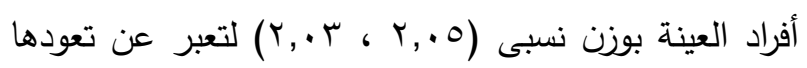

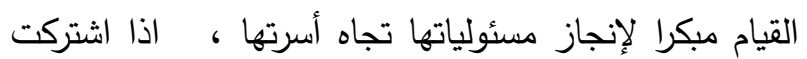
فى عمل جماعى لا تترك الأمور تسير لوحدها دون إهتمام

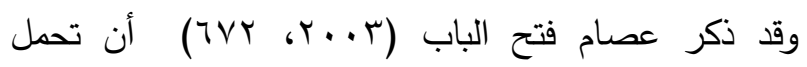
المسئولية تعنى تحمل الأعضاء داخل الجماعة المهام الموكلة

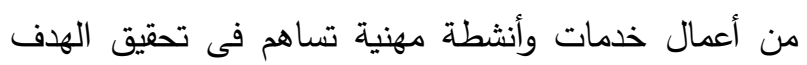
وتتمى المهارة فى تحمل الأعباء وتؤكد قيام الفرد بواجباته تحاته

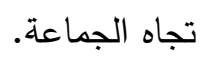

؟- تحمل المسئولية :- يتضح من جدول (9) أن جميع العبارات التى تعبر عن (تحمل المسئولية) تم تحقيقها بوزن

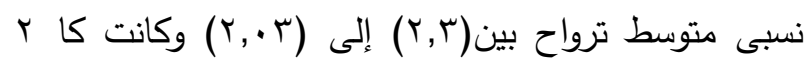
دالة عند مستوى (0., ،1..,) ودرجة حرية ب فيما عدا عبارتين تقاربت نسبة إستجابات أفراد العينة فكانت غير دالة الة الة

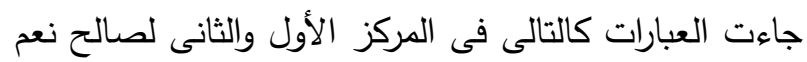

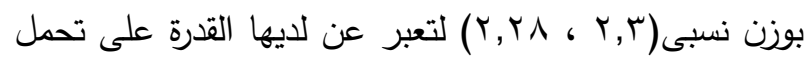

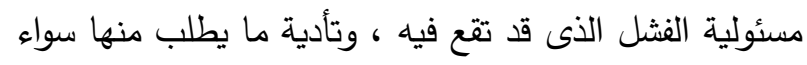
المنزل أو العمل بفاعلية وجاء المركز الثالث لصالح لا بوزن

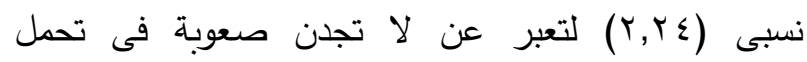

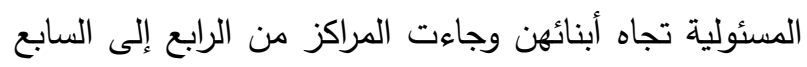

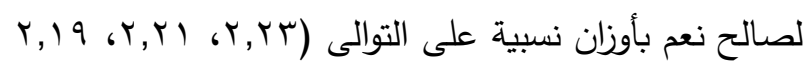

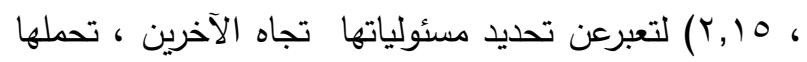

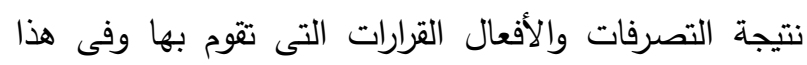
الصدد أوضح 1139,2002) Tierney \& Farmer أن الن النيات تحمل المسئولية تعنى مسؤولية الفرد عن أفعاله وتصرفاته ، ثم جاءت العبارات لتعبر عن مواجهتها للمشكلات وإيجاد

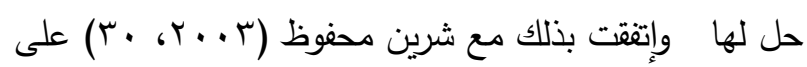
أن من إيجابيات خروج المرأة للعمل زيادة مرونة ربة الأسرة

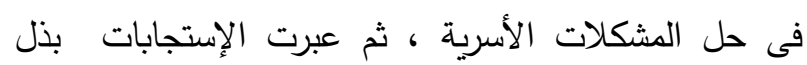

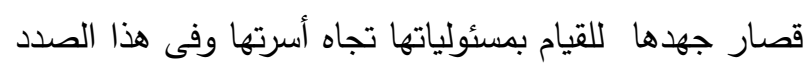

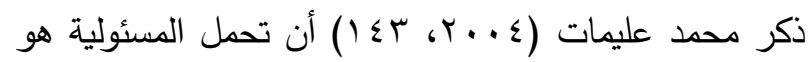

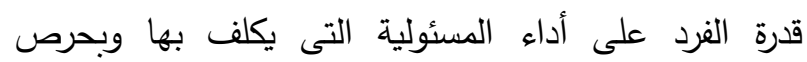




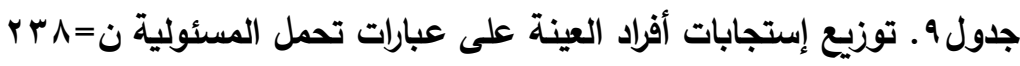

\begin{tabular}{|c|c|c|c|c|c|c|c|c|}
\hline كاr & الترتيب & النسبى الوزن & $\gamma$ & أحياناً & ن نعم & $\begin{array}{l}\text { العدد } \\
\%\end{array}$ & العبارة & p \\
\hline \multirow{2}{*}{$* * r \varepsilon, .09$} & \multirow{2}{*}{$\varepsilon$} & \multirow[t]{2}{*}{ r, r } & 71 & Tr & 110 & عدد & \multirow{2}{*}{ أحدد بوضوح مسئوالياتى تجاه أفراد } & \multirow{2}{*}{1} \\
\hline & & & $r_{0, T}$ & $r 7,1$ & $\varepsilon \wedge, r$ & $\%$ & & \\
\hline \multirow{2}{*}{$* \wedge, \cdot \vee\urcorner$} & \multirow{2}{*}{ V } & \multirow{2}{*}{$r, 10$} & $7 \varepsilon$ & vo & 99 & عدد & \multirow{2}{*}{ 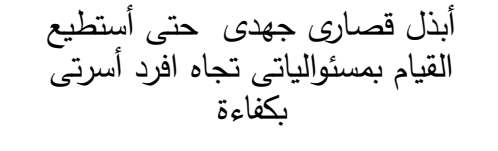 } & \multirow{2}{*}{ r } \\
\hline & & & $r 7,9$ & $r_{1,0}$ & $\varepsilon 1,7$ & $\%$ & & \\
\hline \multirow{2}{*}{ 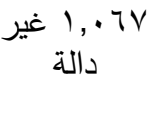 } & \multirow{2}{*}{11} & \multirow[t]{2}{*}{$r, \cdot r$} & $V r$ & $\wedge \uparrow$ & $\vee q$ & عدد & \multirow{2}{*}{ تعودت القيام مبكرا لإنجاز مسئولياتي } & \multirow{2}{*}{$r$} \\
\hline & & & $r \cdot, v$ & $r 7,1$ & 促 & $\%$ & & \\
\hline \multirow[t]{2}{*}{$* * 10, \wedge 91$} & \multirow{2}{*}{$\wedge$} & \multirow[t]{2}{*}{$r, 1 \leq$} & $1 \cdot v$ & $0 \wedge$ & $v r$ & عدد & \multirow{2}{*}{ أنسى القيام بأداء بعض من ما خططت } & \multirow{2}{*}{$\varepsilon$} \\
\hline & & & $\varepsilon 0$, & $r \varepsilon, \varepsilon$ & $r \cdot, v$ & $\%$ & & \\
\hline \multirow[t]{2}{*}{$* * Y \cdot, O \wedge$} & \multirow{2}{*}{7} & \multirow[t]{2}{*}{$r, 19$} & TV & 09 & $11 r$ & عدد & \multirow{2}{*}{ عندما تواجتهى مشكلة أسرية افضل حلثل } & \multirow{2}{*}{0} \\
\hline & & & $r \Lambda, r$ & $r \varepsilon, \wedge$ & $\varepsilon \vee, 1$ & $\%$ & & \\
\hline \multirow[t]{2}{*}{$* \Upsilon, \Upsilon 1 \Gamma$} & \multirow{2}{*}{9} & \multirow{2}{*}{ r,Ir } & 79 & vi & 91 & عدد & \multirow{2}{*}{ لدى القدرة على التفاعل بإيجابية مع الحيات وتحديات } & \multirow{2}{*}{7} \\
\hline & & & $r q, \cdot$ & $r q, \wedge$ & $\varepsilon 1, r$ & $\%$ & & \\
\hline \multirow[t]{2}{*}{$* * \varepsilon \cdot, \cdot 9 r$} & \multirow[t]{2}{*}{$0^{0}>-1$} & $r, r_{1}$ & $v r$ & $\varepsilon r$ & Irt & عدد & أتحمل نتيجة التصرفات والأفعال & V \\
\hline & & & $r \cdot, V$ & $1 \wedge, 1$ & $01, r$ & $\%$ & تى اقوم به & \\
\hline$* * 17,79 \vee$ & 7مكرر & $r, 19$ & 1.9 & 77 & 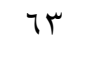 & 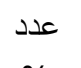 & أترك الأمور ذ & $\wedge$ \\
\hline & & & $\varepsilon 0,1$ & $r V, V$ & $r \uparrow, 0$ & $\%$ & "הر الهوכ & \\
\hline$* * Y \leq, 07 r$ & $r$ & $T, Y \varepsilon$ & 110 & 77 & ov & عدد & أجد صعوبة فى تحمل المسئولية تجاه & 9 \\
\hline & & & $\varepsilon \wedge, r$ & $r V, V$ & $r r, q$ & $\%$ & & \\
\hline ( & 1. & $r, .0$ & $\wedge \varepsilon$ & NT & VY & 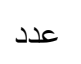 & اذا اشتركت فى عمل جماعى أترك & 1. \\
\hline & 10 & & ro, r & $\Gamma \varepsilon, 0$ & $r \cdot, r$ & $\%$ & & 1. \\
\hline$* * \varepsilon Y, 97 \uparrow$ & 1 & $r, r$ & 00 & 07 & IrV & ع عدد & لدى القدرة على تحمل مسئولية الفشل & 11 \\
\hline & & & $r r, 1$ & $r T, O$ & Or, \& & $\%$ & الذى قد اقع فيه & T \\
\hline$* * r q, .0$ & r & Y,YA & $\leq 9$ & $v r$ & 117 & عدد & أقوم بتأدية ما يطلب منى سواء فى & Ir \\
\hline & & & $r \cdot, v$ & $\varepsilon \wedge, \vee$ & $\varepsilon \vee, 1$ & $\%$ & & \\
\hline
\end{tabular}

وصف مستويات إستبيان المهارات الحياتية يتضح من نتائج جدول(· (1) أن إجمالى المهارات الحياتية المسئولية فى المركز الثانى بوزن نسبى (Y,IVV) ثم جاء متوفر لاى عينة البحث من الزوجات العاملات بدرجة إدارة الوقت في المركز الثالث بوزن (Y,110) وفى المركز

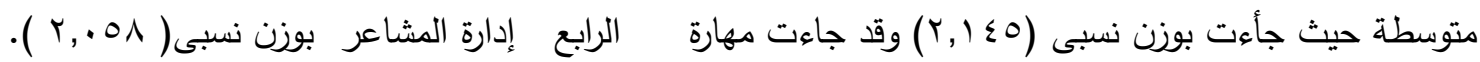

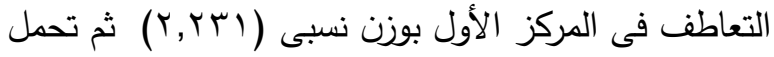


جدول • 1 ـ توزيع مستويات المهارات الحياتية للزوجة العاملة لكل محور

\begin{tabular}{|c|c|c|c|c|c|}
\hline الترتيب & الوزن النسبى & $\%$ & العدد & المستوى & المحاور \\
\hline \multirow{4}{*}{$\overline{3}$} & \multirow{4}{*}{$r, .01$} & TY,V & $0 \leq$ & منخفض (Y (9:1 (1) & \multirow{4}{*}{ إدارة المشاعر } \\
\hline & & $r_{0, V}$ & 10 & متوسط (·.Y:) & \\
\hline & & $\varepsilon 1,7$ & 99 & 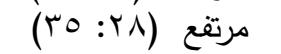 & \\
\hline & & $1 \ldots$ & rr人 & المجموع & \\
\hline \multirow{4}{*}{ 冏 } & \multirow{4}{*}{$r, 110$} & $r Y, V$ & $0 \leq$ & منخفض (10 (Y (Y) & \multirow{4}{*}{ إدارة الوقت } \\
\hline & & $\varepsilon 0,1$ & 1.9 & متوسط (צ:Y:Y) & \\
\hline & & $r_{1,0}$ & vo & مرتفع (سז: ו؟) & \\
\hline & & $1 \ldots$ & rTh & المجموع & \\
\hline \multirow{4}{*}{ নু } & \multirow{4}{*}{ Y,YMI } & $1 r, 9$ & Tr & منخفض (Y (9:1 (I) & \multirow{4}{*}{ التعاطف } \\
\hline & & $r, 1$ & $V \varepsilon$ & متوسط (·V:Y) & \\
\hline & & 00, & וT & مرتفع (人): مب) & \\
\hline & & $1 \ldots$ & rth & المجموع & \\
\hline \multirow{8}{*}{ 鹂 } & \multirow{4}{*}{$r, I V V$} & $r q, \varepsilon$ & $\checkmark \cdot$ & منخفض (T/: . r) & \multirow{4}{*}{ تحمل المسئولية } \\
\hline & & $r r, q$ & or & متوسط (Y): (Y^) & \\
\hline & & $\varepsilon 7, \vee$ & 111 & مرتفع ( (ج: דr) & \\
\hline & & $1 \ldots$ & rth & المجموع & \\
\hline & \multirow{4}{*}{$r, 1 \leq 0$} & 10,1 & Ty & منخفض (OV: & \multirow{4}{*}{ إجمالى المهارات } \\
\hline & & $r$ r,A & $\vee \wedge$ & متوسط (ع>: • 11) & \\
\hline & & or, 1 & IrE & مرتقع (III: VrI) & \\
\hline & & $1 \ldots$ & rr人 & المجموع & \\
\hline
\end{tabular}

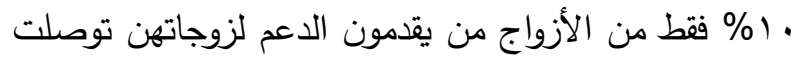

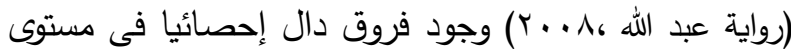
صراع الأدوار المعلمات المتزوجات تعزى إلى تعاون الزوج

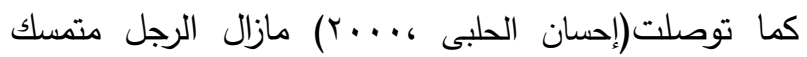
بدوره التقليدى دون أن يشارك المراة مسؤاليات الحياة الأسرية ، ثم جاءت العبارات لتعبر عن وجود صعوبة فى إلتزمها بأداء الواجبات المفروضة تجاه الزوج ،إنتهاز الزوج أى

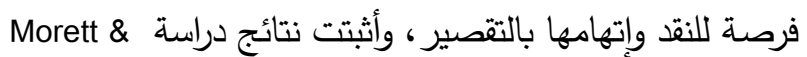
وجود علاقة طردية بين (Rosenbaum,2007) عمل ربة الأسرة وسوء التفاعل والإكتئاب لدى الزوجين وتوصلت نتائج دراسة (دلال عمار، ع ا.ب) إلى وجود فروق دالة إحصائيًا بين متوسط درجات النساء العاملات ومتوسط درجات النساء غير العاملات في توافقهن الزواجي الكلي ثم جاءت العبارات لتعبر عن لايوجد وقت كافى للإهتمام
ثانياً وصف استجابات افراد العينة على إستبيان صراع الأدوار الأسرية 1- صراع الاور كزوجة أشارت نسب الإستجابات المنخفضة إلى إرتفاع صراع الأدوار لاى عينة البحث يتضح من جدول (1 1 ) أن جميع العبارات التى تعبر إلع عن (صراع الدور فى دورها كزوجة) تم تحقيقها بوزن نسبى

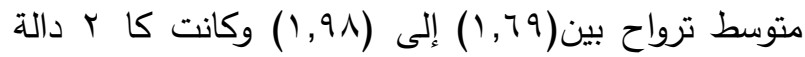
عند مستوى(0., ، 1., ودرجة حرية r فيما عدا عبارة واحدة تقاربت إستجابات أفراد العينة وكانت غير دالة جاءت العبارات كالتالى فى المركز الأول إلى الرابع لصالح نعم

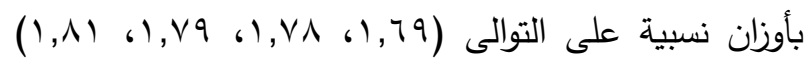
عدم مساندة الزوج تصعب من قدرتها على أداء الأدوار

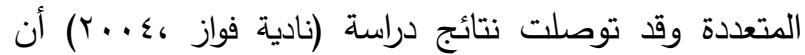
الضغط النفسى للمرأة العاملة ينتج من تعدد الأدوار ويزداد

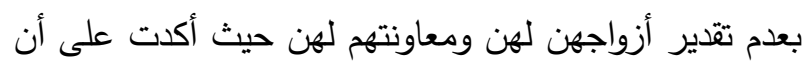




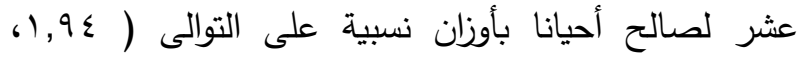

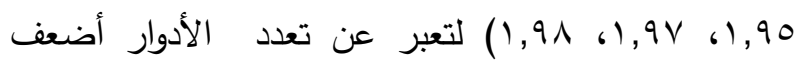
العلاقة بالزوج ، الثعور بالضيق لعدم القدرة على التوفيق

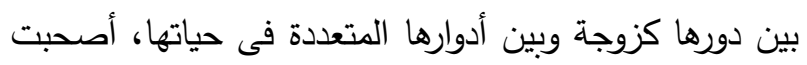

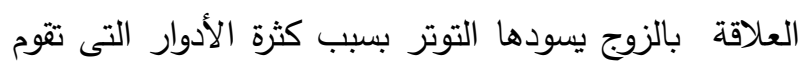

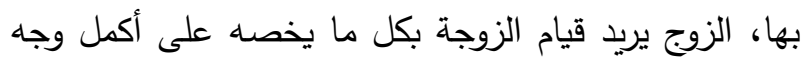

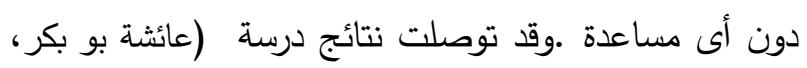

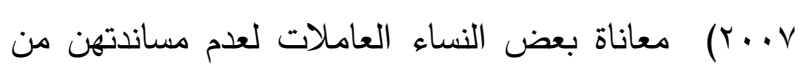

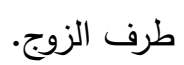

بالزوج بصورة جيدة. جاء المركز الخامس بوزن نسبى(·9, (1)

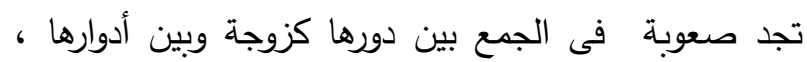

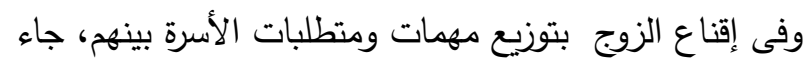

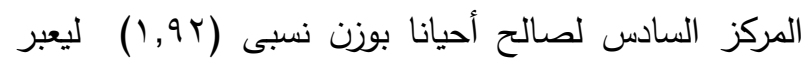

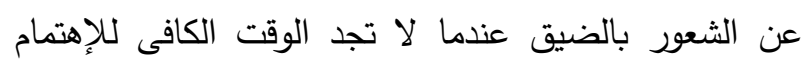
بظظرها الثخصى كزوجة، جاء المركز السابع غير دال

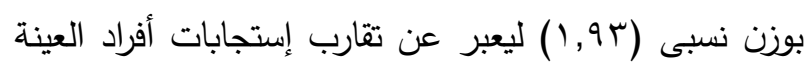

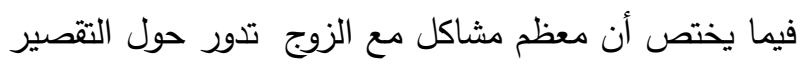

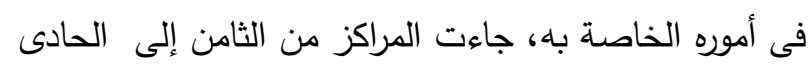

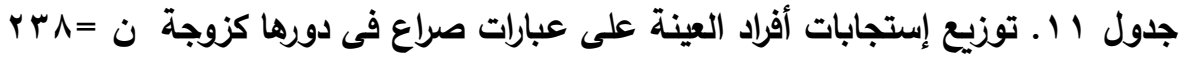

\begin{tabular}{|c|c|c|c|c|c|c|c|c|}
\hline كاץ & الترتيب & 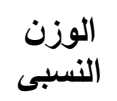 & ע & أحياناً & نعم & 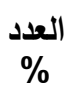 & العبارة ل & $p$ \\
\hline$"{ }^{*}|\xi, \varepsilon| Y$ & 0 & $1,9$. & $\begin{array}{l}\text { or } \\
\text { or }\end{array}$ & $1 . V$ & 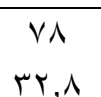 & ع ع عد & كزوجة وبين أدوارى المتعدة فيى الحياة & 1 \\
\hline$*|\varepsilon, 7 \wedge|$ & $\wedge$ & $1,9 \varepsilon$ & $\begin{array}{c}09 \\
r \leq, \Lambda\end{array}$ & $\begin{array}{l}1.7 \\
\varepsilon \leqslant, 0\end{array}$ & $\begin{array}{l}r \cdot, v \\
v e r\end{array}$ & $\begin{array}{l}\text { ع ع } \\
\%\end{array}$ & تعدد أدوارى أضعف علاقتى بزوجى & r \\
\hline$" *$ Y & 9 & 1,90 & $\begin{array}{l}00 \\
r, 1\end{array}$ & $\begin{array}{l}110 \\
\varepsilon \Lambda, r .\end{array}$ & $\begin{array}{c}\uparrow \Lambda \\
r \Lambda, T\end{array}$ & $\begin{array}{l}\text { \% } \\
\text { \% }\end{array}$ & أشعر بالضيق لانتنى لا أسيطيح التئوفيق & r \\
\hline$" 11$, ror & مكرر & 19. & $\begin{array}{l}\text { or } \\
r r, q\end{array}$ & $\begin{array}{l}99 \\
\varepsilon 1,7\end{array}$ & $\stackrel{\wedge r}{r \varepsilon, 0}$ & $\begin{array}{l}\text { \% } \\
\text { \% }\end{array}$ & أجديع معوبة فى و إقناع زوجيات بضرة بضرورة & $\varepsilon$ \\
\hline$" V, V \vee r$ & 1 & 1,95 & $\begin{array}{l}11 \\
r 0,7\end{array}$ & $\begin{array}{l}97 \\
\varepsilon \cdot, r\end{array}$ & $\stackrel{\wedge}{\wedge}$ & 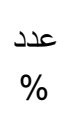 & الكافى للاهتمام بمظهرى أمام زوجى الوقى & 0 \\
\hline 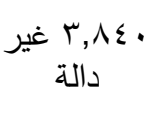 & v & 1,9r & $\begin{array}{l}V 4 \\
r 1,9\end{array}$ & $\begin{array}{l}79 \\
r 9,\end{array}$ & $\begin{array}{l}q r \\
r q, 1\end{array}$ & ع ع & تتظبري فشاكلى مع زوجى الخاصة به حول & 7 \\
\hline " & 11 & 1,91 & $\begin{array}{l}r 4,0 \\
4 \pi\end{array}$ & $\begin{array}{l}1 \cdot v \\
\varepsilon 0, .\end{array}$ & $\begin{array}{l}\uparrow \Lambda \\
r \Lambda, T\end{array}$ & \% ع ع & 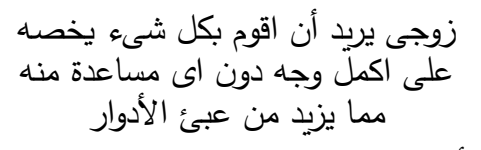 & v \\
\hline$" 1 \cdot, \wedge \wedge q$ & 1. & $1,9 \mathrm{~V}$ & $\begin{array}{l}7 \varepsilon \\
r 7,9\end{array}$ & $\begin{array}{l}1 . r \\
\varepsilon r, r\end{array}$ & $\begin{array}{l}r \\
r q, \Lambda\end{array}$ & 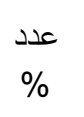 & أصحبت عثلاقتى بزوجي يسودها التوتر & $\wedge$ \\
\hline$" r \leq, .09$ & r & I,VA & $\begin{array}{l}r 4,1 \\
4 T\end{array}$ & $\begin{array}{l}r 1 \\
r 0,7\end{array}$ & $\begin{array}{l}110 \\
\varepsilon \Lambda, r\end{array}$ & 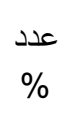 & 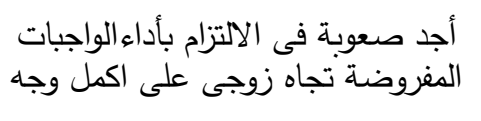 & 9 \\
\hline$" * 0,7.0$ & 1 & 1,79 & $\begin{array}{l}\varepsilon \wedge \\
r \cdot, r\end{array}$ & $\begin{array}{l}79 \\
r 9,\end{array}$ & $\begin{array}{l}|r| \\
0 \cdot, \Lambda\end{array}$ & \% & عدم مساندة زوجى تصعب من ادوارى المتعدة قدرى & 1. \\
\hline$* r \cdot, r \cdot r$ & $r$ & 1,199 & $\begin{array}{l}r, 1 \\
4 \pi, 1\end{array}$ & $\begin{array}{l}T \leqslant \\
r 7,9\end{array}$ & $\begin{array}{l}111 \\
\varepsilon V, 1\end{array}$ & 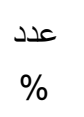 & ينتهز زوجى الى فرصة لينتقدنى & 11 \\
\hline . & $\varepsilon$ & 1,11 & $\begin{array}{c}r \Lambda \\
r \Lambda, T\end{array}$ & $\begin{array}{c}04 \\
\text { rr,O }\end{array}$ & $\begin{array}{l}11 \leqslant \\
\varepsilon V, q\end{array}$ & 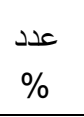 & ليس للى وقت كافى لاهتم بزوجى & Ir \\
\hline
\end{tabular}


إلى عدم مساعدتها للأبناء على استذكار دروسهم وكذلك غيابهر عن المدرسة. وجاءت عبارة تثنعر أننى أكثر شدة

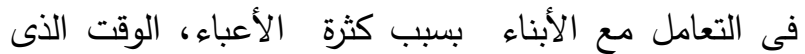

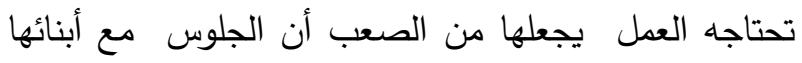

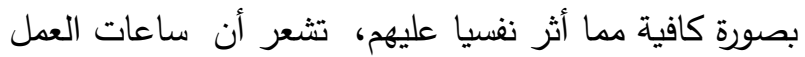

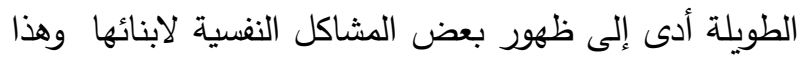

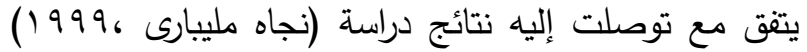

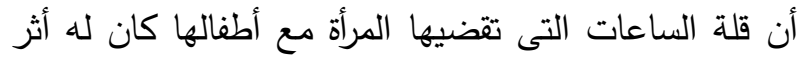

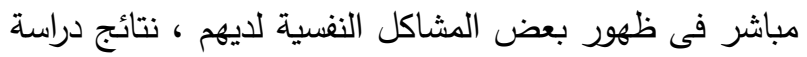

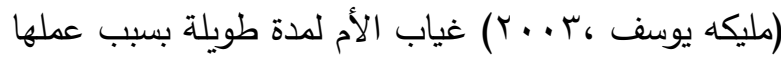

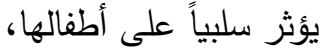

r- صراع الدور كأم يتضح من جدول (rآ) أن جميع العبارات التى تعبر عن (صراع الدور كأم) تم تحقيقها بوزن التون

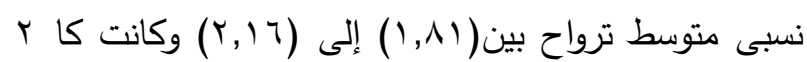

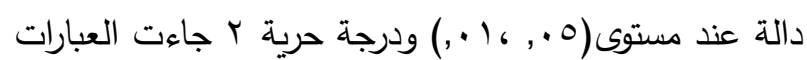

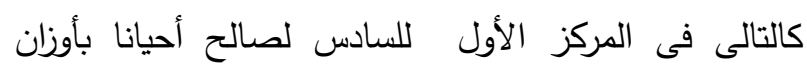

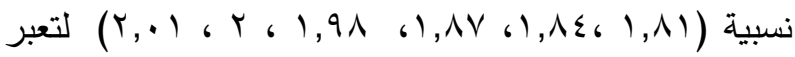
عن مساعدة الأبناء فى مزاكراتهم يزيد من الأعباء وإتنقت

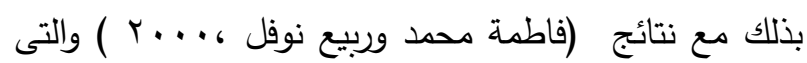
توصلت إلى وجود فروق بين أبناء العاملات وغير العاملات

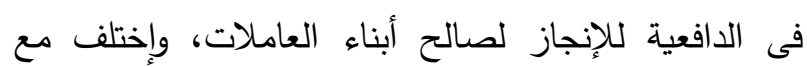

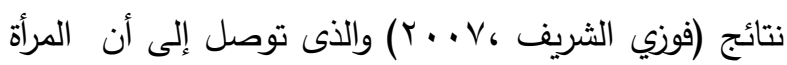

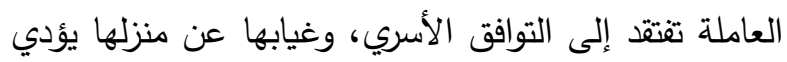

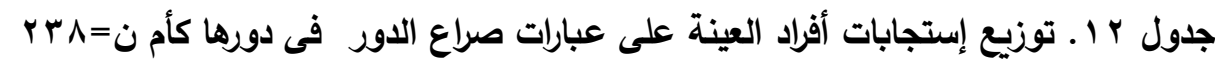

\begin{tabular}{|c|c|c|c|c|c|c|c|c|}
\hline كاץ & الترتيب & 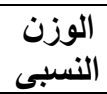 & لا & أحياناً & نعم & 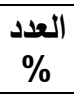 & العبارة & $r$ \\
\hline "Ir,0 & 11 & $r, 17$ & $\begin{array}{l}1.7 \\
\varepsilon \leqslant, 0\end{array}$ & $\begin{array}{l}7 \leq \\
r 7,9\end{array}$ & $\begin{array}{l}T \Lambda \\
Y \Lambda, T\end{array}$ & ع & أشعببالتقصدير الأدوار إلتمى أقوم بأولادى & 1 \\
\hline " " & 1 & $1, \wedge 1$ & $\begin{array}{l}19 \\
17, \varepsilon\end{array}$ & $\begin{array}{l}11 \leqslant \\
\varepsilon \vee, 9\end{array}$ & $\begin{array}{c}\text { No } \\
r 0, V\end{array}$ & $\begin{array}{l}\text { ع } \\
\%\end{array}$ & أعبائى مزاكراتهم يزيد من & $r$ \\
\hline${ }^{* *} 1,, v \leq \Lambda$ & $\varepsilon$ & 1,91 & $\begin{array}{l}\text { To } \\
r V, r\end{array}$ & $\begin{array}{l}1 \cdot r \\
\varepsilon r, r\end{array}$ & $\begin{array}{l}v \cdot \\
r q, \varepsilon\end{array}$ & ع ع & 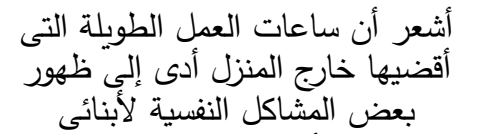 & $r$ \\
\hline "10,07r & 7 & $r, \cdot 1$ & $\begin{array}{l}T Y \\
Y V, V\end{array}$ & $\begin{array}{l}1 \cdot 1 \\
\varepsilon 0, \varepsilon\end{array}$ & $\begin{array}{l}7 \varepsilon \\
Y 7,9\end{array}$ & ع ع ع & 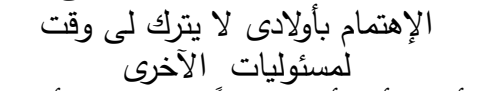 & $\varepsilon$ \\
\hline " " YV, 977 & V & $r, \cdot V$ & $\begin{array}{l}1.7 \\
\varepsilon \leqslant, 0\end{array}$ & $\begin{array}{l}\varepsilon r \\
\mid V, T\end{array}$ & $\begin{array}{ll}q . \\
r v, \Lambda\end{array}$ & ع & أشعر أنى أقل حماساً فيما بتعلق بأمور & 0 \\
\hline$" \wedge, \wedge \wedge r$ & 0 & $r, \cdots$ & $\begin{array}{l}79 \\
r 9,\end{array}$ & $\begin{array}{l}1 \cdot 1 \\
\varepsilon r, \varepsilon\end{array}$ & $\begin{array}{c}\Upsilon \Lambda \\
r \wedge, 7\end{array}$ & ع ع ع & الثعور بالإرهاق من عملى مع أبنائيى يشعرنى & 7 \\
\hline "* |ᄉ,r|| & $\wedge$ & $r, \cdot \Lambda$ & $\begin{array}{l}1 \cdot r \\
\varepsilon r, r\end{array}$ & $\begin{array}{l}0 . \\
r i, \cdot\end{array}$ & $\begin{array}{l}10 \\
r 0, V\end{array}$ & ع & ليس لاى وقت كافيى لمشاركة إبنائى & V \\
\hline$" 10,9 \leq 1$ & 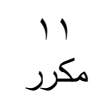 & $r, 17$ & $\begin{array}{l}1 \cdot 1 \\
\varepsilon 0, \varepsilon\end{array}$ & $\begin{array}{l}71 \\
r 0,7\end{array}$ & $\begin{array}{l}79 \\
r 9,\end{array}$ & ع ع & تحول وظيفتى دون قضاء الوقئ الحنى الذى مشاكلهم & $\wedge$ \\
\hline${ }^{*} \wedge, \vee \cdot Y$ & $r$ & $1, \wedge \vee$ & $\begin{array}{l}0 \wedge \\
r \leq, \Sigma\end{array}$ & $\begin{array}{c}q \mathrm{qr} \\
\mathrm{r \Lambda ,V}\end{array}$ & $\begin{array}{c}\wedge \Lambda \\
r v, \cdot\end{array}$ & ع ع & الصعب أنى أجلستاجه وظع ابناءى يجعل بصورة من & 9 \\
\hline$"$ "I Y,VYO & 9 & $r, l$ & $\begin{array}{l}1 \cdot r \\
\varepsilon r, 9\end{array}$ & $\begin{array}{l}\text { OV } \\
r r, q\end{array}$ & $\begin{array}{l}V q \\
r r, r\end{array}$ & ع & يؤثر عملى على مسئوالياتى تجاه & 1. \\
\hline$" * T \cdot, T \cdot O$ & r & $1, \wedge \varepsilon$ & $\begin{array}{l}\varepsilon \wedge \\
r \cdot, r\end{array}$ & $\begin{array}{l}1 \cdot \varepsilon \\
\varepsilon r, v\end{array}$ & $\begin{array}{l}\wedge t \\
r 4,1\end{array}$ & $\begin{array}{l}\text { ع } \\
\%\end{array}$ & 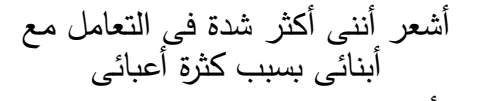 & 11 \\
\hline$" \prime \mid \neg, \vee \leqslant \Lambda$ & 11 & $r, 1$. & $\begin{array}{l}1 \cdot v \\
\leq 0, \cdot\end{array}$ & $\begin{array}{l}07 \\
r r, 0\end{array}$ & $\begin{array}{l}v_{0} \\
r_{1,0}\end{array}$ & ع ع & أجد صعوبة فيى التوفيق بينى وبين & ir \\
\hline
\end{tabular}


)، (2001, Robinson) أن ربة الأسرة يمكنها إنجاز أعمالها المنزلية وتوفير وقتها وجهدها من خلال مشاركة أفراد أسرتها،

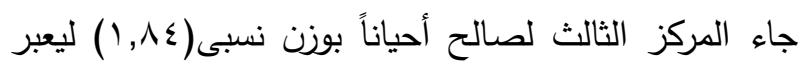
عن إستهالك الوظيفة وقتاً كبير كانت تتمنى تكريسه لإنجاز

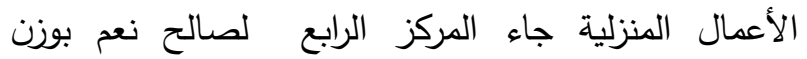
نسبى(1,1, ) ليعبر عن الشعور بالإنزعاج لتفكيرها المستمر بمطالب منزلها جاء المركز الخامس لصالح أحيانا بوزن (1,人T) نسبى يعتمد الزوج والأبناء عليها فى كل ما يتعلق بهم جاء المركز السادس لصالح نعم بوزن نسبى (1,AV) ليعبر عن يمنع إرهقها فى العمل القيام بالأعمال المنزلية جاء

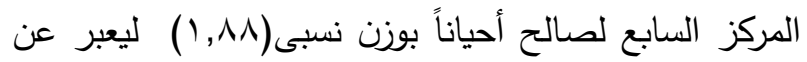
شعورها أن الوقت غير كافى لإنجاز متطلبات المنزل وقد

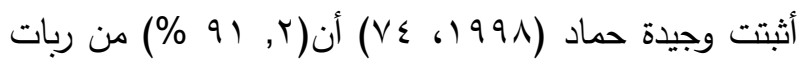
الأسر العاملات لديهن وعى مرتفع تجاه التوفيق بين العمل

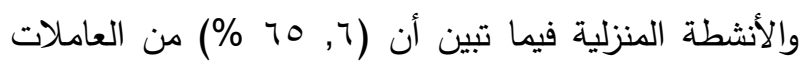
متوسطات الوعى بتخطيط الوقت جاء المركز الثامن لصالح نعم بوزن نسبى (1), (1) ليعبر عن أنه بسبب مطالب الزوج

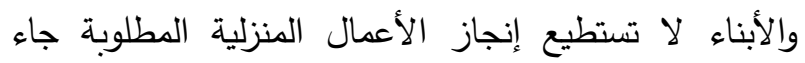

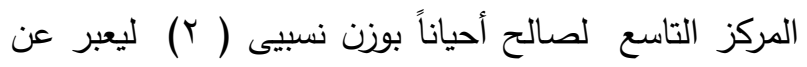
أنها تستطيع إنجاز المهام المنزلية بسبب مسئواليات ومطالب العمل جاءت العبارات من المركز العاشر إلى الثالث عشر

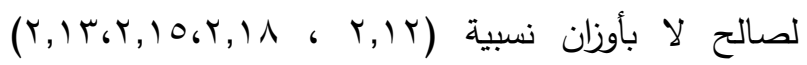
مطالب المنزل تستتفذ قدر كبير من طاقاتى، لا تعتمد على لـ لهان

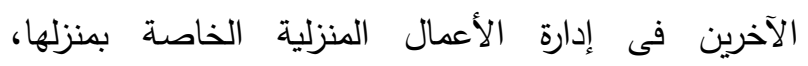
مسؤلياتها المتعددة تجاه منزلها تجعل من الصعب الإهتمام بشئونها الخاصة، لاى القدرة على تحقيق التوازن بين مطالب الزوج والأبناء ومتطلبات المنزل لا تشعرن أن حجم لتونيف مسؤولياتها تجاه المنزل أكثر مما تستطيع.
وعبرت الاستجابات عن أن الأم العاملة غالباً لا تستطيع التوفيق بين العمل الخارجي ورعاية الأطفال، وذكرت أمانى

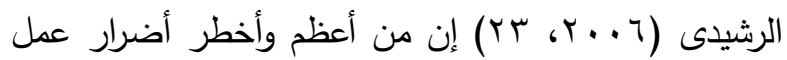
المرأة على طفلها، الإهمال في تربيته فى حين ذكر حسين

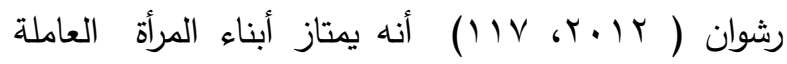
باللباقة اللفظية، حيث أدت عملية الإنفتاح الإجتماعي والثقافي إلى نمو قدرة الأبناء على الكلام غير المستند

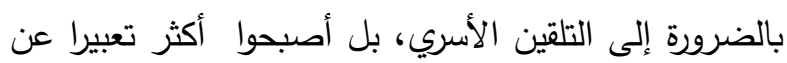

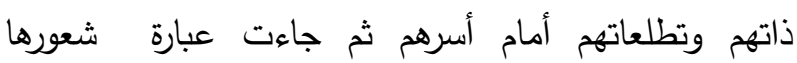

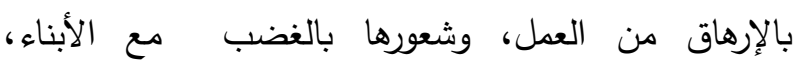

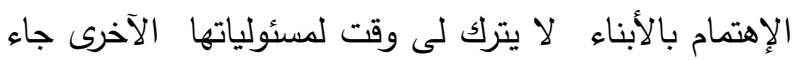
المركز السابع للحادى عشر لصالح لا بأوزان نسبية (v. r. r.

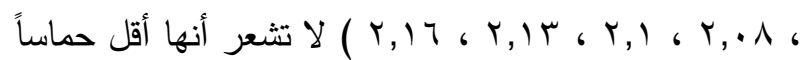
فيما بتعلق بأمور الدراسة الخاصة لأبنائها ، لديها وقت كافى الى الته

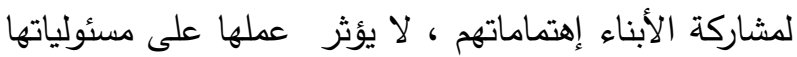
تجاه أبنائها لا تقلل وظيفتها من الوقت الذاء الفى تتمنى مع الأبناء لحل مشاكلهم لا تجد صعوبة فى التوفيق بين الوظيفة وبين

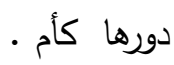
2-صراع الدوار فى الأعمال المنزلية يتضح من جدول (M I) أن جميع العبارات التى تعبر عن (صراع الدور فى أداء الأعمال المنزلية) تم تحقيقها بوزن

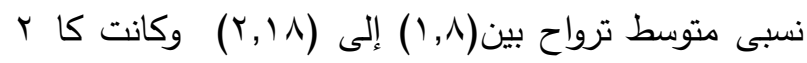

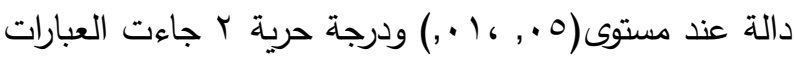
كالتالى المركز الأول لصالح نعم بوزن نسبى (1^, (1) شعورها بالتقصير تجاه مسؤلياتها المنزلية يؤثر على وظيفتها جاء المركز الثانى لصالح لا بوزن نسبى (^, ا ليعبر عن الغالبية العظمى من الأزواج لا يشاركن الزوجات فى الأعمال المنزلية وفى هذا الصدد توصلت دراسة Sponsil (2008 


\begin{tabular}{|c|c|c|c|c|c|c|c|c|}
\hline كاr & الترتيب & النسبي & ע & أحياناً & نعم & العدد & العبارة & b \\
\hline$"$ IV,000 & $r$ & 1,1 & $\begin{array}{l}9 \vee \\
\varepsilon \cdot, \wedge\end{array}$ & $\begin{array}{c}q r \\
r \wedge, V\end{array}$ & $\begin{array}{l}\varepsilon q \\
r \cdot, r\end{array}$ & $\begin{array}{l}\text { ع } \\
\%\end{array}$ & يشاركنى زوجي وابنائى في أداء الواءلية & 1 \\
\hline$"|r, O r|$ & 7 & $1, \wedge \mathrm{V}$ & $\begin{array}{l}V r \\
r \cdot, V\end{array}$ & $\begin{array}{l}7 . \\
\text { ro, r }\end{array}$ & $\begin{array}{l}1.0 \\
\varepsilon \varepsilon, 1\end{array}$ & عد & يمعنى الإرهاق فى العمل من القيام & r \\
\hline$* * 17, v \leq \Lambda$ & 11 & $r, I T$ & $\begin{array}{l}1 \cdot v \\
\leq 0,\end{array}$ & $\begin{array}{l}0 T \\
r T, 0\end{array}$ & $\begin{array}{l}\text { Vo } \\
\text { ri,o }\end{array}$ & $\begin{array}{l}\text { ع } \\
\%\end{array}$ & أعتمد على الآخرين في إدارة الأعمال & r \\
\hline$" \varepsilon 0,1 \wedge 0$ & 1 & 1,71 & $\begin{array}{l}01 \\
r \mid, \varepsilon\end{array}$ & $\begin{array}{l}0 q \\
r \leqslant, \Lambda\end{array}$ & $\begin{array}{l}\text { IrA } \\
\text { or, } 1\end{array}$ & ع ع & شعورى بالتقصير تجاه مسؤلياتى منزلى على وظيفتى & $\varepsilon$ \\
\hline 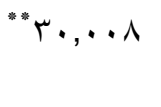 & 0 & $1, \wedge 7$ & $\begin{array}{l}\leqslant 0 \\
11,9\end{array}$ & $\begin{array}{l}11 \leq \\
\leq \vee, 9\end{array}$ & $\begin{array}{l}v q \\
r u, r\end{array}$ & ع ع & يعتمد زوجى وأبنائى على في كلى مالئ المنزليه & 0 \\
\hline 9,110 & $\varepsilon$ & 1,10 & $\begin{array}{l}10 \\
T V, T\end{array}$ & $\begin{array}{l}V Y \\
r \cdot, r\end{array}$ & $\begin{array}{l}1 \cdot 1 \\
\varepsilon r, \varepsilon\end{array}$ & ع ع & أشعر بالانزعاج بسبب تفكيرى المستمر & 7 \\
\hline$" 11,917$ & ir & $r, 10$ & $\begin{array}{l}1.9 \\
\leqslant 0,1\end{array}$ & $\begin{array}{l}00 \\
r T, 1\end{array}$ & $\begin{array}{l}V \varepsilon \\
r, 1\end{array}$ & ع ع & 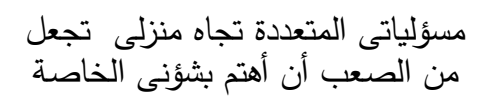 & V \\
\hline$" Y \leqslant, V T 0$ & ir & $r, 1 \Lambda$ & $\begin{array}{l}11 \leq \\
\leq V, 9\end{array}$ & $\begin{array}{l}\text { or } \\
\text { rr, r }\end{array}$ & $\begin{array}{l}v 1 \\
r q, \Lambda\end{array}$ & ع & أشعر أبن حجم مسؤولياتي تجاه المنزل & $\wedge$ \\
\hline$" 11$, or 9 & 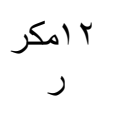 & $r, 10$ & $\begin{array}{l}1 \cdot \varepsilon \\
\varepsilon r, V\end{array}$ & $\begin{array}{l}Y T \\
Y V, V\end{array}$ & $\begin{aligned} \Upsilon \wedge \\
\uparrow \wedge, 7\end{aligned}$ & ع ع & ليس لدى القدرة على تحقيق التوازن بين ومتطلبات المنزل & 9 \\
\hline$* \mid 7, \leq \leq 0$ & V & $1, \wedge \wedge$ & $\begin{array}{l}\text { or } \\
\text { rr, r }\end{array}$ & $\begin{array}{l}l \cdot \varepsilon \\
\varepsilon r, v\end{array}$ & $\begin{array}{c}\Lambda \\
r \varepsilon, \cdot\end{array}$ & ع ع & أشعر ان الوقت غير كافى لإنجاز & 1. \\
\hline 9,011 & $\wedge$ & 1,91 & $\stackrel{\wedge \wedge}{\mathrm{r}}$ & $\begin{array}{l}\text { ov } \\
r r, q\end{array}$ & $\begin{array}{l}94 \\
r q, 1\end{array}$ & ع ع & 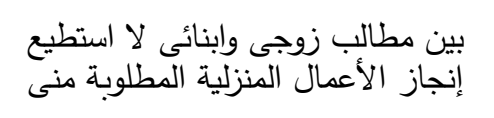 & 11 \\
\hline$" r \mid, Y)$ & 1. & $r, I r$ & $\begin{array}{l}1 \cdot 1 \\
\leqslant 0, \varepsilon\end{array}$ & $\begin{array}{c}01 \\
Y 1, \Sigma\end{array}$ & $\begin{array}{l}V q \\
r u, r\end{array}$ & ع ع & مطالب المنزل تستنف قدر كبير من & ir \\
\hline$* * 17,7 \leqslant V$ & 9 & r & $\begin{array}{l}70 \\
r V, r\end{array}$ & $\begin{array}{l}1 \cdot 9 \\
\leq 0,1\end{array}$ & $\begin{array}{l}r+0 \\
T 4,0\end{array}$ & ع ع & لا استطيع إنجاز المهام المنزلية بسبب العمل ومطالب & 14 \\
\hline$* " Y \cdot, T \cdot 0$ & $r$ & $1, \wedge \varepsilon$ & $\begin{array}{l}\varepsilon \wedge \\
r \cdot, r\end{array}$ & $\begin{array}{l}1.0 \\
\varepsilon \leqslant, r\end{array}$ & $\begin{array}{c}\Lambda \varepsilon \\
\Gamma 0, \varepsilon\end{array}$ & ع ع & تستهلك وظيفتى وقتا كبير كنت أتمنى الإنى المنزلية & $1 \varepsilon$ \\
\hline
\end{tabular}

وصف مستويات إستبيان صراع الأدوار فى الأسرة

نسبى (Y.lV) وترى الباحثتان أن ذلك يثير أن أهم

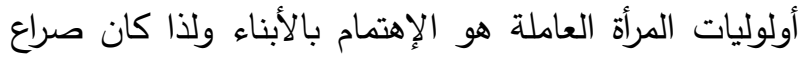
الدور المتعلق بالأبناء أقل (حيث الوزن النسبى المرتفع الدال

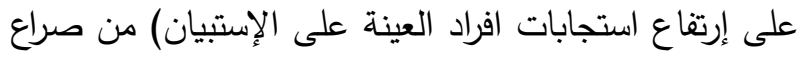

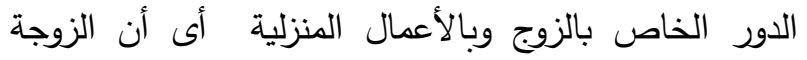

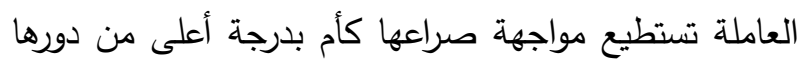
كزوجة ومن دورها فى أداء الأعمال المنزلية
يتضح من نتائج جدول(\& ()) جاء صراع الأدوار فى الأسرة

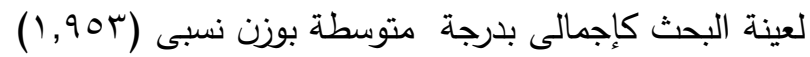
ونظرا لأن الإستبيان سلبى فقد تم الترتيب التصاعدى للدحاور وعبرت النسب المنخفة للوزن النسبى إلى إرتقاع الظاهرة

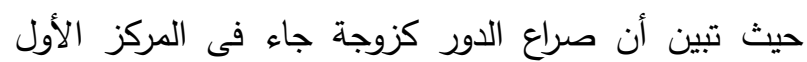

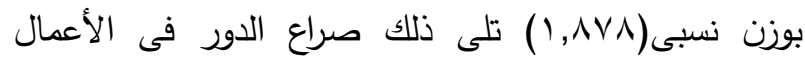

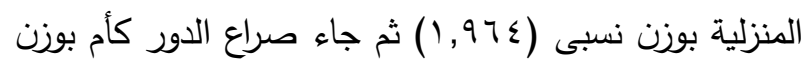


جدول \& 1. توزيع مستويات صراع الأدوار فى الأسرة للزوجة العاملة

\begin{tabular}{|c|c|c|c|c|c|}
\hline الترتيب & الوزن النسبى & $\%$ & العدد & المستوى & المحاور \\
\hline \multirow{4}{*}{ দু̀े } & \multirow{4}{*}{$1, \wedge \vee \wedge$} & Tr, & $V V$ & مرتفع (Y (19:1) & \multirow{4}{*}{ صراع الدور } \\
\hline & & $r q, q$ & 90 & متوسط (r: & \\
\hline & & $r V, V$ & 77 & 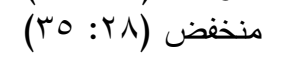 & \\
\hline & & $1 \ldots$ & ra & المجموع & \\
\hline \multirow{4}{*}{ 冏 } & \multirow{4}{*}{$r, .1 V$} & $r q, q$ & 90 & مرتقع (rا: · r) & \multirow{4}{*}{ صراع الدور كأم } \\
\hline & & rq,. & 79 & متوسط (Y^: (Y^) & \\
\hline & & rI, & $V \varepsilon$ & منخفض (q Y: צr) & \\
\hline & & $1 \ldots$ & rTh & المجموع & \\
\hline \multirow{8}{*}{$\sqrt{7}$} & \multirow{4}{*}{$1,97 \varepsilon$} & $r v, \cdot$ & $\wedge \wedge$ & مرتفع (0 1: & \multirow{4}{*}{ الأعمال الأور فئي } \\
\hline & & $r \wedge, l$ & $T V$ & متوسط (צ : & \\
\hline & & $r \varepsilon, q$ & N & منخفض (rr: ו؟) & \\
\hline & & $1 \ldots$ & rth & المجموع & \\
\hline & \multirow{4}{*}{$1,90 \pi$} & $r v, \varepsilon$ & 19 & مرتفع (T؟: & \multirow{4}{*}{ الإجمالى } \\
\hline & & $r q, q$ & 90 & متوسط (דا: ^^) & \\
\hline & & $r, v$ & $0 \leq$ & منخفض (19: (1) (1) & \\
\hline & & $1 \ldots$ & rra & المجموع & \\
\hline
\end{tabular}

الأعمال المنزلية) الإجمالى لاى عينة من الزوجات العاملات

ثالثا النتائج فى ضوء فروض البحث:

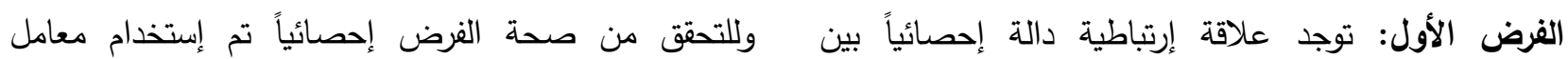
المهارات الحياتية (إدارة المشاعر ، إدارة الوقت، التعاطف، إرتباط بيرسون Correlation Pearson بين المتغيرات الخاصة

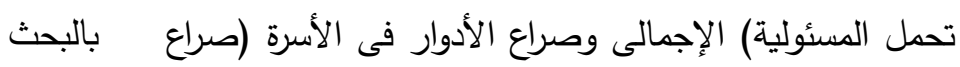

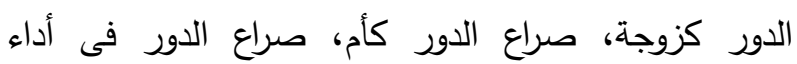

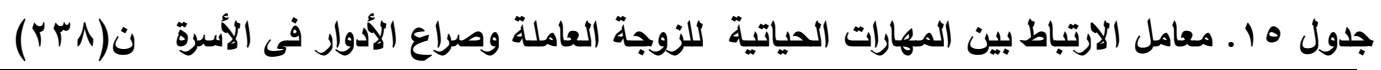

\begin{tabular}{|c|c|c|c|c|c|}
\hline الإجمالى & تحمل المسئولية & التعاطف & إدارة الوقتت & إدارة المشاعر & صراع الأدوار فى الأسيرة \\
\hline$* *, \varepsilon \mid r-$ & $* *$. หา & $* *, r \ldots-$ & $* * \cdot, r \leq q-$ & $* *$. & صراع الدور كزوجة \\
\hline ** • & $* *, \quad, r r \varepsilon-$ & $*, 100-$ & $* *,, Y Y V-$ & $* *, r \circ V-$ & صراع الدور كأم \\
\hline$* *$ * , r01- & $* *$. , $\{1 \leqslant-$ & $\cdot, \cdot \Lambda \cdot-$ & $* *,, r r r-$ & $* *,, r \leqslant V-$ & صراعِعال الدور في أداء المنزلية \\
\hline$* *,, \leq 7 r-$ & $* *, r, r q \varepsilon-$ & $* *,, 1 \wedge .-$ & ** • • & $* *,, \Sigma) \wedge-$ & الإجمالى \\
\hline
\end{tabular}


التغلب على كافة المشكلات والأزمات التي تواجهها كما

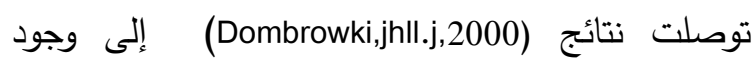
علاقة عكسية بين إدارة الوقت وصراع الأدوار . - وجود علاقة إرتباطية سالبة دالة إحصائياً عند مستوى (1 .,) بين المهارات الحياتية (التعاطف) و صراع الأدوار

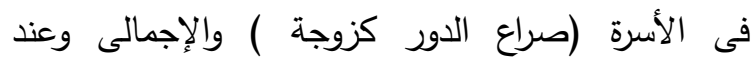

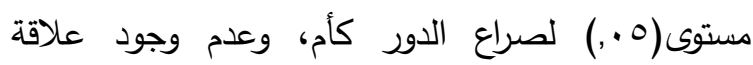

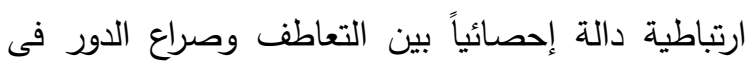

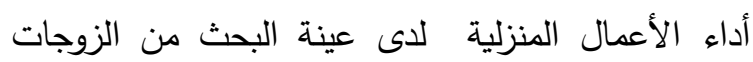

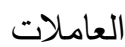
- مجود علاقة إرتباطية سالبة دالة إحصائيا عند مستوى

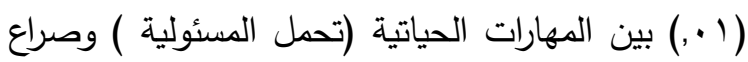
الأدوار فى الأسرة (صراع الدور كزوجة، صراع الدور

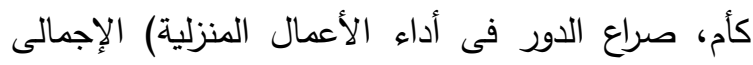
لاى عينة البحث من الزوجات العاملات

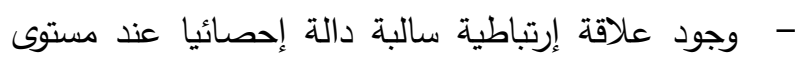

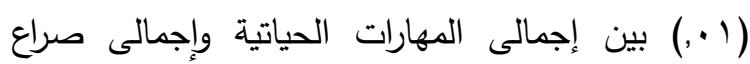
الأدوار فى الأسرة لاى عينة البحث من الزوجات

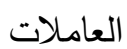

نستخلص مما سبق وجود علاقة إرتباطية سالبة دالة

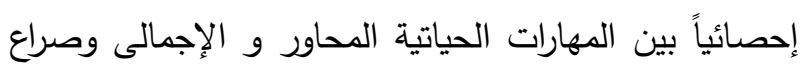

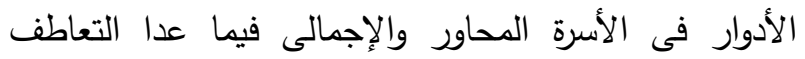

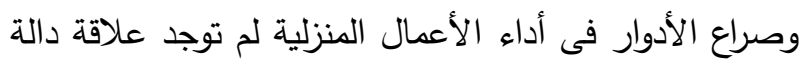

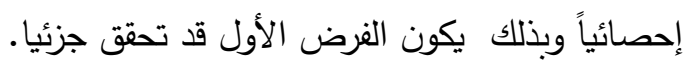

يتضح من نتائج جدول (10) وجود علاقة إرتباطية سالبة دالة إحصائياً عند مستوى (1 . .,) بين المهارات الحياتية (إدارة

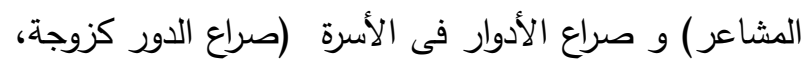

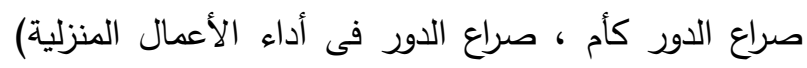
الإجمالى لاى عينة البحث من الزوجات العاملات.

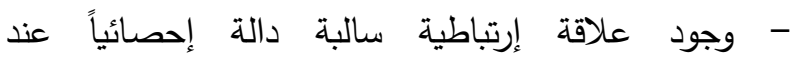

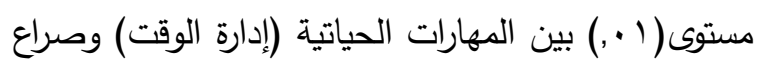

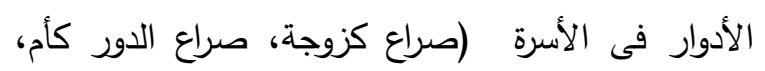

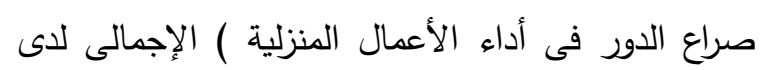

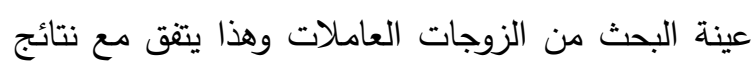

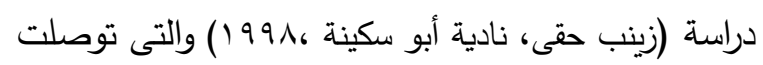

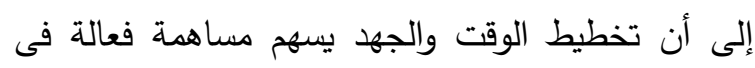

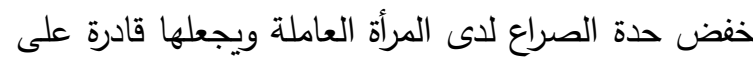
التوافق النفسى مع ظروف الحياة كما بينت نتائج دراسة

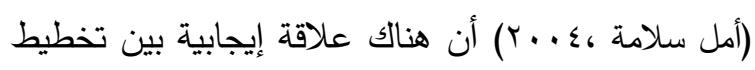

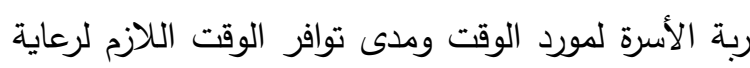

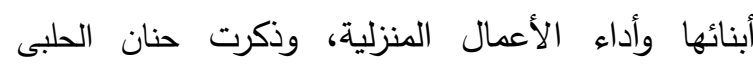

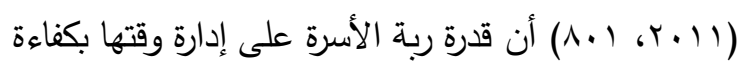
وفعالية تساعدها في إنجاز أعمالها بيسر وسهولة وبأقل التحن وقت وجها وهذا ينعكس بدوره على نفسها وعلى أسرتها

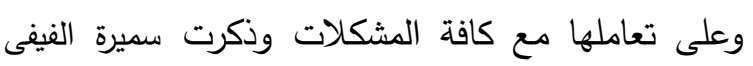

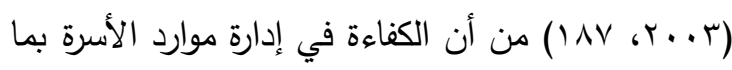

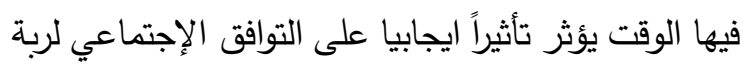

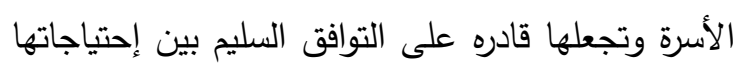
واحتياجات أسرتها ومتطلبات البيئة المحيطة وبالتالي التئي 
جدول 17 ـ دلالة الفروق بين متوسطات درجات عينة البحث فى المهارات الحياتية تبعاً لمكان السكن

\begin{tabular}{|c|c|c|c|c|c|c|c|}
\hline \multirow[b]{2}{*}{ مستوى الدلالة } & \multirow[b]{2}{*}{ قيمة ت } & \multirow[b]{2}{*}{ المتوسطات } & \multicolumn{2}{|c|}{ حضر (Y I I ) } & \multicolumn{2}{|c|}{ ريف (·11) } & \multirow[b]{2}{*}{ المحاور } \\
\hline & & & الإنعيارى & الحسابى المتط & الإنحعيارى & الحستبى & \\
\hline r | , • غير دالة & $1,09 \mathrm{~V}-$ & $1, r \leq 7-$ & $0,79$. & ro, rVT & $7, r \leq \varepsilon$ & $r \varepsilon, \cdot r V$ & إدارة المشاعر \\
\hline هץ •, • دالة عند $ه$ •, & Y,YOY- & $1, \wedge 9 \leq-$ & $7, Y \nearrow \varepsilon$ & $\Gamma \cdot, \varepsilon \wedge \varepsilon$ & $7,79 \leq$ & $r \wedge, 09)$ & إدارة الوقت \\
\hline دالة عند ا •, & r,OYA & 1,700 & $\varepsilon, \wedge \leq V$ & $r \tau, \ldots$ & $0, r \leq 0$ & $r V, 700$ & التعاطف \\
\hline ع أ9, · غير دالة & $\cdot, 1 \cdot 1-$ & $\cdot, 1 \cdot V-$ & V, & $r \neg, 1 \wedge$ & $\Lambda, 1 \cdot 1$ & $r q, \cdot V r$ & تحمل المسئولية \\
\hline ع ا0, • غير دالة & - ,70 10 & $1,09 \cdot-$ & $17, \wedge \wedge r$ & $1 \cdot v, 9 \leq$. & r., & $1 \cdot 7, r_{0}$ & الإجمالى \\
\hline
\end{tabular}

البحث فى التعاطف لصالح سكان الريف حيث كانت قيمة

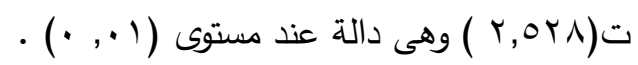
r- السن يتضح من نتائج جدول (VV) وجود تباين دال

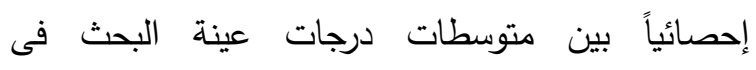
المهارات الحياتية للزوجة العاملة (إدارة المشاعر، إدارة

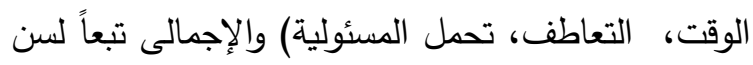

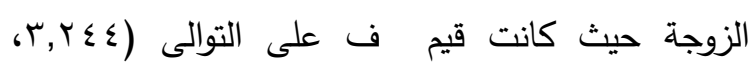

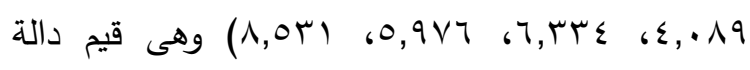
إحصائياً عند مستوى( ( .,، 0 .,.) ولمعرفة إتجاه الفروق تم تطبيق إختبار LSD يتضح من نتائج جدول (1/) وجود فروق دالة إحصائياً بين

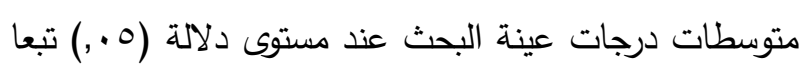
لسن الزوجة فى إتجاه السن الأكبر (حيث المتوسطات

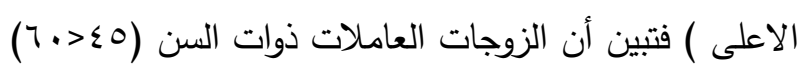

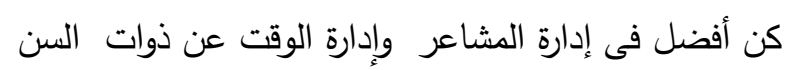
(Y0>)

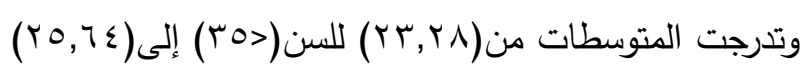

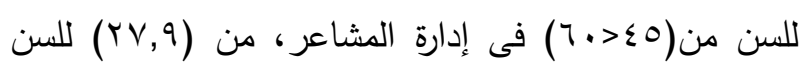

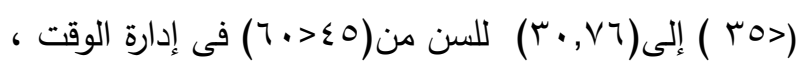

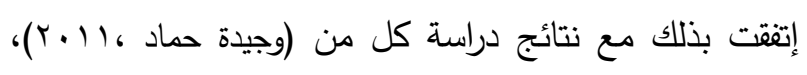

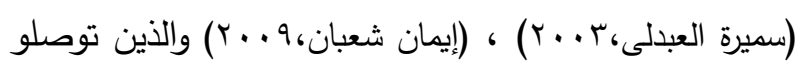

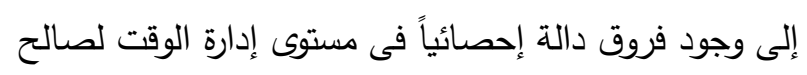

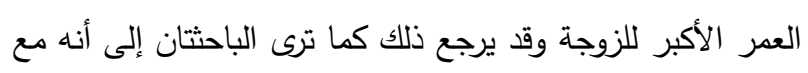

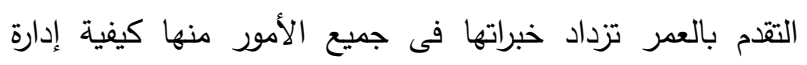

الفرض الثانى: توجد فروق بين متوسطات درجات عينة

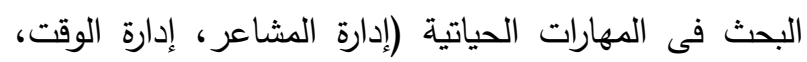

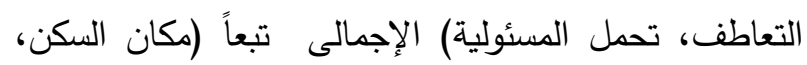

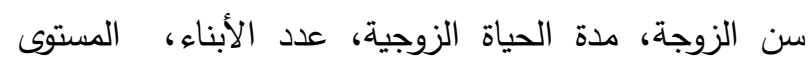

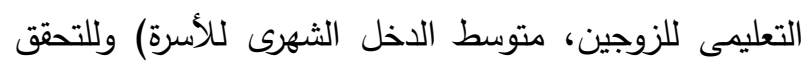
من صحة الفرض إحصائياً تم إستخدام إختبار (T test) للوقوف على دلالة الفروق بين متوسطات درجات عينة البحث فى المهارات الحياتية بمحاورها وفقاً (لمكان السكن) واستخدام أسلوب تحليل التباين الأحادى (One Way Anova) وتطبيق اختبار(LSD) لبيان دلالة إتجاه الفروق ان وجدت

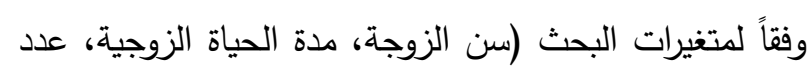

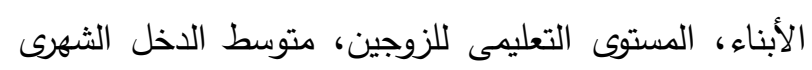
لكلأسرة).

1-مكان السكن يتضح من نتائج جدول (7 1 ) - عدم وجود

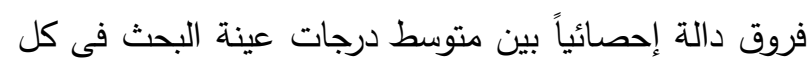
من إدارة المشاعر، تحمل المسئولية وإجمالى المهارات

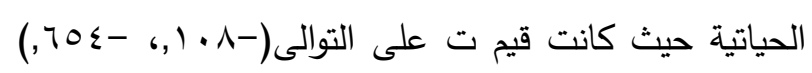
وهى قيم غير دالة إحصائيابينما وجدت فروق بين متوسطات درجات عينة البحث فى المهارات الحياتية (إدارة الوقت)

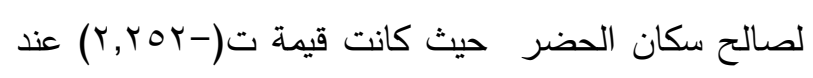
مستوى (0.,) وإتققت بذلك مع ما توصلت إليه نتائج

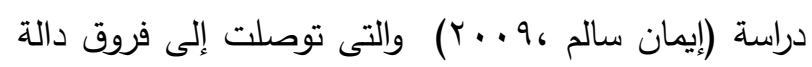
إحصائيا بين ربات أسر الريف والحضر لصالح ربات أسر الحضر ووجود فروق دالة إحصائياً بين متوسط درجات عينة 


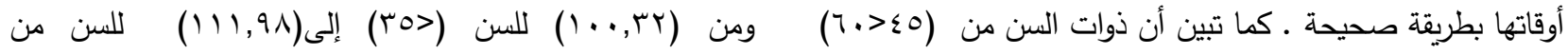

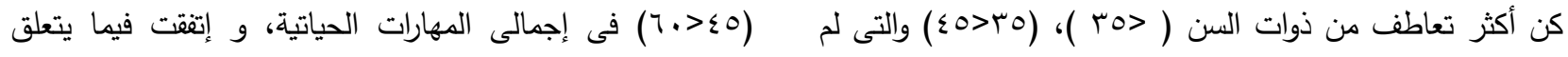

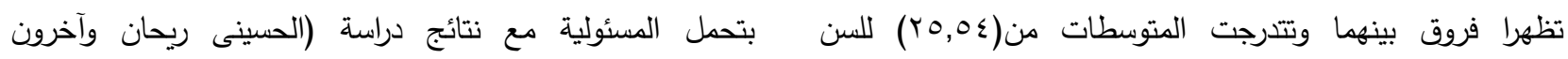

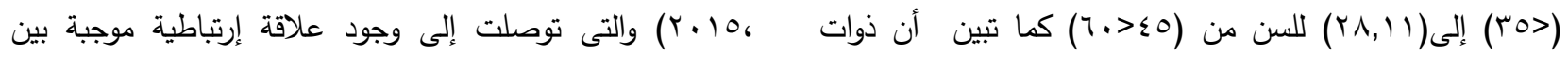

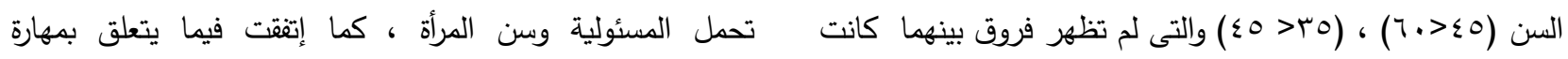

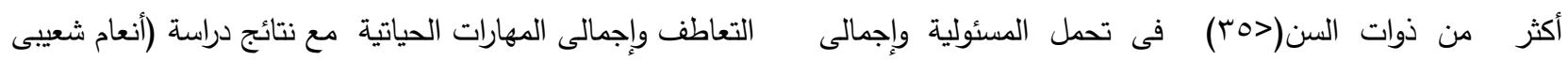

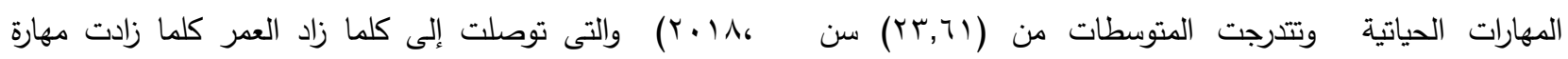

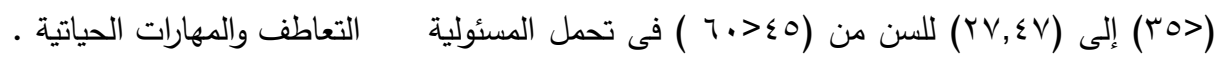
جدول V V ـ تحليل التباين أحادى الإتجاه للفروق بين المتوسطات فى المهارات الحياتية تبعاً لسن الزوجة

\begin{tabular}{|c|c|c|c|c|c|c|}
\hline مستوى الدلالة & قيمة ف & متوسط المربعات & درجات الحرية & مجموع المربعات & مصادر التباين & المحاور \\
\hline إ •, • دال & $r, Y \leq \varepsilon$ & $110, \varepsilon \cdot 1$ & $r$ & $r r \cdot \Lambda \cdot r$ & \multirow{3}{*}{ داخل المجموعات الكلى } & \multirow{3}{*}{ إدارة المشاعر } \\
\hline عند 0., . & & \multirow[t]{2}{*}{ ro, OVY } & oro & $\wedge r \circ q, \Sigma) \vee$ & & \\
\hline & & & $r \mu v$ & $\Lambda 09, ., 11$ & & \\
\hline ג •.,.• دال & $\varepsilon, \cdot \wedge q$ & $179, \leqslant 9$ & r & $r r \Lambda, 9 \Lambda$ & \multirow{3}{*}{ داخل المجموعات الكلى } & \multirow{3}{*}{ إدارة الوقت } \\
\hline عند 0. & & $\leqslant 1, \leqslant 0 \leqslant$ & r tro & $9 \vee \leqslant 1,7 \wedge$ & & \\
\hline & & & $r$ rr & 1.1 .1 .77 & & \\
\hline دال عند ا •, & T,TM & $10 V, 17 Y$ & $r$ & MI $\leq, T r \varepsilon$ & & \multirow{3}{*}{ التعاطف } \\
\hline & & $r \leq, \wedge \mid 1$ & r tro & $\Delta \wedge r \cdot, 0$ & داخل بيل المحمهعوعات الكا & \\
\hline & & & $r T V$ & $7) \leqslant \varepsilon . \wedge Y \leqslant$ & & \\
\hline \multirow[t]{3}{*}{ دال عند ا ., } & $0,9 \vee 7$ & $r T \cdot, \lambda \leq r$ & r & $741,7 \wedge r$ & المحموعات & \multirow{3}{*}{ تحمل المسئولية } \\
\hline & & $00, r 09$ & O THO & $1 r \ldots q, r \vee q$ & داخل المحموعات الكلـ & \\
\hline & & & $r M V$ & $1 K 7 V .97 r$ & & \\
\hline \multirow[t]{3}{*}{ دال عند ا •, } & $\Lambda, 0 Y 1$ & $r \wedge \cdot 0, Y \wedge)$ & $r$ & $071 \cdot, 074$ & \multirow{3}{*}{ داخل المجموعات الكلى } & \multirow{3}{*}{ الإجمالى } \\
\hline & & TYA,ATr & ro & VVYVO, VOY & & \\
\hline & & & rTV & AYAA7, Y 19 & & \\
\hline
\end{tabular}

جدول LSD I I لمعرفة إتجاه الفروق فى المهارات الحياتية تبعاً لسن الزوجة

\begin{tabular}{|c|c|c|c|c|c|c|c|}
\hline \multicolumn{3}{|c|}{ إدارة الوقت } & \multicolumn{3}{|c|}{ إدارة المشاعر } & \multirow{2}{*}{$\dot{ن}$} & \multirow{2}{*}{ السن } \\
\hline$r \cdot, V \tau=p$ & $r q, V Y={ }_{r}$ & $r V, q \cdot=p$ & $Y 0, T \leqslant=p$ & $r \varepsilon, \wedge I=p$ & $r M, Y \wedge=p$ & & \\
\hline \multirow[b]{3}{*}{ - } & & - & & & - & V) & ro> \\
\hline & - & l,Arr_ & & - & 1,or99- & 79 & من هץ>> \\
\hline & 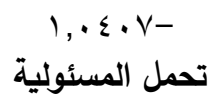 & "Y,Ат & - & التعاطف זוrA. & "Y,Yчו- & 91 & من 0ع >> \\
\hline \multirow[t]{3}{*}{$T V, \varepsilon V=p$} & $Y\urcorner, \wedge r=2$ & $r(T, T)=\rho$ & $r \wedge, 11=\rho$ & $r \tau, 1 Y=\rho$ & $Y_{0,0}=2$ & ن ن & السن \\
\hline & & - & & & - & VI & ros \\
\hline & - & "r,YYI- & & - &,$O \Lambda \cdot V r-$ & 79 & من 0ب> 0؛ \\
\hline \multirow[t]{5}{*}{-} & , $T \leqslant r-$ & " & - & $1,997-$ & "r, OVV- & 91 & من 0 \> .7 \\
\hline & & & $1119 \Lambda=$ & الإجمالى & 1. & ن & السن \\
\hline & & & & & $-r$ & vi & ro> \\
\hline & & & & - & $" v, 10 \leqslant-$ & 79 & من هץ> 0؛ \\
\hline & & & & $\{, 01 Y-$ & - & 91 & من 0 \> . \\
\hline
\end{tabular}


فى المهارات الحياتية (المحاور والإجمالى) من مدة الزواج

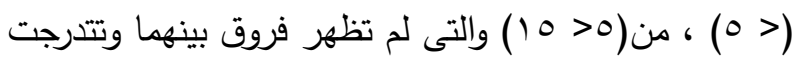

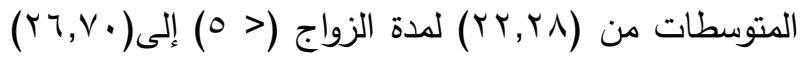
لدة الزواج (10 فأكثر) فى إدارة المشاعر ومن (rآז,)

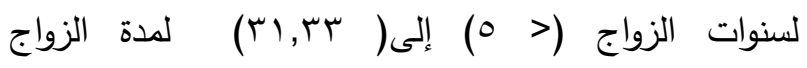

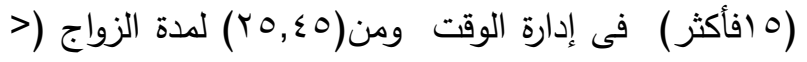

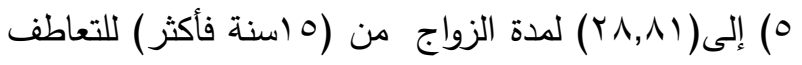

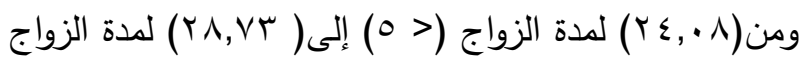

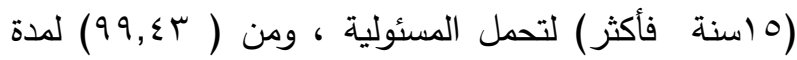
الزواج (> 0) إلى(10,0v) لمدة الزواج من (10) اسنة

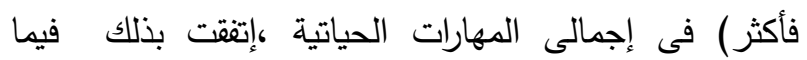

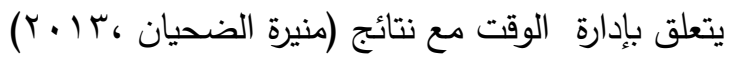

r- سنوات الزواج تثير النتائج الموضحة بجدول (9) وجود تباين دال إحصائياً بين متوسطات درجات عينة البحث فى الدهارات الحياتية لدى الزوجة (إدارة المشاعر، إدارة الوقت، التعاطف، تحمل المسئولية)

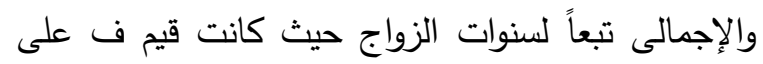

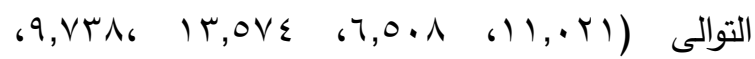

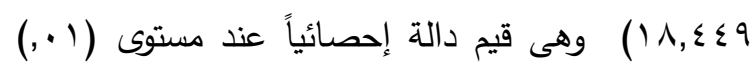
ولمعرفة إتجاه الفروق تم تطبيق إختبار LSD يتضح من نتائج جدول (·r) وجود فروق دالة إحصائياً بين متوسطات درجات عينة البحث فى المهارات الحياتية المحاور و الإجمالى عند مستوى دلالة ( 0. ) ) تبعاً لسنوات الزواج

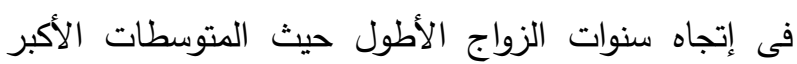
فتبين أن الزوجات ذات مدة الزواج (10 سنه فأكثر) أفضل الزطل

جدول 9 ـ ا لمعرفة اتجاه الفروق فى المهارات الحياتية لاى الزوجة تبعا سنوات الزواج

\begin{tabular}{|c|c|c|c|c|c|c|}
\hline مستوى الدلالة & قيمة ف & متوسط المربعات & درجات الحرية & مجموع المربعات & مصادر التباين & المحاور \\
\hline دال عند |., & $(1, \cdot r)$ & $\begin{array}{l}r \Psi \Lambda, r r \varepsilon \\
r r, \varepsilon, 9\end{array}$ & $\begin{array}{l}\text { rer } \\
\text { reg } \\
\text { rut }\end{array}$ & $\begin{array}{l}V r r, T \leq q \\
V \wedge O r, O V \\
\wedge 09 ., Y \backslash 1\end{array}$ & داخل الدجموعات & إدارة المشاعر \\
\hline دال عند ا ·, & $7,0 \cdot 1$ & $\begin{array}{l}Y \Psi \varepsilon, O Y Y \\
\varepsilon \cdot, T \leqslant O\end{array}$ & $\begin{array}{l}\text { r } \\
r \text { ro } \\
\text { rru }\end{array}$ & $\begin{array}{l}0 Y q, \cdot V r \\
9001,014 \\
1 \ldots \lambda ., 74\end{array}$ & داخل المجموعات & إدارة الوقت \\
\hline دال عند ا ·, & $\mid r, O V \leq$ & $\begin{array}{l}M \Lambda, I V Y \\
r,, \varepsilon \varepsilon\end{array}$ & $\begin{array}{l}\text { red } \\
\text { reg } \\
\text { rud }\end{array}$ & $\begin{array}{l}T r \Psi, r \circ r \\
00 \cdot \Lambda, \leqslant V \\
T \leq \varepsilon, \Delta Y \leq\end{array}$ & داخل الدجموعات & التعاطف \\
\hline دال عند ا ·, & $9, \vee \curlyvee \wedge$ & $\begin{array}{l}\text { OrT, I }\{9 \\
\text { Or,YKr }\end{array}$ & 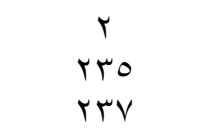 & $\begin{array}{l}1 . \leq 7, Y 91 \\
1 Y 7 r \leq, 770 \\
1 r 7 V ., 974\end{array}$ & داخل الدجموعات & تحمل المسئولية \\
\hline دال عند ا ·, & $11, \leqslant \leqslant 9$ & $\begin{array}{l}0 \pi r r, q \leq q \\
r . \leq, \wedge \leq \varepsilon\end{array}$ & 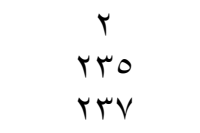 & 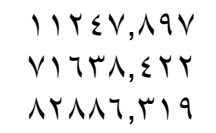 & داخل الدجموعات & الإجمالى \\
\hline
\end{tabular}




\begin{tabular}{|c|c|c|c|c|c|c|c|}
\hline \multicolumn{3}{|c|}{ إدارة الوقتت } & \multicolumn{3}{|c|}{ إدارة المشاعر } & \multirow[b]{2}{*}{$\dot{ن}$} & \multirow[b]{2}{*}{ عدد سنوات الزواج } \\
\hline ק & $r q, \cdot q=p$ & $r V, T Y=5$ & $r T, V \cdot=5$ & $r \varepsilon, \mid V=\rho$ & $K Y, Y \wedge=P$ & & \\
\hline \multirow{12}{*}{$r \Lambda, V r=\beta$} & & - & & & - & 71 & o> \\
\hline & & $1, \leqslant \vee 1-$ & & & $1, \wedge 9 \vee-$ & Nr & من 0> 10 \\
\hline & $" r, Y \leqslant 1-$ & - & & "r,orV- & $" \varepsilon, \varepsilon Y T-$ & 90 & من 0 افأكثر \\
\hline & تحمل المسئولية & & & التعاطف & & & عدد سنهات الزهاج \\
\hline & $r\{, Y)=$ ? & $r \varepsilon, \cdot \Lambda=\beta$ & $\langle\wedge, \Lambda)=\rho$ & $r_{0, \Sigma T=}$ & Yo, $\varepsilon 0=r$ & ن & عدد سشوات الرواج \\
\hline & & - & & & - & $0 \wedge$ & $0>$ \\
\hline & & , Тイ & & & $\cdot, \cdot 11 \leq 9$ & $\Lambda V$ & من \\
\hline & $* \varepsilon, .19-$ & ${ }^{*} \leq, 7 \leq 0-$ & & $" r, r \leq V-$ & "r, r०ᄉ- & $q \pi$ & من ه (فأكثر \\
\hline & & & $110,0 V=\rho$ & 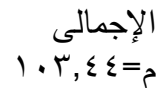 & $q 9, \varepsilon r=$ & & عدد سنوات الزواج \\
\hline & & & & & - & $0 \wedge$ & $0>$ \\
\hline & & & & & $\varepsilon, \ldots \circ \Lambda_{-}$ & $\Lambda V$ & من \\
\hline & & & & -سזו, & $" 17,119-$ & $q \pi$ & من 0 افأكثر \\
\hline
\end{tabular}

نتائج (Dombrowki,jhll.j,2000) والتى توصلت إلى وجود علاقة عكسية بين إدارة الوقت وعدد الأبناء وكذلك

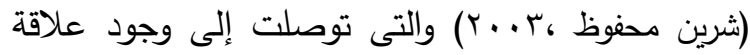

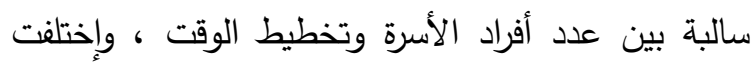
فيما يتعلق بتحمل المسئولية مع نتائج دراسة (الحسينى ريحان وآخرون ، 10 ب ب) والتى توصلت إلى وجود علاقة ارتباطية عكسية بين تحمل المسئولية وعدد الأبناء. •-تعليم الزوج :- تشير النتائج الموضحة بجدول (Y Y) عدم وجود تباين دال إحصائياً بين متوسط درجات عينة

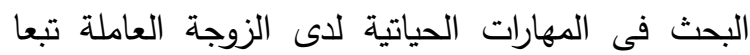
لتعليم الزوج فى (إدارة المشاعر، إدارة الوقت، التعاطف، تحمل المسئولية، الإجمالى حيث كانت قيمة ف على

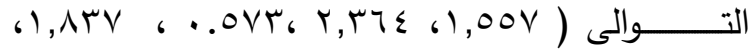
هY, 1, وهى قيم غير دالة احصائياً فيما يتعلق بإدارة

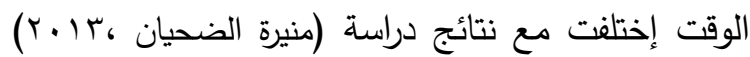
والتى توصلت إلى وجود علاقة إرتباطية موجبة بين إدارة الوقت ومستوى تعليم الزوج.
والتى توصلت إلى وجود علاقة إرتباطية موجبة بين إدارة

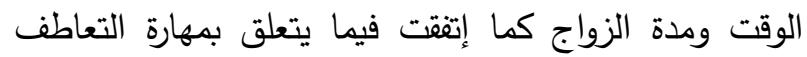

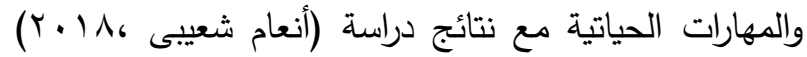
والتى توصلت إلى كلما زادت مدة الزواج كلما ذادت مهارة التعاطف وإجمالى المهارات الحياتية، و إختلفت فيما يتعلق بتحمل المسئولية مع نتائج دراسة (الحسينى ريحان وآخرون

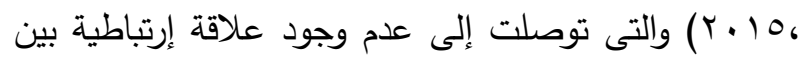
تحمل المسئولية وعدد سنوات الزواج. צ- عدد الأبناء يتضح من نتائج جدول (Yl) عدم وجود تباين دال إحصائياً بين متوسطات درجات عينة البحث فى المهارات الحياتية لدى عينة البحث تبعا لعدد الأبناء فى (إدارة المشاعر ، إدارة الوقت، التعاطف ، ، تحمل المسئولية، الإجمالى) كانت قيمة ف ف على إلى التوالى

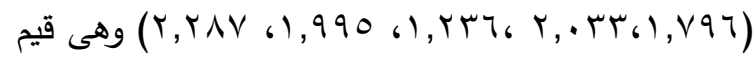
غير دالة إحصائياً و إتفقت بذلك فيما يتعلق بإدارة الوقت

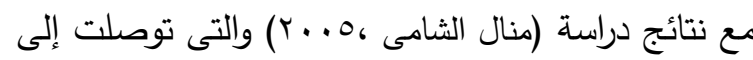
عدم وجود علاقة بين تعليم ربة الأسرة العاملة فى إدارة الوقت وبين عدد الأبناء وكذلك نتائج دراسة (منيرة

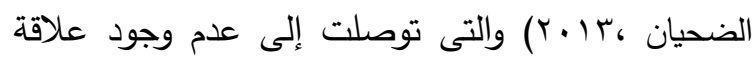

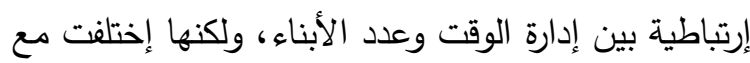


جدول اب . تحليل التباين أحادى الإتجاه للفروق بين المتوسطات فى المهارات الحياتية تبعاً لعدد الأبناء

\begin{tabular}{|c|c|c|c|c|c|c|}
\hline مستوى الدلالة & قيمة ف & متوسط المربعات & درجات الحرية & مجموع المربعات & مصادر التباين & المحاور \\
\hline سا دالة • غير & $T, \cdot r r$ & $\begin{array}{l}\text { VTr,.ro } \\
0, q T r\end{array}$ & 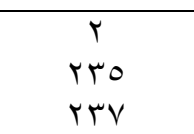 & $\begin{array}{c}1 \leq 7, \cdot 79 \\
\wedge \leq \varepsilon \varepsilon, 1 \leqslant 9 \\
109,, Y 1 \wedge\end{array}$ & داخل المجموعات المبات & إدارة المشاعر \\
\hline 17 1الة · غير & $1, \vee 997$ & $\begin{array}{l}V 0, \wedge V 1 \\
\sum Y, Y O 1\end{array}$ & 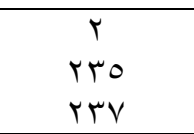 & $\begin{array}{l}101, V \leqslant r \\
994 \Lambda, 91 \vee \\
1 \ldots 1 ., 74\end{array}$ & داخل المجموعات المجوعات & إدارة الوقت \\
\hline بو دالة, غير & 1, & $\begin{array}{l}\text { rI,9VI } \\
\text { ro,AV4 }\end{array}$ & 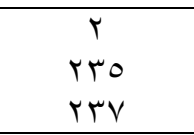 & $\begin{array}{l}T r, q \leq 1 \\
T \cdot \Lambda \cdot, \wedge \wedge r \\
T) \leq \varepsilon, \wedge Y \leq\end{array}$ & داخل المجموعات المجمات & التعاطف \\
\hline 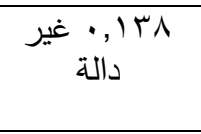 & 1,990 & $\begin{array}{l}11 \varepsilon, 1 \cdot 7 \\
\text { OV,r.r }\end{array}$ & 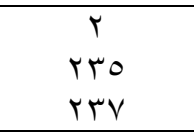 & $\begin{array}{c}\text { YYA,YIT } \\
\mid r \varepsilon \varepsilon Y, V 0 \\
\mid r T V \cdot, 97 r\end{array}$ & داخل المجموعات المجمعات & تحمل المسئولية \\
\hline ع • ا, · غير & Y,YAV & $\begin{array}{l}\vee \vee q 1, \bullet \wedge q \\
r \leqslant 0, q \vee 0\end{array}$ & $\begin{array}{l}\text { h } \\
\text { reo } \\
\text { rth }\end{array}$ & 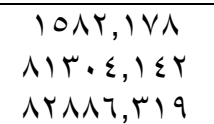 & داخل المجموعات الكموعات & الإجمالى \\
\hline
\end{tabular}

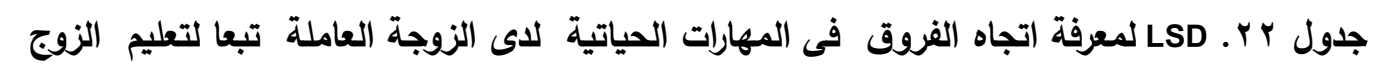

\begin{tabular}{|c|c|c|c|c|c|c|}
\hline مستوى الدلالة & قيمة ف & متوسط المربعات & درجات الحرية & مجموع المربعات & مصادر التباين & المحاور \\
\hline$\cdot, Y M$ & $1,00 \mathrm{~V}$ & $07,1 \vee 7$ & $r$ & IIr,ror & بين المجموعات & \\
\hline \multirow[t]{2}{*}{ غير دالة } & & Tצ, & oro & 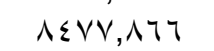 & داخّل المجموعات & إدارة المشاعر \\
\hline & & & rTV & $109 \cdot, r) 1$ & الكلى & \\
\hline$\cdot, .97$ & Y,TY & $99, \Sigma) r$ & r & $19 \wedge, \wedge Y \varepsilon$ & بين المجموعات & \\
\hline \multirow[t]{2}{*}{ غير دالة } & & $\varepsilon r, .0$ & rro & 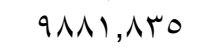 & داخل المجموعات & إدارة الوقت \\
\hline & & & rTV & $1 \cdots 1 \cdot, 74$ & الكلى & \\
\hline., $07 \varepsilon$ &.,$O V Y$ & $1 \leqslant, 919$ & $r$ & 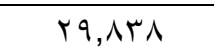 & بين المجموعات & \\
\hline \multirow{2}{*}{ غير دالة } & & $r r, \cdot r)$ & rro & $71 \leqslant, 9 \wedge 7$ & داخل المجموعات & التعاطف \\
\hline & & & rrv & $\prod \leqslant \varepsilon, \wedge r \varepsilon$ & الكلى كلى & \\
\hline$\cdot, 17 r$ & $1, \wedge r V$ & $1.0, Y Y \leq$ & $r$ & $Y \cdot \cdot, \varepsilon \leqslant \Lambda$ & بين المجموعات & \\
\hline \multirow{2}{*}{ غير دالة } & & OV, YVq & RTO & $\mid \pi \leq 7 \cdot, 01 \leq$ & داخل المجموعات & تحمل المسئولية \\
\hline & & & rTV & 1 ITV.,974 & الكلى & \\
\hline$\cdot, Y 97$ & 1, YYO & $\varepsilon r V, 00 V$ & $r$ & $100,11 \leqslant$ & بين المجموعات & \\
\hline \multirow[t]{2}{*}{ غير دالة } & & $r \leq q, \cdot 79$ & rmo & $A Y \cdot T, Y, O$ & داخل المجموعات & الإجمالى \\
\hline & & & rTV & ArANT, rIq & الكلى & \\
\hline
\end{tabular}

ووجود تباين دال إحصائياً بين متوسطات درجات عينة

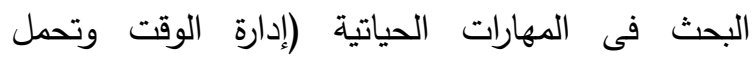
المسئولية) والإجمالى تبعاً لمستوى تعليم الزوجة حيث

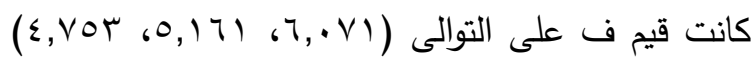

צ- تعليم الزوجة:- تشير النتائج الموضحة بجدول (rr) عدم وجود تباين دال إحصائياً بين متوسطات درجات عينة البحث فى المهارات الحياتية ( إدارة المشاعر والتعاطف) تبعا لتعليم الزوجة حيث كانت قيم ف على

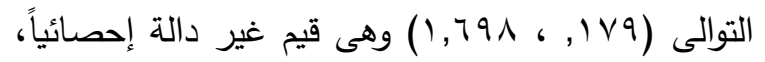




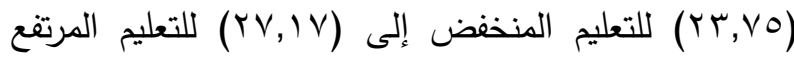

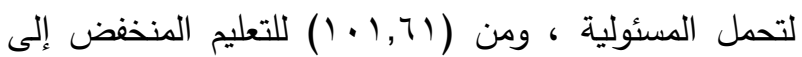

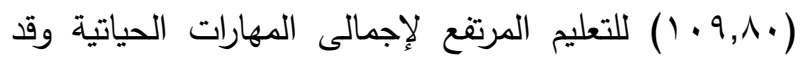
إتنقت هذه النتائج فيما يتعلق بمهارة التعاطف والمهارات

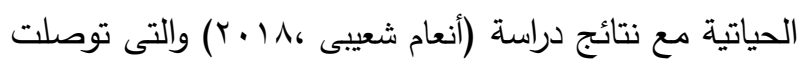
إلى كلما زادت تعليم كلما ذادت مهارة التعاطف والمهارات

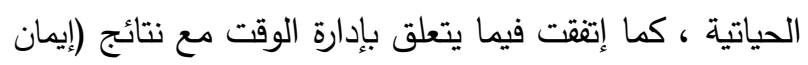

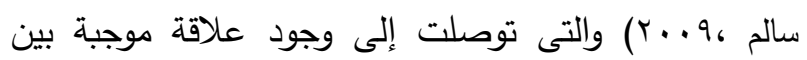
إدارة الوقت وتعليم الأم ولكنها إختلفت مع نتائج (منيرة

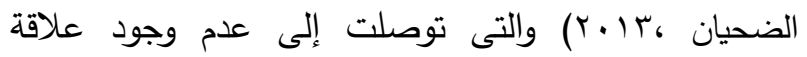
إرتباطية بين إدارة الوقت ومستوى تعليم الأم
وهى قيم دالة إحصائياً عند مستوى( ا .,) ولمعرفة إتجاه LSD الفروق تم تطبيق إختبار يتضح من نتائج جدول (؛ Y) وجود فروق دالة إحصائياً بين متوسطات درجات عينة البحث فى المهارات الحياتية للزوجة

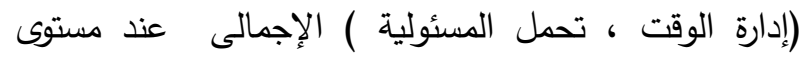
دلالة(0. ) ) تبعاً لتعليم الزوجة فى إتجاه التعليم المرتفع

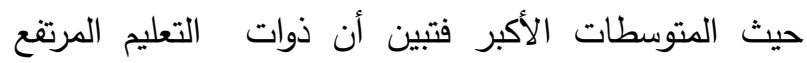
والمتوسط والتى لم تظهر فروق بينهما كانتا أفضل في إدارة الوقت وتحمل المسئولية وإجمالى المهارات الحياتية من ذوات التهات

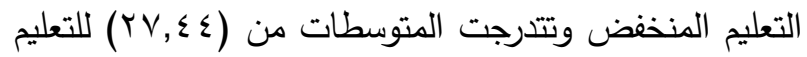

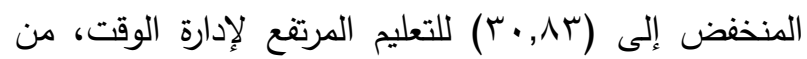

جدول rr ت تحليل التباين أحادى الإتجاه للفروق بين المتوسطات فى المهارات الحياتية تبعا لتعليم الزوجة

\begin{tabular}{|c|c|c|c|c|c|c|}
\hline مستوى الدلالة & قيمة ف & متوسط المربعات & درجات الحرية & مجموع المربعات & مصادر التباين & المحاور \\
\hline \multirow{3}{*}{ دالة · غير } & $\cdot, 1 \vee 9$ & 7,019 & $r$ & 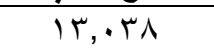 & بين المجموعات & \multirow{3}{*}{ إدارة المشاعر } \\
\hline & & r4, & rto & NOVV,11 & داخل المجموعات & \\
\hline & & & rTV & $\wedge \circ 9 \cdot, r) \wedge$ & الكلى & \\
\hline \multirow[t]{3}{*}{ دال عند ا •, • } & $7, \cdot \sqrt{ } 1$ & $r \leqslant V, T 10$ & $r$ & $\{90, r M l$ & بين المجموعات & \multirow{3}{*}{ إدارة الوقت } \\
\hline & & $\varepsilon \cdot, \vee \wedge q$ & rro & $90 \wedge 0, \leqslant Y q$ & داخل المجموعات & \\
\hline & & & rTV & $1 \cdots 1 \cdot, 74$ & الكلى & \\
\hline \multirow{3}{*}{ غير دالة } & 1,791 & $\varepsilon r, \vee \vee \uparrow$ & $r$ & $\Lambda \vee, 001$ & بين المجموعات & \multirow{3}{*}{ التعاطف } \\
\hline & & YO, VVT & מ tro & $7.0 V, Y V Y$ & داخل المجموعات & \\
\hline & & & rrv & T) $\leq \varepsilon, \wedge r \leq$ & الكلى & \\
\hline \multirow[t]{3}{*}{ دال عند ا •, · } & 0,171 & YAV,OAI & $r$ & OV0,17r & بين المجموعات & \multirow{3}{*}{ تحمل المسئولية } \\
\hline & & $00, V Y V$ & rro & $1 \% \cdot 90,1 \cdot 1$ & داخل المجموعات & \\
\hline & & & rrv & IrTV.,974 & الكلي & \\
\hline \multirow[t]{3}{*}{ دال عند ا •, • } & $\varepsilon$, VOr & Trו,171, & $r$ & TYYY,Y & بين المجموعات & \multirow{3}{*}{ الإجمالى } \\
\hline & & Tr人, & Tro & V৭Tтะ,・VT & داخل المجموعات & \\
\hline & & & TrV & $\wedge Y \wedge \wedge \neg, \Gamma \backslash q$ & الكلى & \\
\hline
\end{tabular}

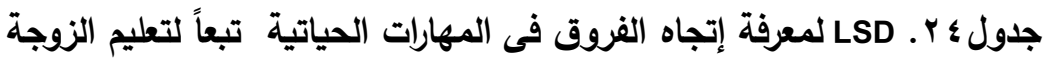

\begin{tabular}{|c|c|c|c|c|c|c|c|}
\hline \multicolumn{3}{|c|}{ تحمل المسئولية } & \multicolumn{3}{|c|}{ إدارة الوقت } & \multirow[b]{2}{*}{ ن } & \multirow{2}{*}{ المستوى التعليمى } \\
\hline$T V, I V=5$ & $\langle V, \|=5$ & $\langle r, V O=5$ & $r \cdot, \lambda r=\rho$ & 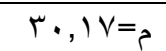 & $T V, \varepsilon \varepsilon=\rho$ & & \\
\hline \multirow{6}{*}{-} & \multirow{6}{*}{. TVYO- } & - & & \multirow{5}{*}{ 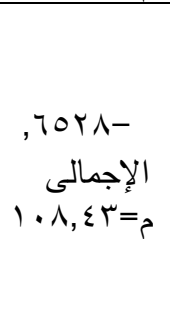 } & - & vi & مستوى تعليم منخفض \\
\hline & & 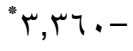 & & & $" Y, V \mu \nu-$ & vo & مستوى تعليم متوسط \\
\hline & & ${ }^{r} r, \varepsilon r v-$ & - & & ${ }^{\circ} r, r \wedge 90-$ & $9 \mathrm{~T}$ & مستوى تعليم مرتفع \\
\hline & & & $1 \cdot 9, \Lambda \cdot=8$ & & $|\cdot|, 7 \mid=$ ? & ن & المستوى التعليمى \\
\hline & & & & & & vi & مستوى تعليم منخفض \\
\hline & & & & - rror & $\begin{array}{l}A, r T V- \\
\text { "V,AVI- }\end{array}$ & $\begin{array}{l}\text { Vo } \\
\text { qr }\end{array}$ & مستتوى تعليم متوسط \\
\hline
\end{tabular}


وهى دالة إحصائياً عند مستوى (1 +.,) ولمعرفة إتجاه الغروق تم تطبيق إختبار يتضح من نتائج جدول († Y) وجود فروق دالة إحصائياً بين متوسطات درجات عينة البحث فى المهارات الحياتية للزوجة (إدارة الوقت ) عند مستوى دلالة) • . ) تبعاً لمستوى الدخل الثهرى للأسرة فى اتجاه الدخل المرتفع حيث المتوسطات الأكبر فتبين أن الزوجات العاملات من الأسر ذات الدخل

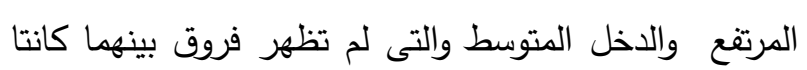

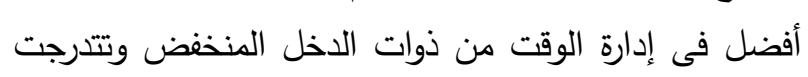

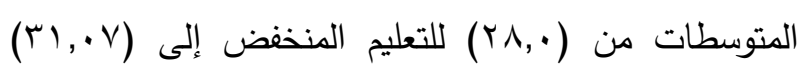

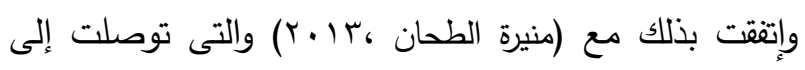
إدارة الوقت والدخل الشهرى للأسرة.
يتضح من نتائج جدول († ro) عدم وجود تباين دال إحصائياً بين متوسط درجات عينة البحث فى المهارات الحياتية ( إدارة المشاعر والتعاطف وتحمل المسئولية والإجمالى) لدى الزوجة

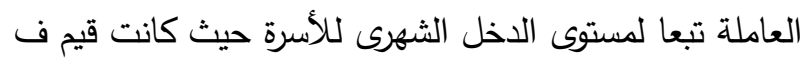

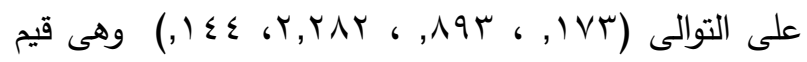
غير دالة إحصائياً ، إختلفت فيما يتعلق بتحمل المسئولية مع نتائج دراسة (الحسينى ريحان وآخرون، 10 • ب) والتى توصلت إلى وجود علاقة إرتباطية موجبة بين تحمل المسئولية ودخل الأسرة، وكذلك إختلفت فيما يتعلق بمهارة التعاطف والمهارات

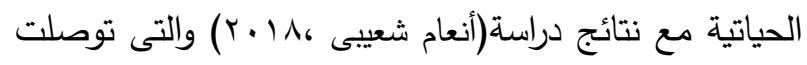
إلى كلما زادت الدخل كلما ذات مهارة التعاطف والمهارات الحياتية. ووجود تباين دال إحصائياً بين متوسطات درجات

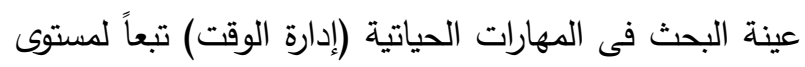

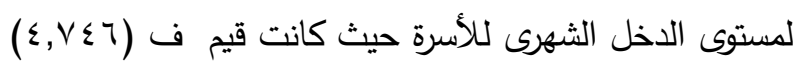

جدول ه • تحليل التباين أحادى الإتجاه للفروق بين المتوسطات فى المهارات الحياتية تبعاً لمستوى الدخل الشهرى للأسرة

\begin{tabular}{|c|c|c|c|c|c|c|}
\hline مستوى الدلالة & قيمة ف & متوسط المربعات & درجات الحرية & مجموع المربعات & مصادر التباين & المحاور \\
\hline الة دالة غير & $\cdot, I V T$ & $\begin{array}{l}7, \pi 19 \\
47,0\end{array}$ & $\begin{array}{l}\text { r } \\
\text { rro } \\
\text { rut }\end{array}$ & $\begin{array}{c}\mid r, T r \wedge \\
\wedge 0 \gamma V, 0 \Lambda \\
\wedge 09 \cdot, r \mid \Lambda\end{array}$ & داخل المجموعات المجوعات & إدارة المشاعر \\
\hline دال عند ا •, & $\varepsilon, \vee \leqslant 7$ & $\begin{array}{l}190,741 \\
\varepsilon 1, Y \text { וT }\end{array}$ & $\begin{array}{l}\text { tre } \\
\text { reo } \\
\text { red }\end{array}$ & 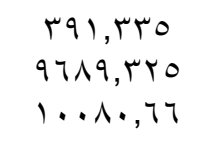 & داخل المجموعات المجموعات & إدارة الوقت \\
\hline || دالة, غير & $\cdot, \wedge 94$ & $\begin{array}{l}r, Y T \Sigma \\
\text { ro,TVI }\end{array}$ & $\begin{array}{l}\text { red } \\
\text { reg } \\
\text { red }\end{array}$ & $\begin{array}{l}\leq 7, r 7 r \\
7.9 \wedge, \leq 71 \\
7) \leq \varepsilon, \wedge T \leq\end{array}$ & داخل المجموعات المجوعات & التعاطف \\
\hline 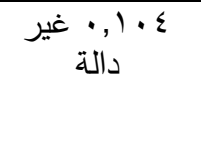 & $r, Y \wedge r$ & $\begin{array}{l}|r \cdot, r| r \\
O V, \cdot T r\end{array}$ & $\begin{array}{l}\text { red } \\
\text { reg } \\
\text { red }\end{array}$ & 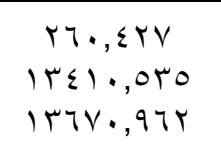 & داخل المجموعات المجوعات & تحمل المسئولية \\
\hline غير دالة & $\cdot, 1 \leq \varepsilon$ & $\begin{array}{l}\{1,907 \\
r 01, \leqslant 0 \leqslant\end{array}$ & $\begin{array}{l}\text { hrd } \\
\text { reg } \\
\text { red }\end{array}$ & 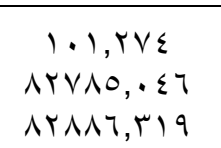 & داخل المجموعات المجوعات & الإجمالى \\
\hline
\end{tabular}



دعاء عوضين ابراهيم المرسي واخرون.: المهارات الحياتية وعلاقتها بصراع الأدوار فى الأسرة لدى عينة من....

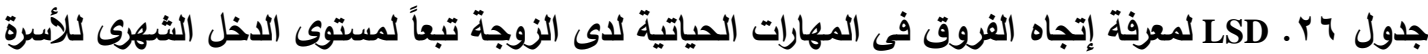

\begin{tabular}{|c|c|c|c|c|}
\hline \multicolumn{3}{|c|}{ إدارة الوقت } & \multirow{2}{*}{ ن ن } & \multirow{2}{*}{ الدخل } \\
\hline$r_{1}, \cdot v=s$ & $r \cdot, \cdot \Lambda=r_{\gamma}$ & $r \Lambda, \cdots=r$ & & \\
\hline & & - & AV & دخل شهرى منخفض \\
\hline 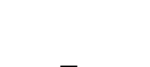 & 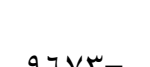 & $\begin{array}{l}r, r \cdot v 0- \\
* r \leq r\end{array}$ & $\wedge$. & دخل شهرى متوسط \\
\hline
\end{tabular}

One Way Anova الفروق إن وجدت وفقاً لدتغيرات البحث (سن الزوجة ، مدة النيات

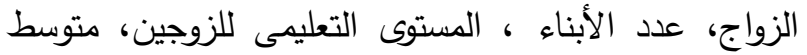

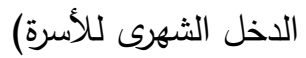
1- مكان السكن يتضح من نتائج جدول (YV) - عدم وجود فروق دالة إحصائياً بين متوسطات درجات عينة البحث فى صراع الأدوار فى الأسرة (صراع الدور كأم)

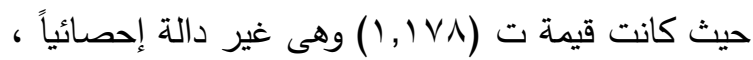
ووجود فروق دالة إحصائياً بين متوسطات درجات عينة

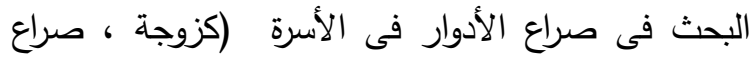

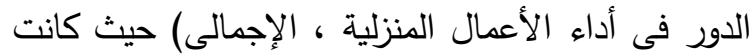

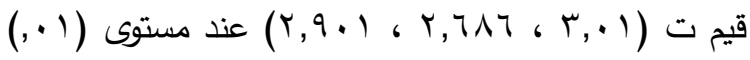
في اتجاه الزوجات قاطنى الحضر حيث سجلت الزوجات العاملات قاطنى الحضر متوسط حسابى منخفض بالمقارنة بالزوجات العاملات قاطنى الريف ممل يدل

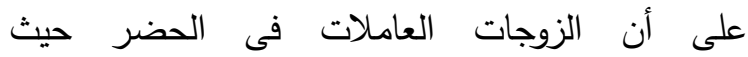

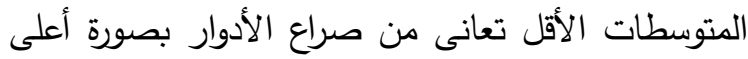
من الزوجات العاملات فى الريف حيث المتوسطات

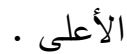

وترى الباحثتان أن الزوجات قاطنى الريف إستطاعت أن تواجهن صراع الأدوار كزوجة وصراع الدور في أداء الأعمال

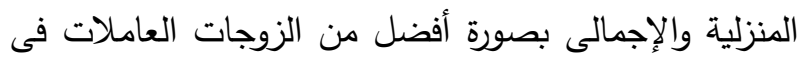

نستخلص مما سبق عدم وجود فروق دالة إحصائياً بين متوسطات درجات عينة البحث فى المهارات الحياتية المحاور و الإجمالى تبعا للسكن فيما عدا إدارة الوقت وجدت فروق لصالح سكان الحضر، والتعاطف لصالح سكان التهان الريف، ووجود فروق دالة إحصائياً بين متوسط درجات عينة

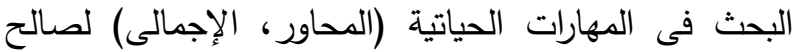

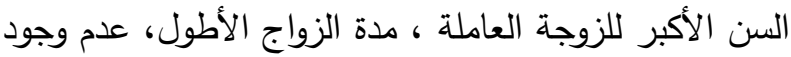
فروق بين متوسطات درجات عينة البحث فى المهارات الحياتية (المحاور، الإجمالى) تبعا لعدد الأبناء وتعليم الزوج،

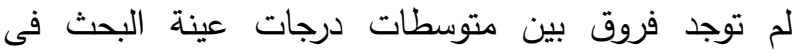
التعاطف وإدارة المشاعر تبعا لتعليم الزوجة ووجود فروق دالة إحصائياً بين متوسط درجات عينة البحث فى (إدارة الوقت وتحمل المسئولية والإجمالى) عدم وجود فروق بين متوسطات درجات عينة البحث فى (المهارات الحياتية ) المحاور

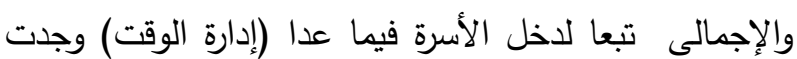

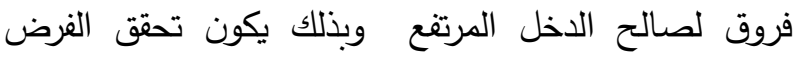

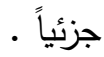
الفرض الثالث:- توجد فروق بين متوسطات درجات عينة البحث فى صراع الأدوار فى الأسرة (صراع الدور كزوجة ، صراع الدور كأم ، صراع الدور فى أداء الأعمال المنزلية ) الإجمالى تبعاً (مكان السكن، سن الزوجة، مدة الحياة الزوجية

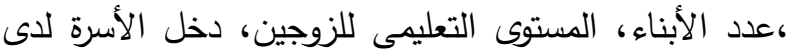
عينة البحث وللتحقق من صحة الفرض إحصائياً تم إستخدام إختبار T test للوقوف على دلالة الفروق بين متوسطات درجات عينة البحث فى صراع الأدوار فى الأسرة بحاورها

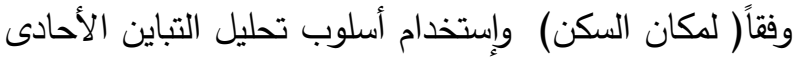


جدول Y. . دلالة الفروق بين متوسطات درجات عينة البحث فى صراع الأدوار فى الأسرة تبعاً لمكان السكن

\begin{tabular}{|c|c|c|c|c|c|c|c|}
\hline \multirow[b]{2}{*}{ مستوى الدلالة } & \multirow[b]{2}{*}{ قيمة ت } & \multirow{2}{*}{ المتروقطات } & \multicolumn{2}{|c|}{ حضر(r) } & \multicolumn{2}{|c|}{ ريف (·11) } & \multirow[b]{2}{*}{ المحاور } \\
\hline & & & المعيارى الإتحر & الحسابى المسط & الإلحيراف & الحسابى المتط & \\
\hline دالة عند ا •, & $r, \cdot 1$. & $r, 00$. & $7, \cdot \wedge \cdot$ & r), roq & $7,99$. & $r r, q . q$ & صراع الدور كزوجة \\
\hline ع ז, • غير دالة & $1,1 \vee \wedge$ & $1,1 \leqslant \wedge$ & $v, \mid r$. & $r \mu, \uparrow \wedge$. & $V, \wedge 91$ & $r \varepsilon, \lambda T V$ & صراع الدور كأم \\
\hline دالة عند ا •, & $r, T \wedge 4$ & r,VTr & $V, \Lambda T V$ & $r 7,190$ & $\Lambda, \ldots \uparrow$ & $r \wedge, 9 \wedge r$ & صراع الدور في أداء الأعمال \\
\hline دالة عند ا •, & $r, q .1$ & $7, \leq 7$. & $17,1 \leq 0$ & $V 1, r O 1$ & $M, r \cdot V$ & $V V, V \backslash A$ & الإجمالى \\
\hline
\end{tabular}

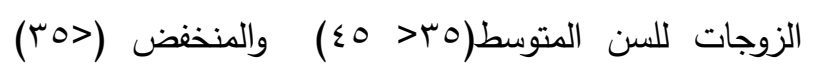

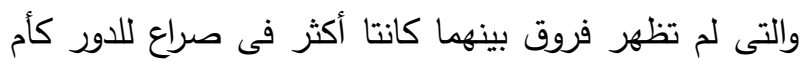

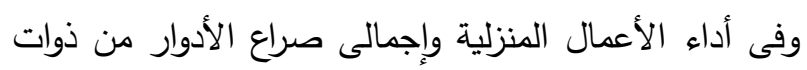

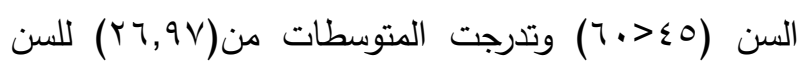

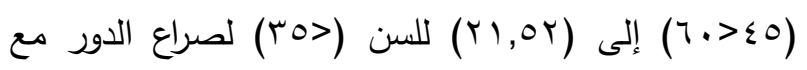

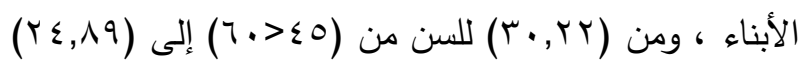

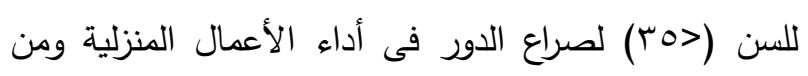

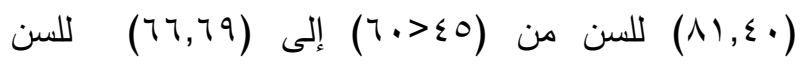

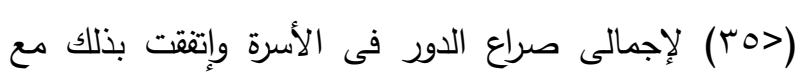

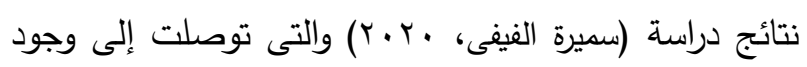

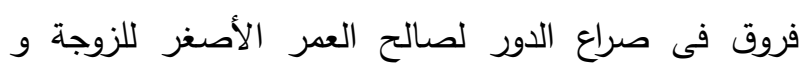

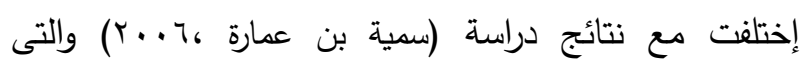
توصلت إلى أن صراع الأدوار لا يتأثر بعمرهن.
ץ- سن الزوجة يتضح من جدول (^^) وجود تباين دال

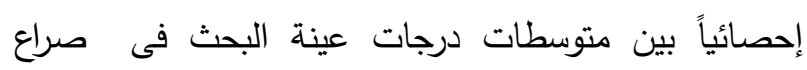

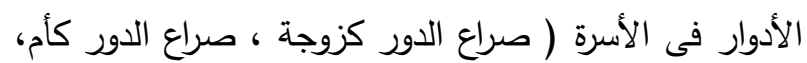

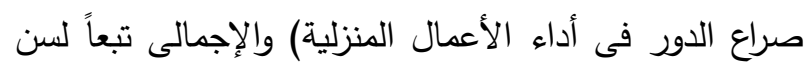

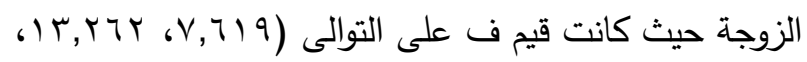

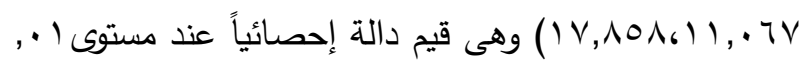
ولمعرفة إتجاه الفروق تم تطبيق إختبار LSD يتضح من جدول (9) وجود فروق دالة إنصائية بين متوسطات درجات عينة البحث فى صراع الأدور فى الأسرة

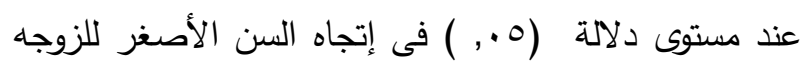
(حيث المتوسط الحسابى الأقل ) فتبين أن الزوجات العاه العاملات

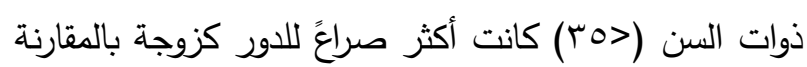
من ذوات السن (0ro>

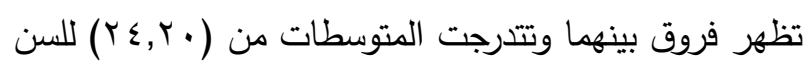

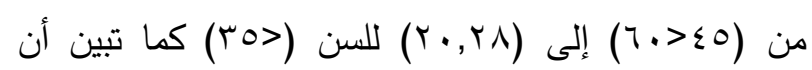


جدول ^^. تحليل التباين أحادى الإتجاه للفروق بين المتوسطات فى صراع الأدوار فى الأسرة تبعاً لسن الزوجة

\begin{tabular}{|c|c|c|c|c|c|c|}
\hline مستوى الدلالة & قيمة ف & متوسط المربعات & درجات الحرية & مجموع المربعات & مصادر التباين & المحاور \\
\hline دال عند مستوى & $V, 719$ & $\begin{array}{c}|7, \lambda| \varepsilon \\
\varepsilon 1,0 \wedge 1\end{array}$ & $\begin{array}{l}\text { r } \\
\text { ret } \\
\text { red }\end{array}$ & 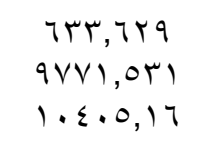 & داخل المجموعات المجوعات & صراع الدور كزوجة \\
\hline دال عند مستوى & אוצוTו & $\begin{array}{l}T \vee 0,001 \\
0 ., 941\end{array}$ & 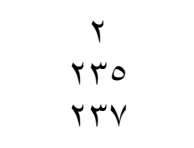 & $\begin{array}{l}1101,1 \\
1198 \cdot, 490 \\
1 \% 4,1, \Sigma 97\end{array}$ & داخل المجموعات & صراع الدور كأم \\
\hline دال عند مستوى & $11, \cdot 7 \mathrm{~V}$ & $\begin{array}{c}700, \text { YT } \\
\text { 09,YY }\end{array}$ & $\begin{array}{l}\text { tre } \\
\text { reg } \\
\text { red }\end{array}$ & $\begin{array}{l}M \mid \cdot, V Y V \\
\mid r q 17, V 79 \\
10 Y r V, \Sigma 97\end{array}$ & داخل المجموعات المجوعات & صرإع الدور فيى أداء \\
\hline دال عند مستوى & $V, 719$ & $\begin{array}{c}r \mid 7, \lambda 1 \varepsilon \\
\varepsilon 1,0 \wedge 1\end{array}$ & 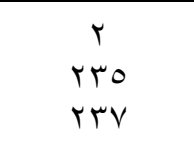 & $\begin{array}{l}\text { רr, Trq } \\
9 \vee 1,041 \\
1.5 .0,17\end{array}$ & داخل المجموعات المجوعات & صراع الدور كزوجة \\
\hline
\end{tabular}

جدول 9 Y. LSD لمعرفة إتجاه الفروق فى صراع الأدوار فى الأسرة تبعاً لسن الزوجة

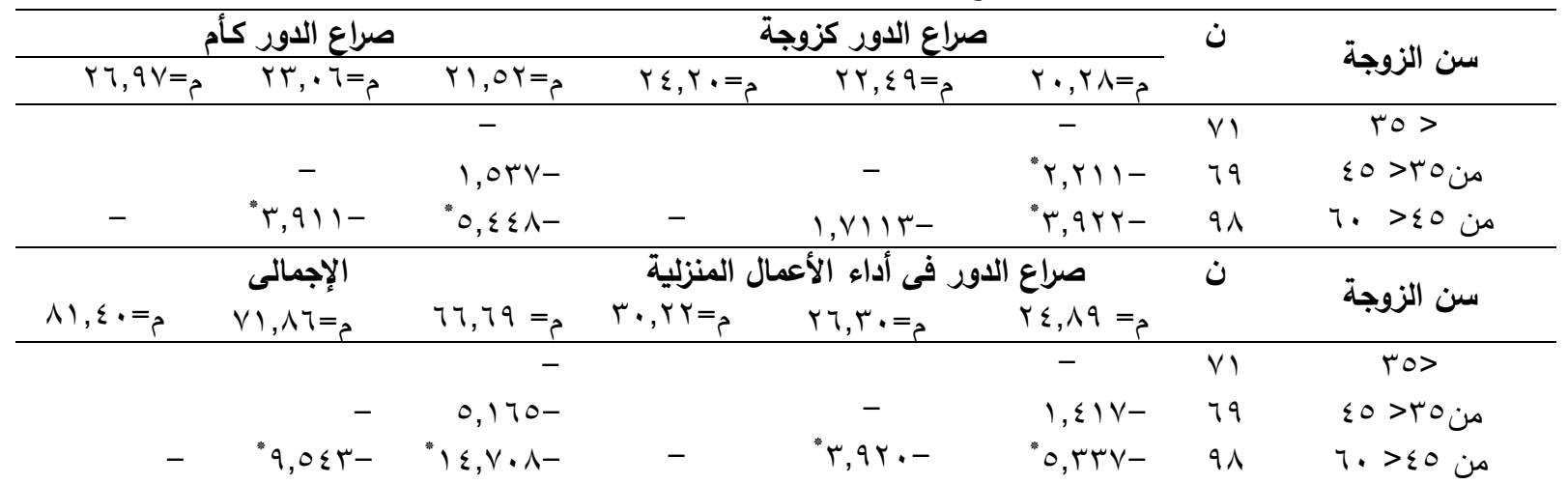

إلى أنه لا توجد فروق بين العاملات فى صراع الأدوار في الأسرة يرجع إلى مدة الزواج.

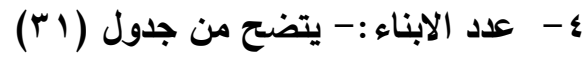

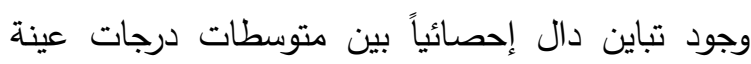

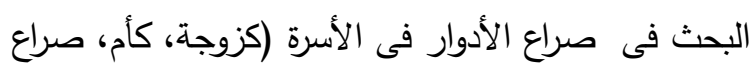

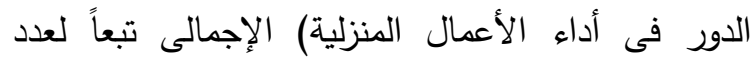

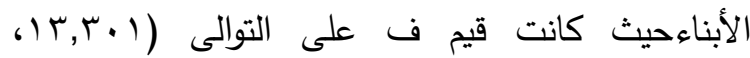

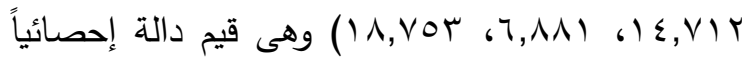
عند مستوى(1.,) ولمعرفة إتجاه الفروق تم تطبيق

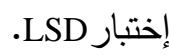

r- عدد سنوات الزواج يتضح من جدول (·r) عدم وجود تباين دال إحصائياً بين متوسطات درجات عينة البحث فى صراع الأدوار فى الأسرة (صراع الدور كزوجة، صراع الدور كأم، صراع الدور فى أداء الأعمال المنزلية)

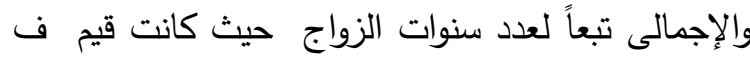
على التوالى (乏 ( (Grau, وهى قيم غير دالة وهذا يتقق مع نتائج دراسة

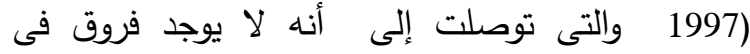
مستوى صراع الأدوار تبعا لددة الزواج ونتائج دراسة

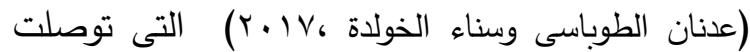


جدول · ·. تحليل التباين أحادى الإتجاه للفروق بين المتوسطات فى صراع الأدوار فى الأسرة تبعاً سنوات زواج

\begin{tabular}{|c|c|c|c|c|c|c|}
\hline مستوى الدلالة & قيمة ف & متوسط المربعات & درجات الحرية & مجموع المربعات & مصادر التباين & المحاور \\
\hline 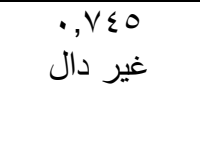 & $r, r q \varepsilon$ & $\begin{array}{l}1 T, \ldots 1 \\
\varepsilon \varepsilon, 1 T V\end{array}$ & 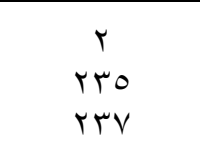 & $\begin{array}{l}r q, . . r \\
1 . r v 9,10 V \\
1 . \varepsilon .0,17\end{array}$ & داخل المجموعات المجوعات & صراع الدور كزوجة \\
\hline غير دال: & $r, r \cdot V$ & $\begin{array}{l}1 Y \Lambda, Y 00 \\
00,097\end{array}$ & 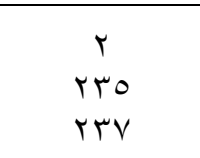 & $\begin{array}{l}r 07,01 \\
1 Y \cdot T\{, 917 \\
1 \text { rrr, }\{97\end{array}$ & داخل المجموعات & صراع الدور كأم \\
\hline غير دال & r,Aro & $\begin{array}{l}\mid v q, r \leqslant v \\
T r, r v \mid\end{array}$ & 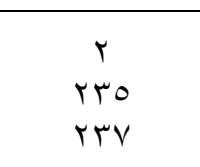 & $\begin{array}{l}r O \Lambda, T 9 \varepsilon \\
1 \leq \Lambda T \Lambda, \Lambda \cdot r \\
10 Y r V, \Sigma 97\end{array}$ & داخل المجموعات المجلى & صراعمال الدور فئلية أداء \\
\hline غير دال & $r, Y \wedge)$ & $\begin{array}{l}\text { TAr, NO9 } \\
\text { raq,rrA }\end{array}$ & 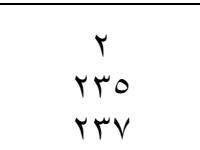 & $\begin{array}{l}I r 40, V I V \\
V \cdot r \leqslant r, I \leqslant A \\
V I V \cdot V, \Lambda T r\end{array}$ & داخل المجموعات & الإجمالى \\
\hline
\end{tabular}

جدول ابـ تحليل التباين أحادى الإتجاه للفروق بين المتوسطات فى صراع الأدوار فى الأسرة تبعاً لعدد الأبناء

\begin{tabular}{|c|c|c|c|c|c|c|}
\hline مستوى الدلالة & قيمة ف & متوسط المربعات & درجات الحرية & مجموع المربعات & مصادر التباين & المحاور \\
\hline دال عند مستوى . . . . & $\mid r, r \cdot 1$ & $\begin{array}{l}\text { Orq, } r V \\
r q, \vee V \nabla\end{array}$ & $\begin{array}{l}\text { the } \\
\text { reg } \\
\text { rug }\end{array}$ & $\begin{array}{l}1.01,000 \\
9 r \leqslant V, 1.0 \\
1.5 .0,17\end{array}$ & داخل المجموعات المجوعات & صراع الدور كزوجة \\
\hline دال عند مستوى . . . . & $|\varepsilon, V| r$ & $\begin{array}{l}\vee \leqslant 1,1 \wedge 7 \\
0 ., r \vee q\end{array}$ & 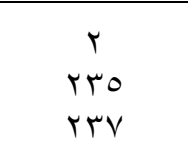 & $\begin{array}{l}1 \varepsilon \wedge r, r \vee r \\
1) \wedge q, \mid r \varepsilon \\
|r r r|, \varepsilon q 7\end{array}$ & داخل المجموعات المجات & صراع الدور كأم \\
\hline دال عند مستوى ., . . & $7, \wedge \wedge 1$ & $\begin{array}{l}\varepsilon r I, Y Y T \\
r, Y I r\end{array}$ & $\begin{array}{l}\text { tro } \\
\text { rug } \\
\text { rug }\end{array}$ & 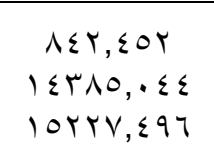 & داخل المجموعات المجات & صراع الدور فيى أداء \\
\hline دال عند مستوى . . . . & IA, vor & $\begin{array}{l}\varepsilon q r \varepsilon, v q \mu \\
r q r, 1 \leq r\end{array}$ & $\begin{array}{l}\text { tro } \\
\text { rto } \\
\text { red }\end{array}$ & $\begin{array}{l}q \wedge \neg q, 0 \wedge 7 \\
\neg) \wedge \wedge, r \vee q \\
\vee / \vee \cdot \vee, \wedge \neg 7\end{array}$ & داخل المجموعات المجوعات & الإجمالى \\
\hline
\end{tabular}

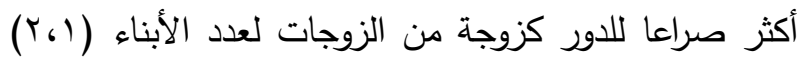

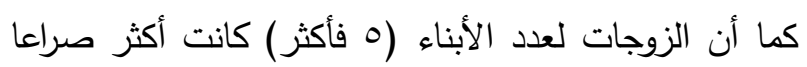

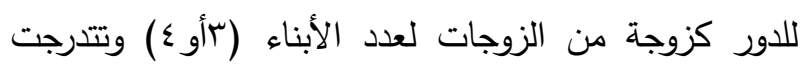

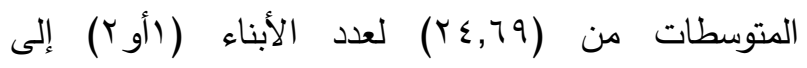

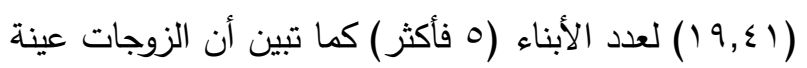
البحث لعدد الأبناء (0 فأكثر) كانت أكثر صراعاً للدور كأم الأ
يتضح من نتائج جدول (r Y) وجود فروق دالة إحصائية بين متوسطات درجات عينة البحث فى صراع الأدور فى الأسرة

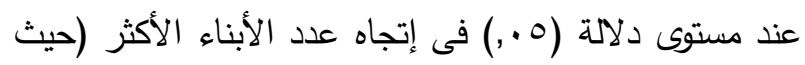

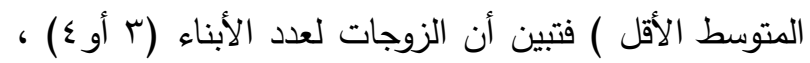

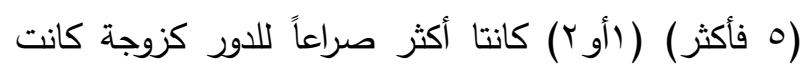




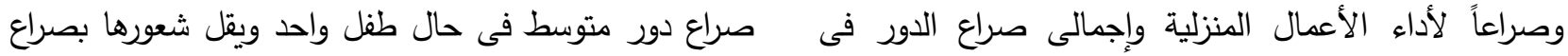
الأدوار فى حال عدم وجود أطفال كما يتفق مع مال ما أكدته

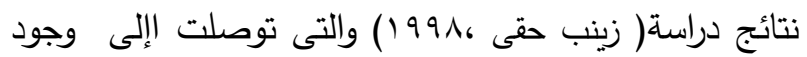

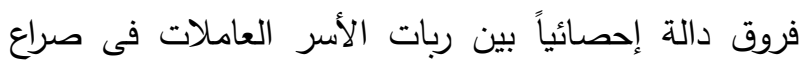

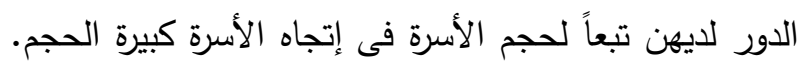

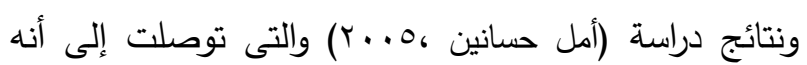

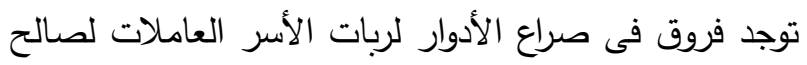

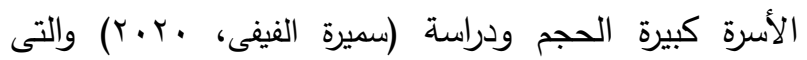

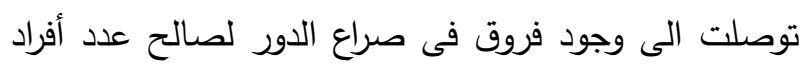

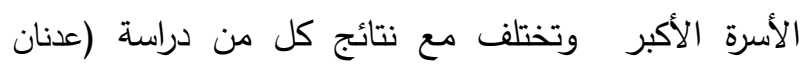

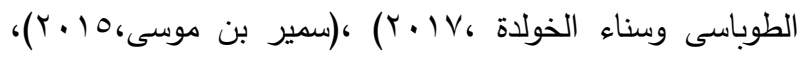

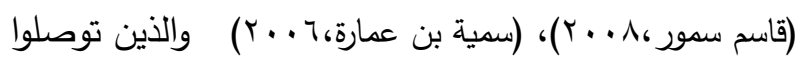
إلى عدم وجود فروق فى صراع الأدور تبعا لعدد الأبناء

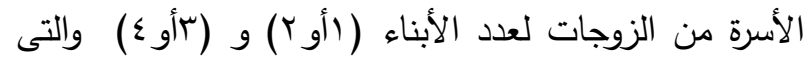

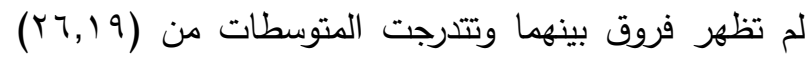

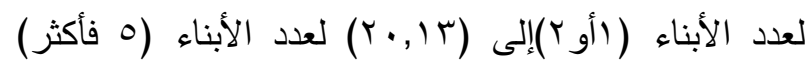

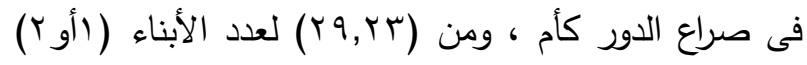

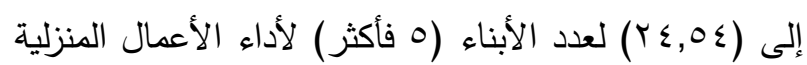

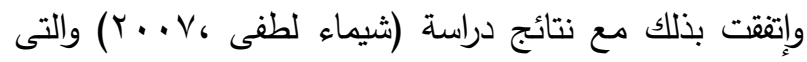
توصلت إلى وجود علاقة إرتباطية سالبة بين عدد أفراد

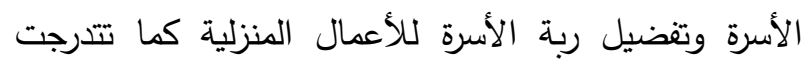

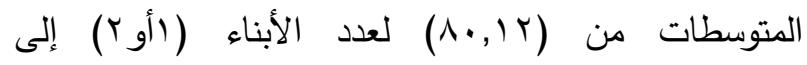

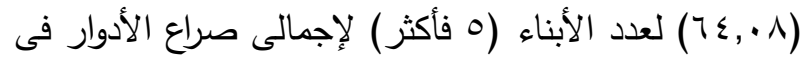

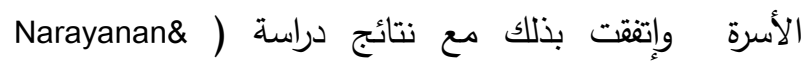
والتى توصلت إلى أن مستوى صراع (Savarimuthu, 2013 الأدوار يزداد بإزدياد عدد الأبناء وأن المرأة تعانى من مستوى الث دنتي

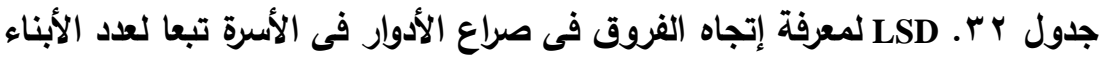

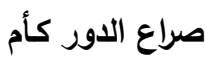

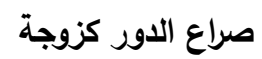
عدد الأبناء

\begin{tabular}{|c|c|c|c|c|c|c|c|}
\hline$r$ & $r_{0}, \cdot \Lambda=p$ & $r \tau, 19=r$ & $|9, \varepsilon|=p$ & $r r, \varepsilon \varepsilon=$ P & $r \varepsilon, 7 q=p$ & & \\
\hline & & - & & & - & 90 & $r-1$ \\
\hline & - & $1,11 \leq 0$ & & - & "r, YOV & $\wedge$. & $\varepsilon-r$ \\
\hline \multirow[t]{2}{*}{ - } & $" \varepsilon, q \leqslant \wedge$ & ס ס י , & - & $" r, r \leqslant 1$ & "0,rAr & זד & 0 فأكثر \\
\hline & الإجمالى & & \multicolumn{3}{|c|}{ صراع الدور فى أداء الأعمال المنزلية } & ن ن & عدد الأبناء \\
\hline \multirow[t]{3}{*}{$T \varepsilon, \wedge=$ P } & $V 0, Y \Lambda={ }_{P}$ & $\Lambda \cdot, I Y=$ P & $Y \leq, 0 \leqslant=$ R & $Y V, V T=\rho$ & $r q, r r=r$ & & \\
\hline & & - & & & - & 90 & $r-1$ \\
\hline & - & $\varepsilon, \wedge \varepsilon 1$ & & - & 1,8791 & $\wedge$. & r \\
\hline- & $" 11,197$ & $17, . \varepsilon$ & - & سY,r"r" & $" \varepsilon, T / 9 r$ & זד & 0 فأكثر \\
\hline
\end{tabular}


الأدوار فى الأسرة من الزوجات للأزواج من ذوات التعليم

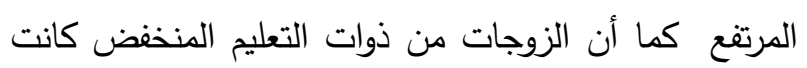

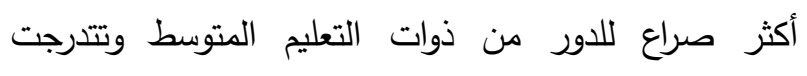

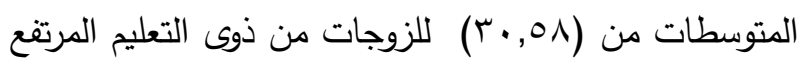

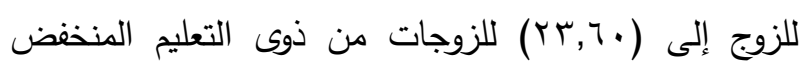

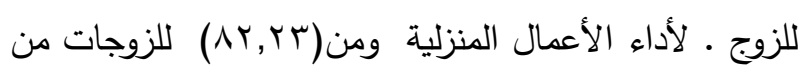

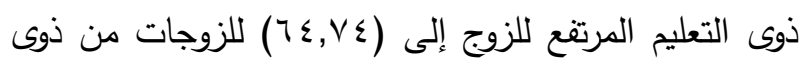

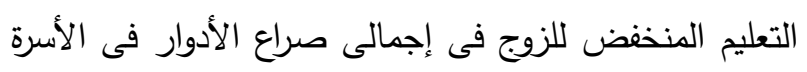

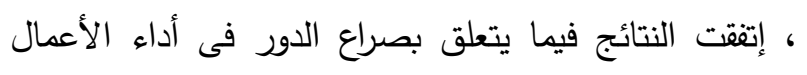

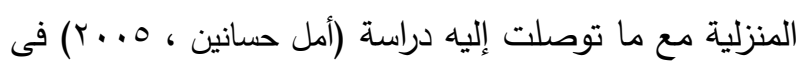
أنه يوجد تفاعل دال إحصائياً بين صراع الأعمال المنزلية

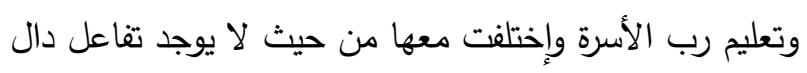
احصائياً بين صراع رعاية الأبناء وتعليم رب الأسرة وكذلك دألك

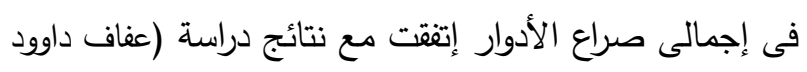

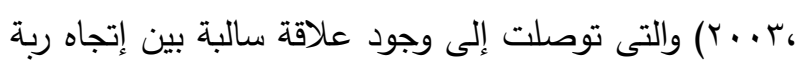

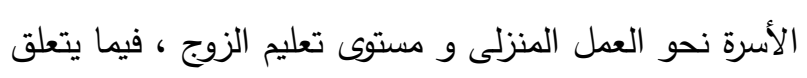

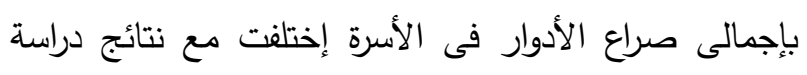

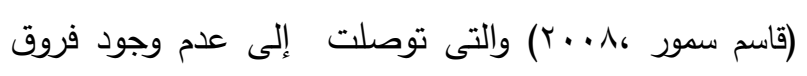

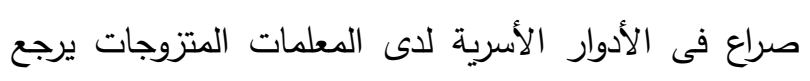

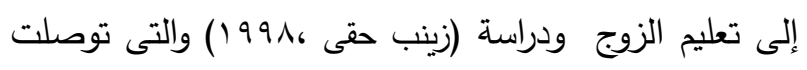

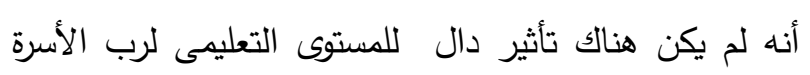

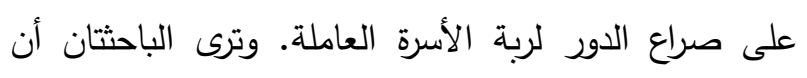

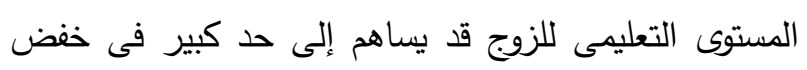

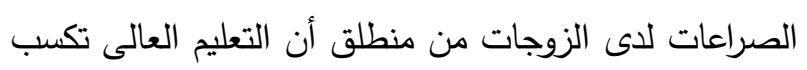
مرونة وأساليب متميزة لفهم ظروف الزوجة وتقدير أوضاعها.
ه- تعليم الزوج :- يتضح من جدول (Tr) وجود تباين دال

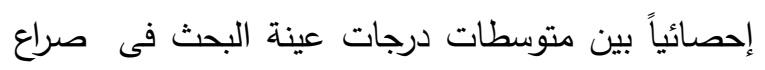
الأدوار فى الأسرة (صراع الدور كزوجة، صراع الدور

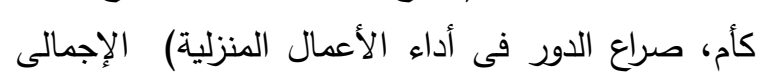

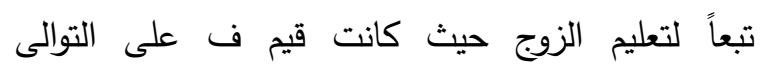

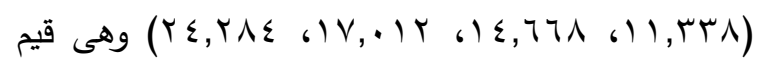
دالة إحصائياً عند مستوى ل ., ولمعرفة إتجاه الفروق تم تطبيق إختبار LSD

يتضح من نتائج جدول (؟ ب) وجود فروق دالة إحصائية بين متوسطات درجات عينة البحث فى صراع الأدور فى الأسرة

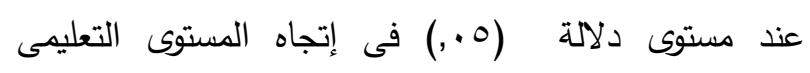
الدنخفض للزوج ( حيث المتوسط الحسابى الأقل ) فتبنين

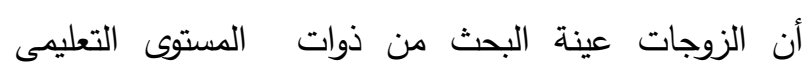

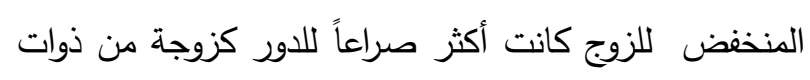

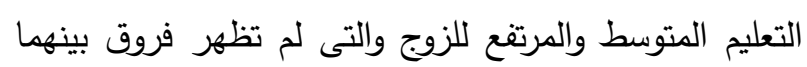

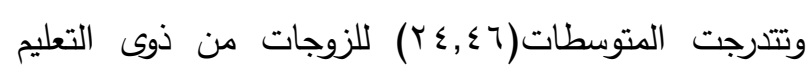

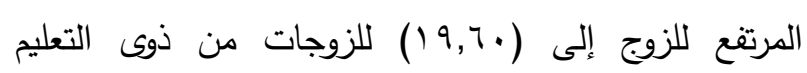

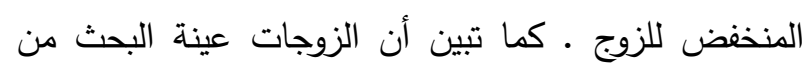

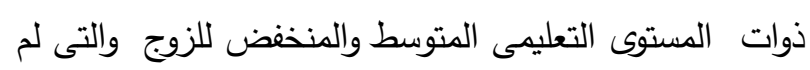

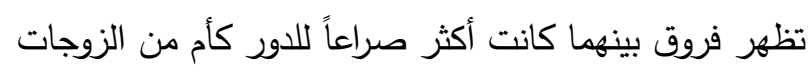

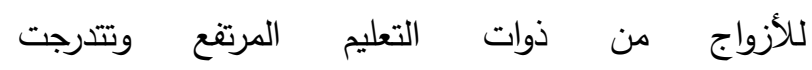

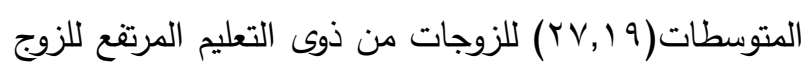

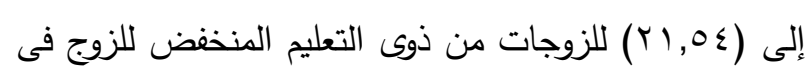

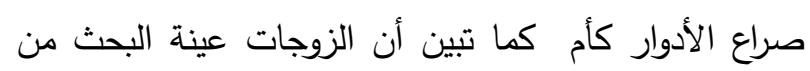

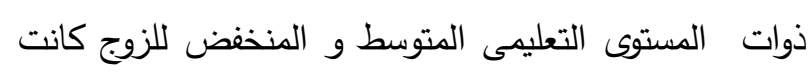

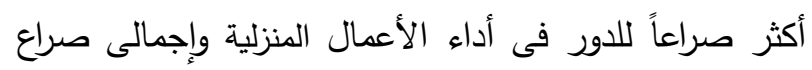




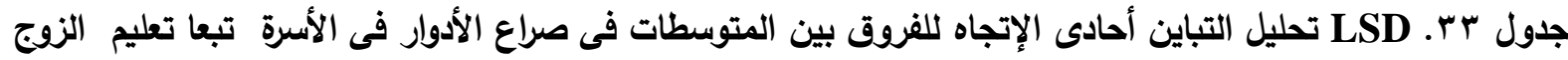
المحاور مصادر التباين مجموع المربعات درجات الحرية متوسط المربعات قيمة ف مستوى الدلالة

\begin{tabular}{|c|c|c|c|c|c|c|}
\hline دال عند مستوى ., . . & 11, MTA & $\begin{array}{l}\varepsilon O V, \wedge r \varepsilon \\
\varepsilon \cdot, r \wedge 1\end{array}$ & 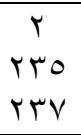 & $\begin{array}{l}910,7 \leq 1 \\
9 \leq 19,011 \\
1 \cdot \leq .0,17\end{array}$ & داخل المجموعات المبل & صراع الدور كزوجة \\
\hline دال عند مستوى ., . . & $1 \leqslant, 771$ & $\begin{array}{l}V r q, r \cdot r \\
0 ., r q 4\end{array}$ & 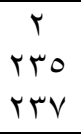 & $\begin{array}{l}1 \leqslant \vee \wedge, \varepsilon .0 \\
\mid \backslash \wedge \leqslant r, .91 \\
|r r r|, \leqslant 97\end{array}$ & داخل المجموعات المجوعات & صراع الدور كأم \\
\hline دال عند مستوى ., . . & $I V, \cdot I T$ & $\begin{array}{l}97 Y, 9 \leq \leq \\
07,7.4\end{array}$ & 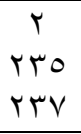 & $\begin{array}{l}19 Y 0, \wedge \wedge V \\
1 r r .1,7.9 \\
10 Y r V, \Sigma 97\end{array}$ & داخل المجموعات المجوعات & صراع الدور فى أداء \\
\hline دال عند مستوى . . . . & $r \varepsilon, Y \wedge \varepsilon$ & $\begin{array}{l}7) \varepsilon \cdot, 91 V \\
\text { ror, AVV }\end{array}$ & $\begin{array}{l}\text { h } \\
\text { reg } \\
\text { red }\end{array}$ & $\begin{array}{l}\text { IYYAI,ATE } \\
\text { OQSYT, RY } \\
\text { VIV.V,NTY }\end{array}$ & داخل المجموعات المجوعات & الإجمالى \\
\hline
\end{tabular}

جدول \& ب. LSD لمعرفة إتجاه الفروق فى صراع الأدوار فى الأسرة تبعاً لتعليم الزوج

\begin{tabular}{|c|c|c|c|c|c|c|c|}
\hline \multicolumn{3}{|c|}{ صراع الدور كأم } & \multicolumn{3}{|c|}{ صراع الدور كزوجة } & \multirow[b]{2}{*}{$\dot{ن}$} & \multirow[b]{2}{*}{ المستوى التعليمى } \\
\hline$r V, 19=p$ & 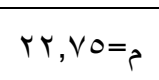 & $r_{1,0}, 0 \varepsilon=p$ & $r\{, \Sigma\rceil=\beta$ & $r, T Y=$ P & $19,7 \cdot=$ & & \\
\hline \multirow[b]{3}{*}{-} & & - & & & - & 70 & تعليم منخفض \\
\hline & - & $1, r 10-$ & & - & "r,,$r r-$ & VV & تعليم متوسط \\
\hline & $" \varepsilon, \varepsilon \Gamma \varepsilon-$ & $" 0,7 \leq 9-$ & - & 1, גז०.- & $" \varepsilon, \wedge \circ \wedge-$ & 97 & تعليم مرتفع \\
\hline \multicolumn{3}{|c|}{ الإجمالى } & \multicolumn{3}{|c|}{ صراع الدور فى أداء الأعمال المنزلية } & $\therefore$ & المستهى، التعليد \\
\hline$A r, r r=5$ & 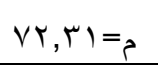 & $T \leq, V \Sigma=p$ & $r \cdot, 0 \Lambda={ }_{5}$ & $r ד, 9 \varepsilon=p$ & 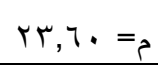 & 0 & المتنول التعيلى \\
\hline & & - & & & - & 70 & تعليم منخفض \\
\hline & - & "V,OVTr- & & - & ( & VV & تعليم متوسط \\
\hline- & $9,91 \wedge-$ & "IV, $₹ 9 r-$ & - & "r,T TیAr- & "7,9人रrT- & 97 & تعليم مرتفع \\
\hline
\end{tabular}

وهى قيم دالة إحصائياً عند مستوى( (.,) ولمعرفة إتجاه

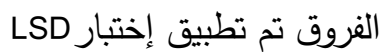
يتضح من نتائج جدول († آم) وجود فروق دالة إحصائية بين متوسطات درجات عينة البحث فى صراع الأدور فى الأسرة

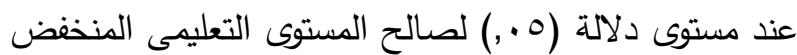

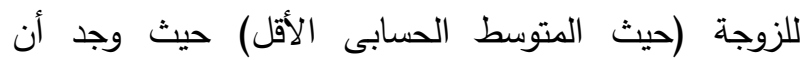

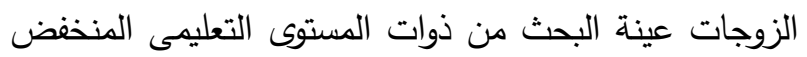

צ- تعليم الزوجة: - يتضح من جدول (ب0) وجود تباين دال إحصائياً بين متوسطات درجات عينة البحث فى جلى

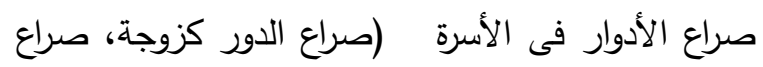
الدور كأم، صراع الدور فى أداء الأعمال المنزلية)

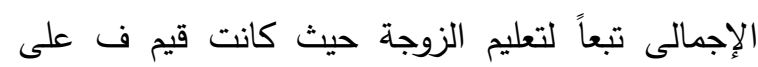

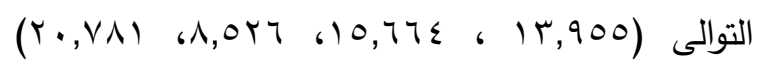


وفيما يتعلق بإجمالى صراع الأدوار فى الأسرة إتنقت مع دائت

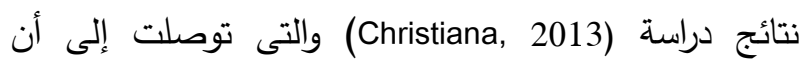

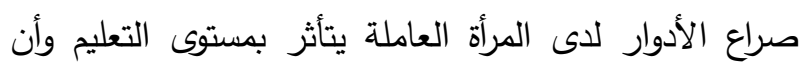

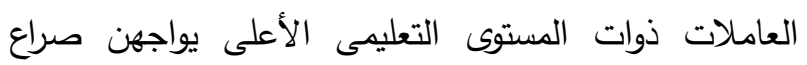

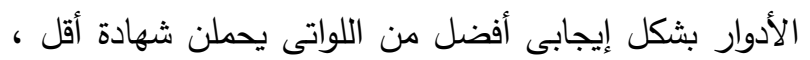

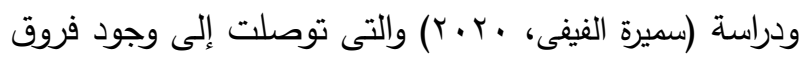

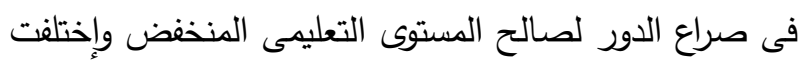

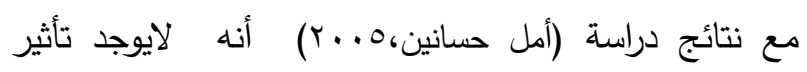
للمستوى التعليمى لربة الأسرة على صراع الدور لربة الأهن الأسرة

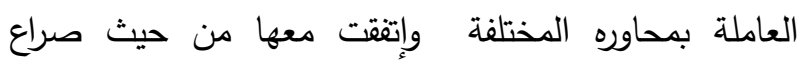

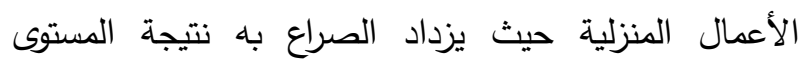

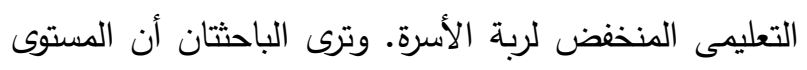

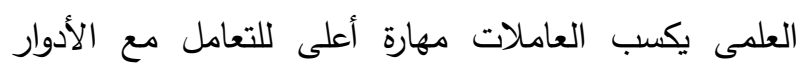
المتعددة فهى أقدر على تنظيم الوقت واتمام المطلوب. (سمية

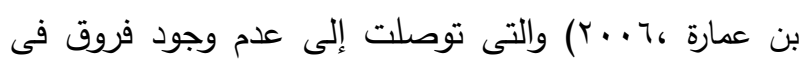

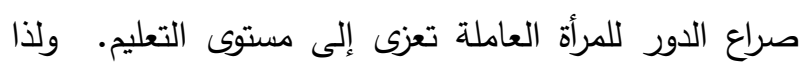
ترى الباحثتان ان المستوى التعليمى المرتفع للزوجين ساعد التعاد

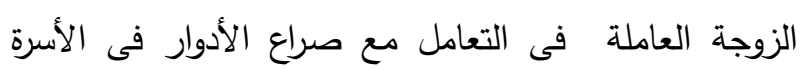
بكفاءة أعلى من ذوات المستوى التعليمى المنخفض.
كانت أكثر صراعاً للاور كأم من ذوات التعليم المتوسط

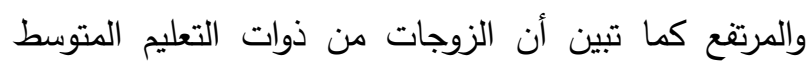

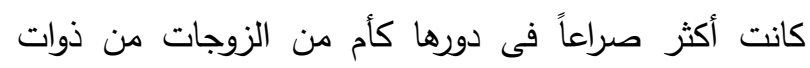

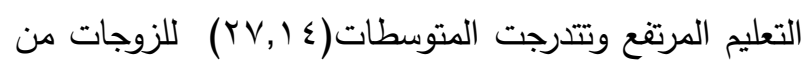

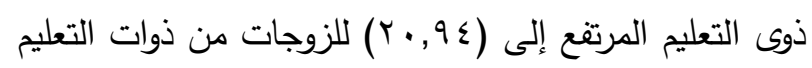

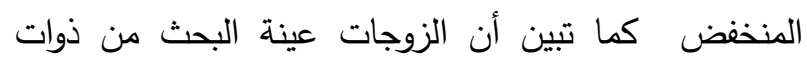
المستوى التعليمى المتوسط و المنخفض والتى لم تظهر فروق التهات بينهما كانت أكثر صراعاً للدور كزوجة وفى أداء الأعمال

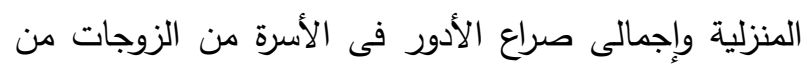

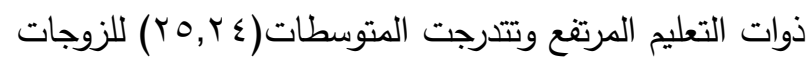

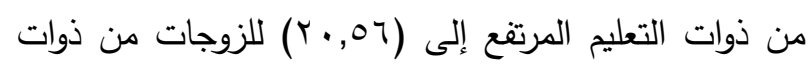

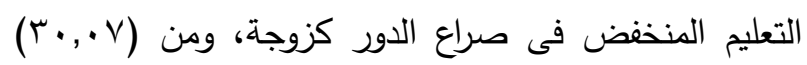

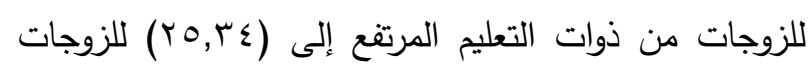

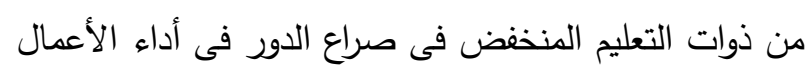

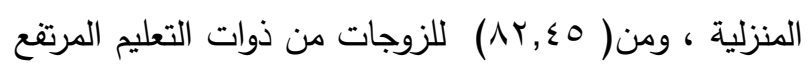

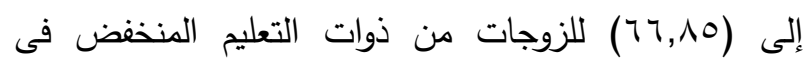
إجمالى صراع الأدوار فى الأسرة ، إتنقت هذه النقات النتائج فيما

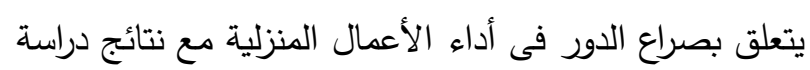

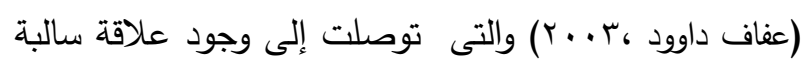
بين إتجاه ربة الأسرة نحو العمل المنزلى و مستوى تعليمها،

جدول هץ. تحليل التباين أحادى الإتجاه للفروق بين المتوسطات فى صراع الأدوار فى الأسرة تبعا لتعليم الزوجة

\begin{tabular}{|c|c|c|c|c|c|c|}
\hline مستوى الدلالة & قيمة ف & متوسط المربعات & درجات الحرية & مجموع المربعات & مصادر التباين & المحاور \\
\hline دال عند مستوى & $1 \pi, 900$ & $\begin{array}{l}.00 Y, r \cdot 0 \\
r 9,0 V Y\end{array}$ & $\begin{array}{l}\text { the } \\
\text { trug } \\
\text { red }\end{array}$ & $\begin{array}{l}11 \cdot 5,7.9 \\
97.9,001 \\
1.5 .0,17\end{array}$ & داخل المجموعات المجوعات & صراع الدور كزوجة \\
\hline دال عند مستوى & $10,74 \varepsilon$ & $\begin{array}{l}\text { VArT, } 0.4 \\
0 ., .19\end{array}$ & 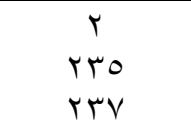 & $\begin{array}{l}107 V, \cdot 11 \\
11 V 0 \varepsilon, \varepsilon \Lambda \varepsilon \\
1 K r \mid, \varepsilon 97\end{array}$ & داخل المجموعات الكموعات & صراع الدور كأم \\
\hline دال عند مستوى & 1,OYT & $\begin{array}{l}010,1 \cdot V \\
7 \cdot, \varepsilon 1 \leqslant\end{array}$ & $\begin{array}{l}\text { the } \\
\text { trug } \\
\text { the }\end{array}$ & $\begin{array}{l}\text { l.r.,YIr } \\
1 \leq 19 V, Y \wedge r \\
\text { lorrV, }\{94\end{array}$ & داخل المجموعات الكموعات & صراع الدور فيى أداء \\
\hline دال عند مستوى & $r \cdot, V \wedge l$ & $\begin{array}{l}\text { OrAA,YYY } \\
\text { YOQ, YAT }\end{array}$ & 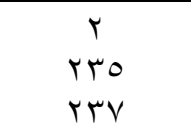 & $\begin{array}{l}\text { I.VVT, }\{00 \\
Y .9 Y 1, \varepsilon 11 \\
V \mid V \cdot V, \lambda T 4\end{array}$ & داخل المجموعات الكموعي & الإجمالى \\
\hline
\end{tabular}


جدول بال ـ LSD لمعرفة إتجاه الفروق فى صراع الأدوار فى الأسرة تبعاً لتعليم الزوجة

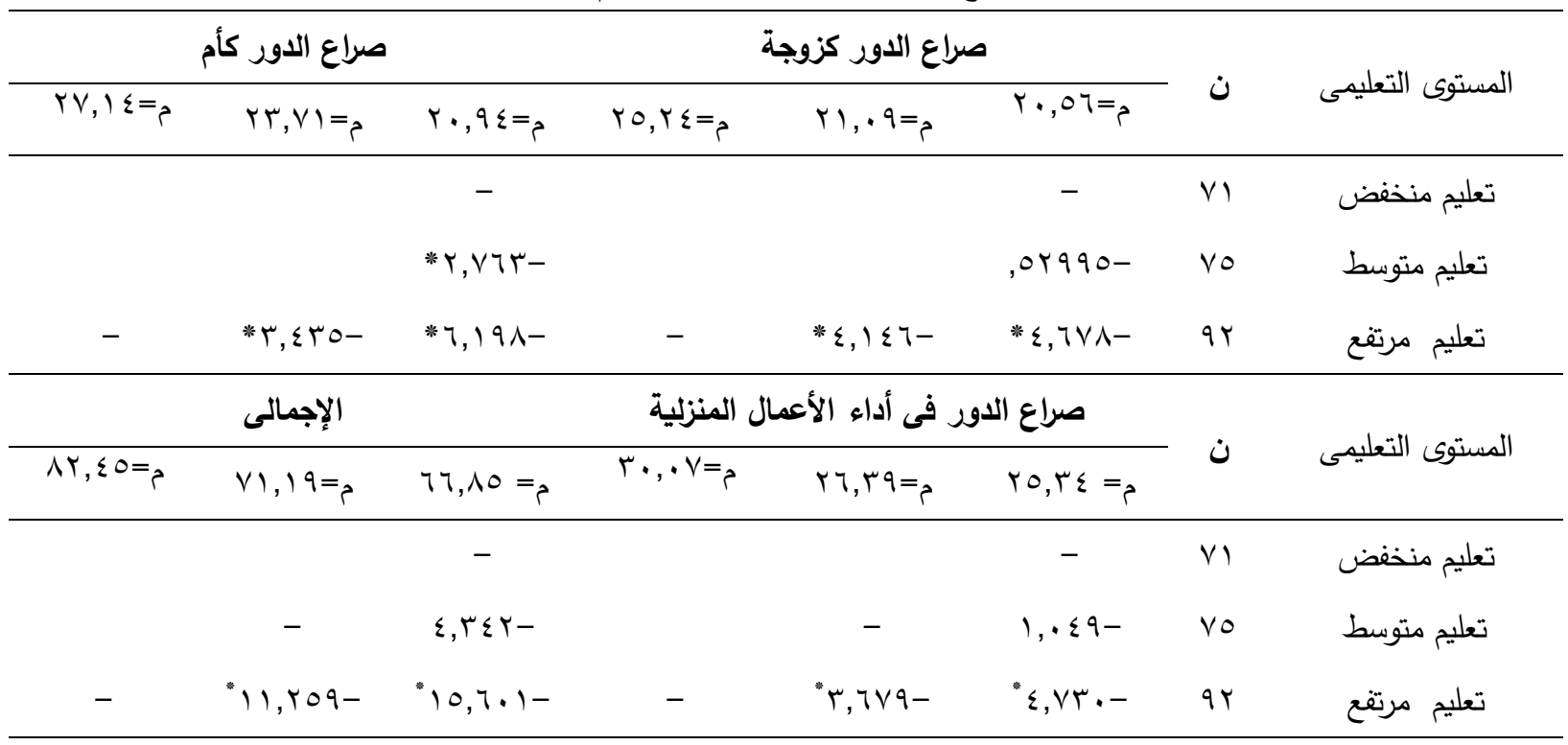

الاخل المنخفض كانت أكثر صراعا للدور في أداء الأعمال

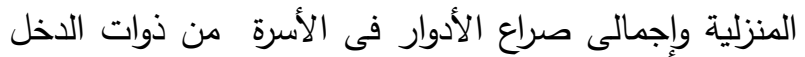

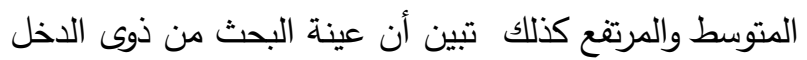
الهتوسط كانت أكثر صراعاً للدور فى أداء الأعمال المنزلية

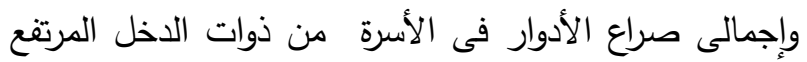

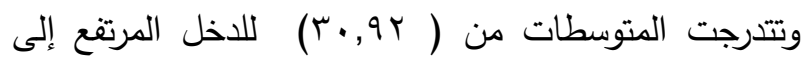

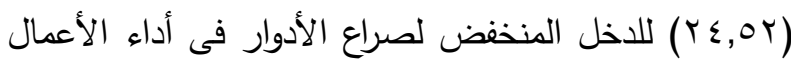

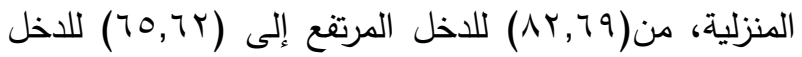
المنخفض لإجمالى صراع الأدوار فى الأسرة وإتفقت هذه التهاته

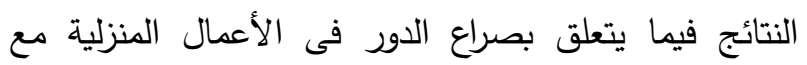

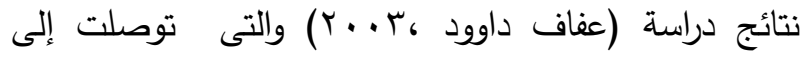
وجود علاقة سالبة بين إتجاه ربة الأسرة نحو العمل المنزلى و

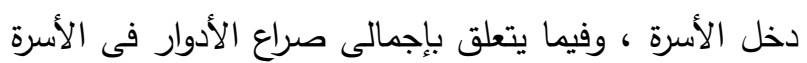

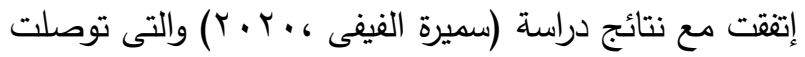
إلى وجود فروق فى صراع الدور لصالح الدخل المنخفض

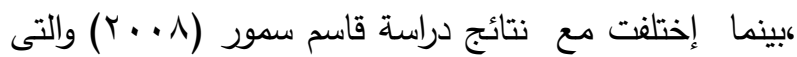
توصلت إلى عدم وجود فروق صراع فى الأدوار الأسرية لاى المعلمات المتزوجات يرجع إلى الدخل الثهرى ونتائج

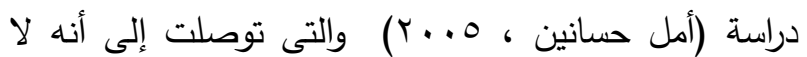

V- مستوى الاخل الثهرى للاسرة :- يتضح من جدول وجود تباين دال إحصائياً بين متوسطات درجات : (rV) عينة البحث فى صراع الأدوار فى الأسرة (صراع الدور كزوجة، صراع الدور كأم، صراع الدور فى أداء الأعمال

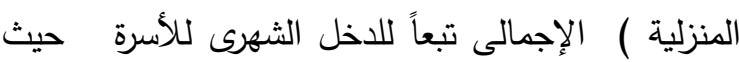

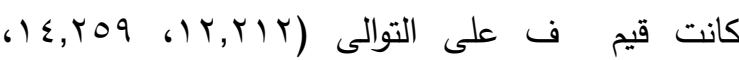

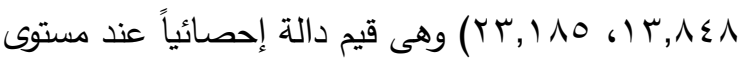

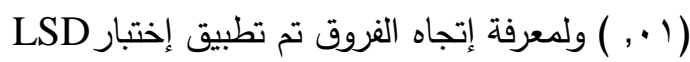
يتضح من نتائج جدول (^^) وجود فروق دالة إحصائية بين متوسطات درجات عينة البحث فى صراع الدور فى الأسرة

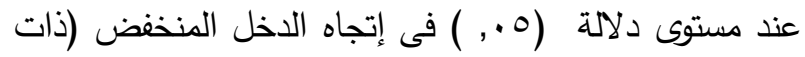
المتوسط الحسابى الأقل ) فتبين أن الزوجات عينة البحث من التهاه

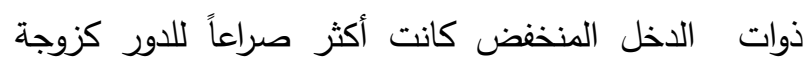

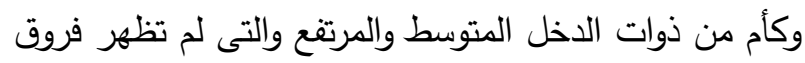

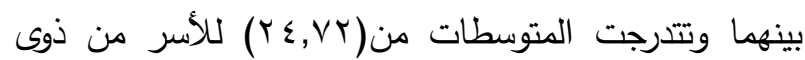
الدخل المرتفع إلى (19,90) للأسر ذوى الدخل الدنخفض

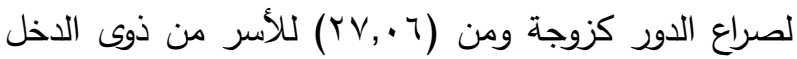

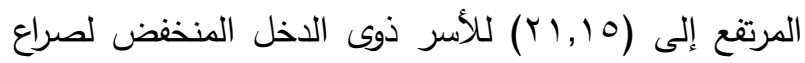

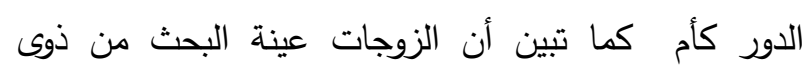




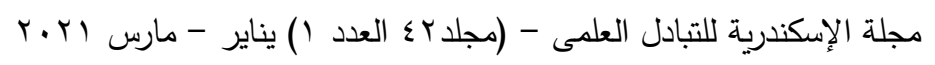

يوجد تأثير لاخل الأسرة على صراع الدور لربة الأسرة عينة البحث فى صراع الأدوار فى الأسرة المحاور والإجمالى تبعا لصالح السن الأقل، عدم وجود فروق بين البن

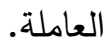
متوسط درجات عينة البحث فى صراع الأدوار فى الأسرة (المحاور ، الإجمالى) تبعا لسنوات الزواج وجود فروق بين متوسط درجات عينة البحث فى صراع الأدوار فى الاسرة

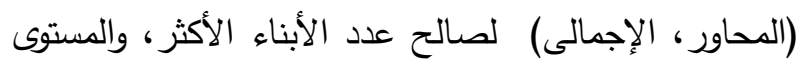
التعليمى الأقل للزوجين ومستوى الاخل الثهرى الأقل للأسرة وبذلك يكون تحقق الفرض جزئيا.

وترى الباحثتان أن الزوجات من ذوات الدخل المرتفع (ذات المتوسطات الاعلى ) إستطاعت التعامل مع صراع الأدوار فى الأسرة بطريقة أفضل من الزوجات من ذوات الدخل المنخفض (ذات المتوسطات الأقل) نستخلص مما سبق وجود فروق بين متوسطات درجات عينة

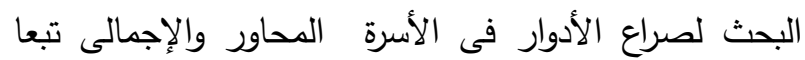
لمكان السكن لصالح سكان الريف، فيما عدا صراع الدور كأم الرداع لم توجد فروق، وجود فروق دالة احصائيا بين متوسط درجات

جدول LSD . لمعرفة إتجاه الفروق فى صراع الأدوار فى الأسرة تبعاً لمستوى الاخل الثهرى للأسرة المحاور مصادر التباين مجموع المربعات درجات الحرية متوسط المربعات قيمة ف مستوى الدلالة

صراع الدور كزوجة

صراع الدور كأم

صراع الدور في أداء الأعنزلية

\begin{tabular}{|c|c|c|c|c|c|}
\hline دال عند مستوى . . . . & $r r, 110$ & $\begin{array}{l}09 \cdot \wedge, V Y 0 \\
Y O s, \wedge O r\end{array}$ & 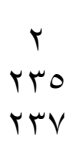 & $\begin{array}{l}11 \wedge \mid \vee, \leqslant 0 \\
09 \wedge 9 \cdot, \leqslant 17 \\
\vee \backslash \vee \cdot \vee, \wedge T 4\end{array}$ & داخل المجموعات المجوعات \\
\hline
\end{tabular}




\begin{tabular}{|c|c|c|c|c|c|c|c|}
\hline \multicolumn{3}{|c|}{ صراع الدور كأم } & \multicolumn{3}{|c|}{ صراع الدور كزوجة } & \multirow[b]{2}{*}{$\dot{ن}$} & \multirow{2}{*}{ 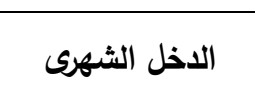 } \\
\hline$Y V, \cdot T=p$ & $r 0, \cdot 1=p$ & $r 1,10=p$ & $r \xi, V Y=\rho$ & $r T, \Sigma l=5$ & $19,90=p$ & & \\
\hline \multirow[b]{3}{*}{-} & & - & & & - & $\Lambda \vee$ & دخل شهرى منخفض \\
\hline & - & - "ז,人ז" & & - & $" r, \varepsilon 09-$ & $\wedge$. & دخل شهرى متوسط \\
\hline & $r, \cdot \Sigma r \Lambda-$ & $0,9 \cdot v-$ & - & $1, r \cdot 7-$ & $" \varepsilon, \vee \vee \varepsilon-$ & v) & دخل شهرى مرتفع \\
\hline \multicolumn{3}{|c|}{ الإجمالى } & \multicolumn{3}{|c|}{ صراع الدور فى أداء الأعمال المنزلية } & \multirow[b]{2}{*}{ ن } & \multirow{2}{*}{ الاخل الشهرى } \\
\hline$M r, T Q=s$ & $V \tau, 1 Y=\rho$ & $10,71=5$ & $r \cdot, q r=5$ & $r V, V \cdot=5$ & $r \leqslant, O r={ }^{2}$ & & \\
\hline & & - & & & - & $\Lambda V$ & دخل شهرى منخفض \\
\hline & & $1 \cdot, 0 \cdot \varepsilon-$ & & - & 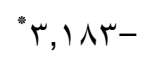 & $\wedge$. & دخل شهرى متوسط \\
\hline- & $" 7,070-$ & "IV, $\cdot v \cdot-$ & - & "r,YוY- & $" ч, r q \wedge-$ & v) & دخل شهرى مرتفع \\
\hline
\end{tabular}

الأسرة والذى شارك بنسبة (ץ, ؟1\%)، ثم تعليم الزوجة

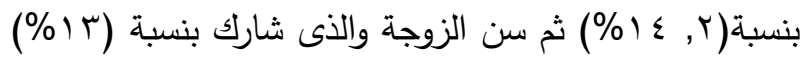
وعدد الأبناء الذى شارك بنسبة( 9 , r (1\%) نستخلص جاء تأثير لبعض متغيرات المستوى الإجتماعى والإقتصادى (تعليم زوج والدخل وسن الزوجة وعدد الأبناء)

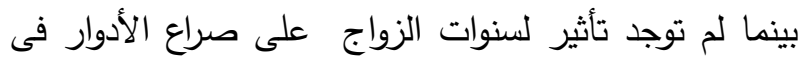
الأسرة وبذلك يكون تحقق الفرض جزئيا
الفرض الرابع: تختلف نسبة مشاركة متغيرات المستوى الإجتماعى والإقتصادى فى تفسير نسبة التباين على المتغير (صراع الأدوار فى الأسرة ) وللتحقق من صحة هذا الفرض تم حساب الأهمية النسبية بإستخدام معامل الإنحدار (الخطوة

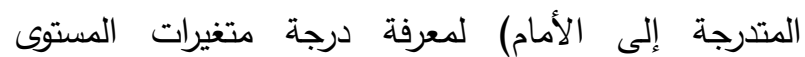
الإجتماعى والإقتصادى على صراع الأدوار فى الأسرة. يتضح من نتائج جدول (q⿳) أن تعليم الزوج كان من أكثر العوامل التى ساعدت الزوجة العاملة التعامل مع صراع

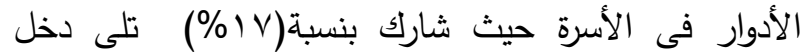

جدول q ب. الانحدار الخطى للعلاقة بين صراع الأدوار فى الأسرة (متغيرات المستوى الإجتماعى والإقتصادى)

\begin{tabular}{|c|c|c|c|c|c|c|}
\hline (ت) & \multicolumn{2}{|c|}{ معامل الإنحدار } & $\mathbf{F}$ & $\mathbf{R 2}$ & $\mathbf{R}$ & المتغيرات \\
\hline$* * 19,1 \vee 0$ & $\begin{array}{l}00, \leqslant 0 \leqslant \\
\wedge, \wedge Y .\end{array}$ & $\begin{array}{c}\text { الثابت } \\
\text { B }\end{array}$ & $* * \varepsilon \Lambda, \leqslant \Gamma V$ & $\cdot, I V$. & $\cdot, \varepsilon \mid r$ & تعليم زوج \\
\hline$* * Y$, , $00 Y$ & $\begin{array}{c}\text { ov, } 711 \\
\wedge, 7.1\end{array}$ & الثابت & $* * \leqslant 0,0,0$ & • , 17r & $\cdot, \varepsilon \cdot r$ & دخل ل \\
\hline$* * r_{\cdot}, 19 \leq$ & $\begin{array}{l}O V, T O \wedge \\
V, q \leq Y\end{array}$ & الثابت & $* * r \wedge, 9 \wedge 1$ &, $1 \leq r$ & • , TVV & تعليم زوجة \\
\hline • ז, سז" & $\begin{array}{l}\wedge \wedge, \vee \wedge \vee \\
\vee, \vee ৭ ৭\end{array}$ & $\begin{array}{c}\text { الثابت } \\
\text { B }\end{array}$ & $* * r 0, r \leq V$ & . .1r. & • & عدد الأبناء \\
\hline$* * Y, r Y V_{0}$ & $\begin{array}{l}\diamond \wedge, \varepsilon \wedge r \\
\vee, \varepsilon \diamond \vee\end{array}$ & الثابت & $* * r \leqslant, \wedge 00$ & $\cdot, 1<9$ & · r. & سن الزوجة \\
\hline
\end{tabular}




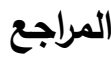

إبتسام بنت عبد الله حسين (10 ب) : المعوقات الاجتماعية التى في

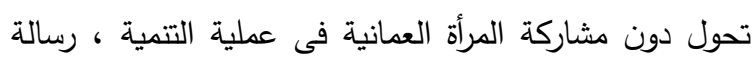

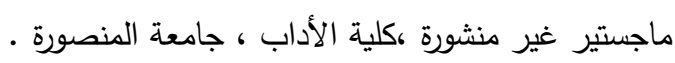

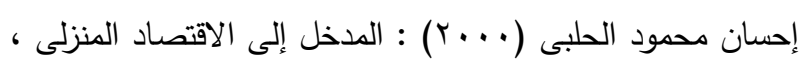

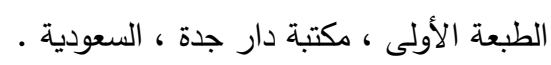

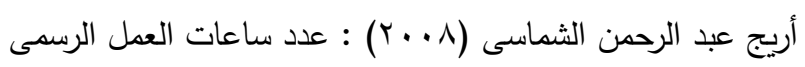

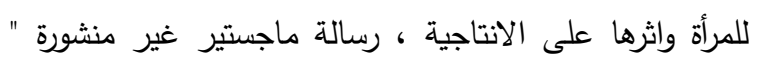

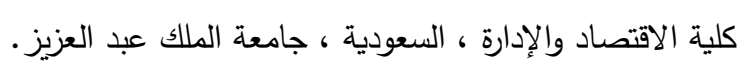

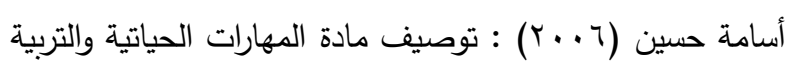

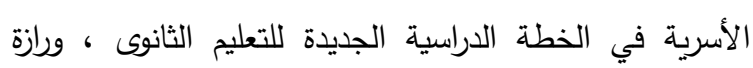

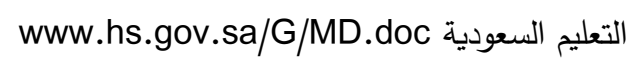

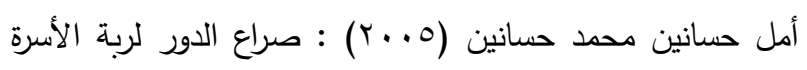

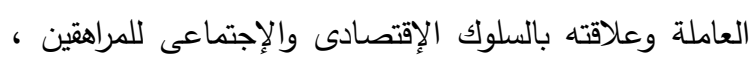

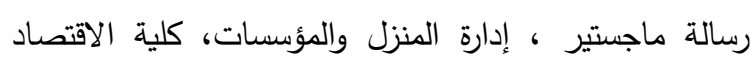

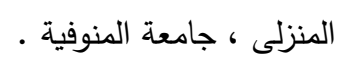

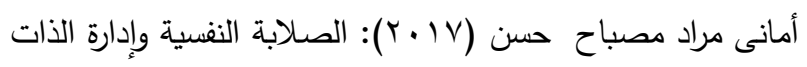

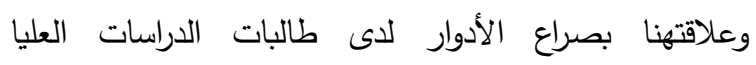
المتزوجات ، ماجستير ، كلية التربية ، قسم الصحة النفسية

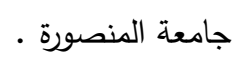

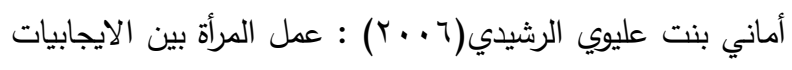

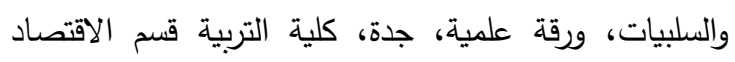

$$
\text { المنزلي، جامعة الملك عبد العزيز. }
$$

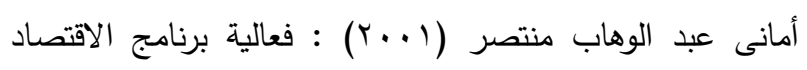

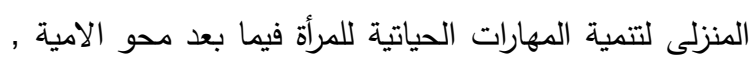

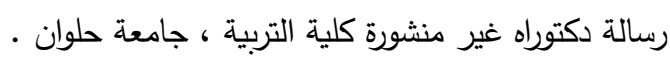

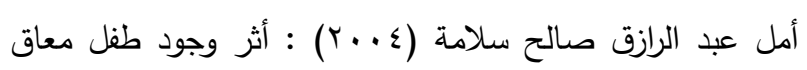

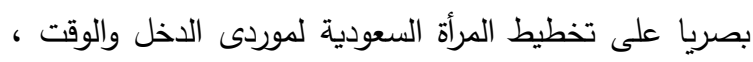

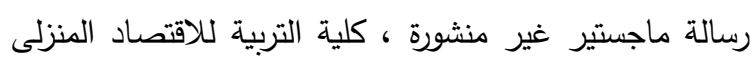
والتربية الفنية وزارة التربية والتعليم جدة المكلكة العربية

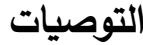

ا-زيادة تغعيل دور مكاتب الإرشاد والتوجيه الأسرية والجهات

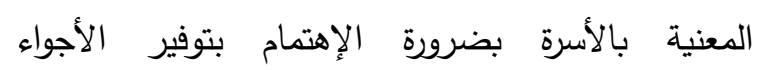
والمستلزمات الضرورية التي تخفف عن كاهل المرأة الأعباء المنزلية وعمل دورات تدريبية لربة الأسرة

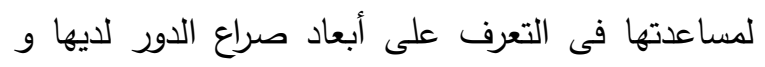
العمل على حل تلك الصراعات باستخدام أساليب إدارة

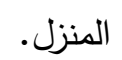

r- إعداد برامج إرشادية تقدم عن طريق وسائل الإعلام المختلفة وخاصة الإعلام المرئى لتوعية الزوجة العاملة

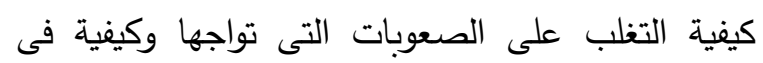

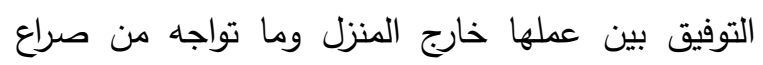

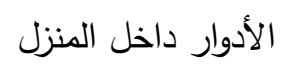

ץ- إستثمار وسائل الإعلام والتتثيف في غرس التئ التيم والهفاهيم الإيجابية نحو تتشئة المرأة ودورها في الحياة

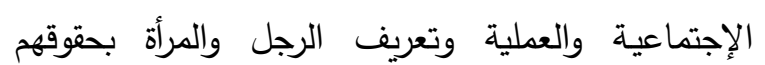
وواجباتهم وأدوارهم في الحياة وضرورة المشاركة بينهم . ع- على كل أسرة تدريب الأبناء دائماً للمشاركة فى الأعمال الكنزلية دون التميز بين جنس الأبناء وخلق روح المشاركة و التعاون بين أفراد الأسرة

0- تفعيل دور المجلس القومى للمرأة بعمل برامج توعية

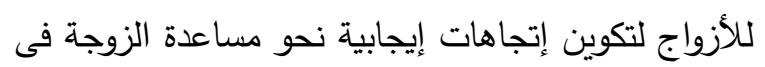

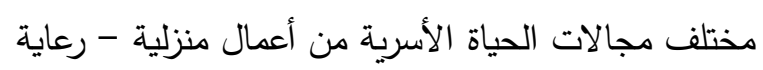

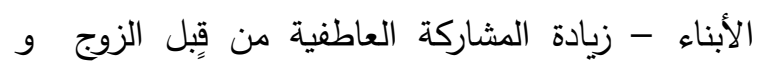
تحسين صورة الزوجة عن ذاتها 
الحسينى رجب ريحان ، سلوى محمد زغلول طه ، شرين عبد

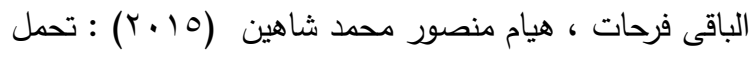

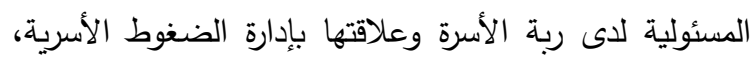

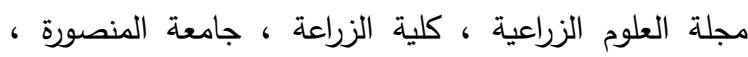

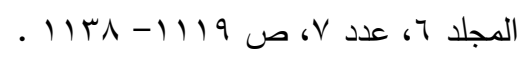

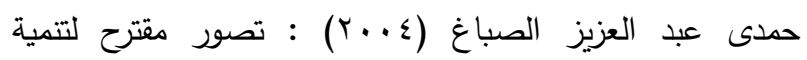

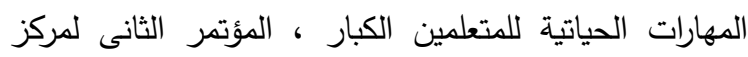

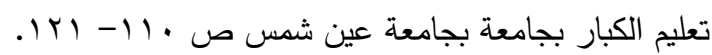

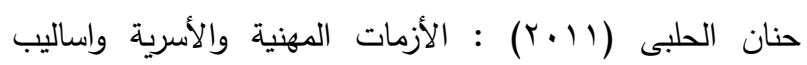
الزوجات فى التعامل معها ، مجلة جامعة دمشق ، المجلد

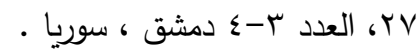

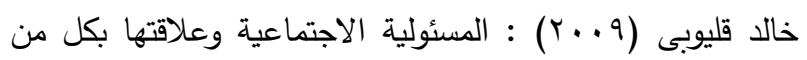
وجهة الضبط وفاعلية الذات لاى عينة من طلاب جامعة

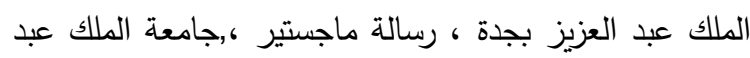

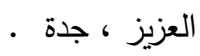

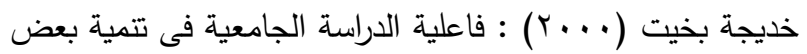

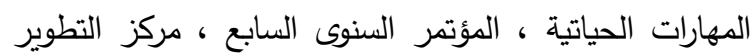
الجامعى ، نوفمبر ، جامعة عين شمس.

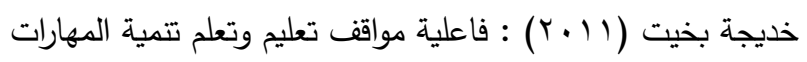

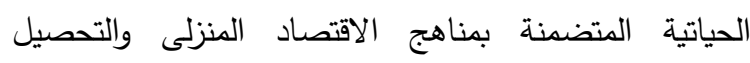
وإتجاهات طالبات المحلة الثانوية ، جامعة المللك عبد العزيز ، كلية التربية للاقتصاد المنزلى والتربية الفنية .

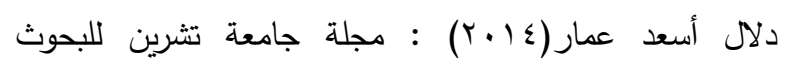
والدراسات العلمية ، سلسلة الآداب والعلوم الإنسانية ، المجلد

دنيال جولمان ( . . . ب) : الذكاء العاطفى ، ترجمة ليلى الجبإلى ،

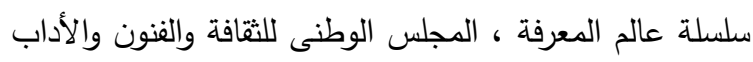

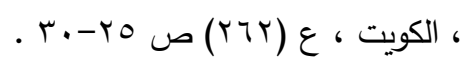

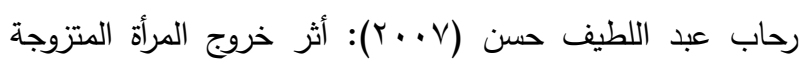

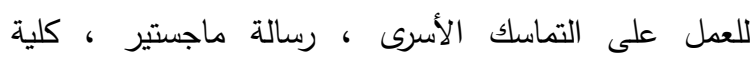

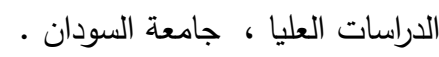

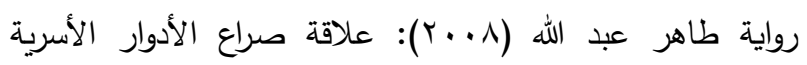

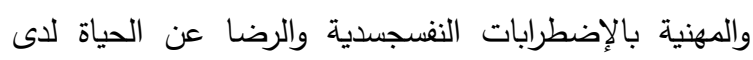

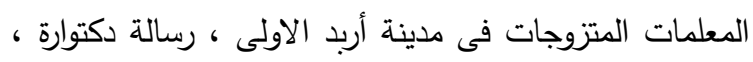
جامعة اليرموك ، كلية التربية ، الأردن •

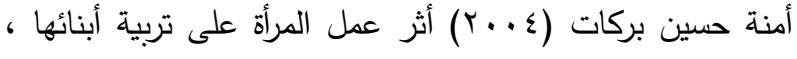
رسالة ماجستير غير منشورة ، كلية الآداب ، جامعة طرابلس.

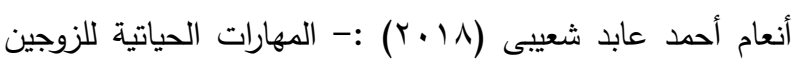

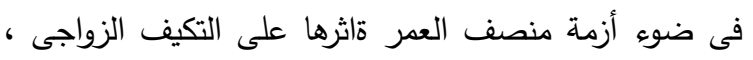

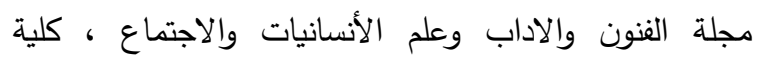

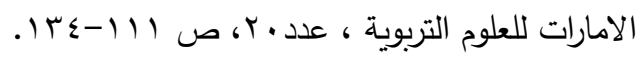

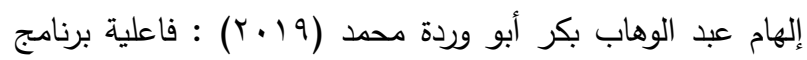

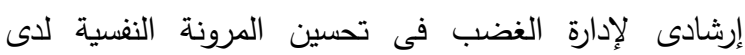

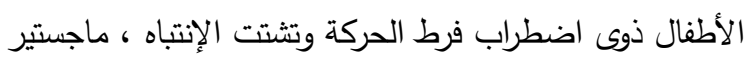

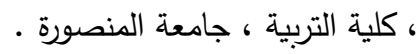

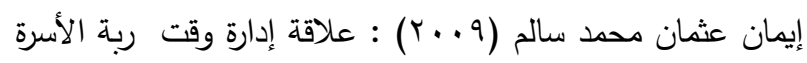

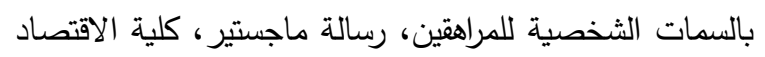

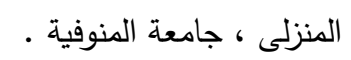
إيمان شعبان أحمد (q . . †) : إدارة موارد الأسرة للزوجة العاملة

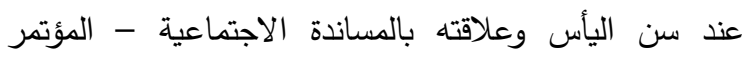

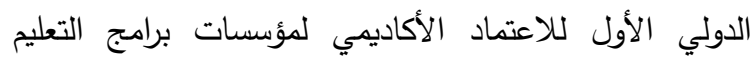

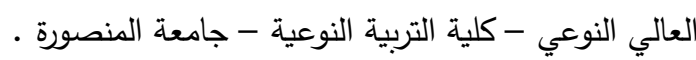

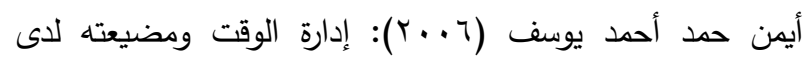
مديرى ومديرات المدارس الأساسية فى محافظة رام الله والبيرة

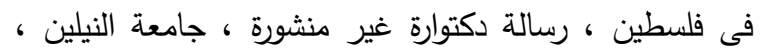

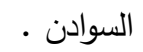
بتول محى الدين صالح خليفة (1 ( . ب) : دراسة لبعض مشكلات

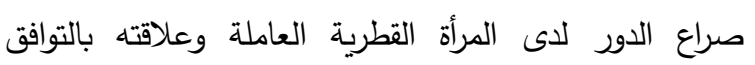
النفسى للأم والأولاد، قسم الصحة النفسية، كلية التربية، جامعة الترأ

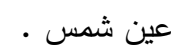

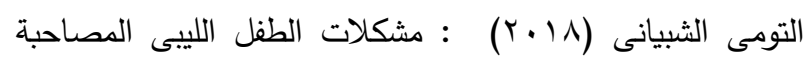
لخروج المرأة إلى العمل "دراسة ميدانية على منطقة أبو سليم

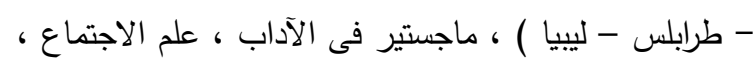

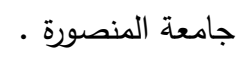

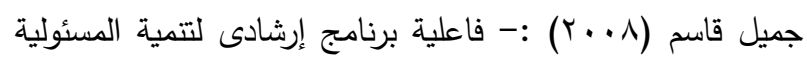
الاجتماعية لدى طلاب المرحلة الثانوية رسالة ماجستير ، كلية التربية ، الجامعية الإسلامية ، غزة ، فلسطين •

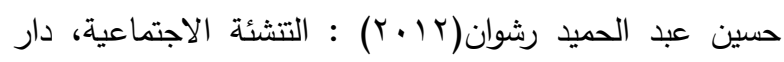

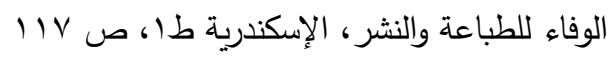




$$
\text { مجلة الإسكندرية للتبادل العلمى - (مجلد إع العدد () يناير - مارس (Y.r }
$$

سميرة أحمد حسن العبدلى الفيفى (ץ. . ب) : إدارة موارد الأسرة

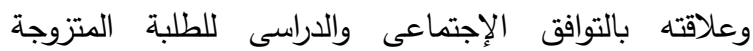
بالمرحلة الجامعية بمكة كلية التربية للاقتصاد المنزلى ، وزارة

المعارف ، مكة المكرمة ، المملكة العربية السعودية .

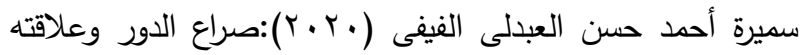

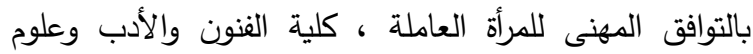

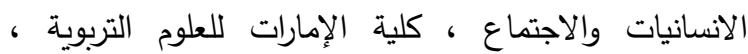

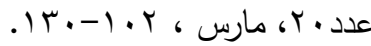

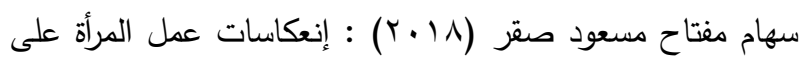

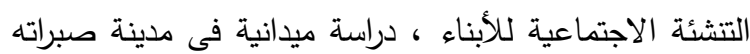

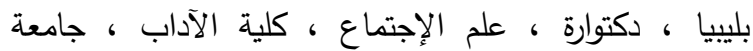

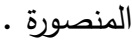
شرين جلال محفوظ (ץ+..ץ): دراسة تحليلة لوقت ربة الأسرة وأثرها على توافقها الزواجى ، رسالة دكتوارة غير منشورة ، كلية الاقتصاد المنزلى ، جامعة المنوفية .

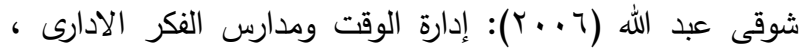
عمان ، دار أسامة للنشر والتوزيع ·

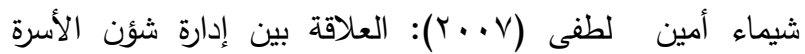

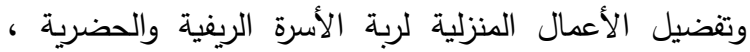
رسالة ماجستير ، كلية الاقتصاد المنزلى ، جامعة المنوفية .

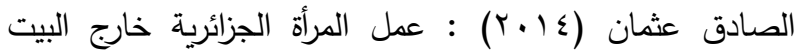
وصراع الأدوار الأسرية ، لرسالة ماجستير ، قسم علم الإجتماع

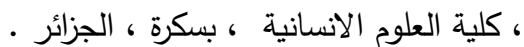
طلعت منصور، مروة حمدى الدمرداش ، سميرة محمد شند

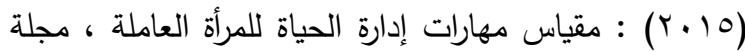

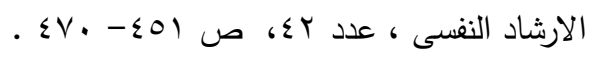

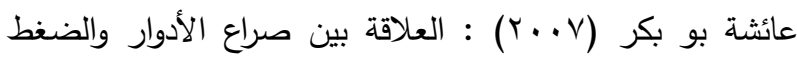
النفسى لدى الزوجة العاملة ، رسالة ماجستير ، كلية العلوم الإجتماعية والإنسانية ، جامعة منتورى قسطنطينة ، الجزائر .

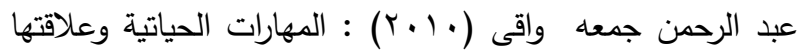
بالذكاءات المتعددة لدى طلبة المرحلة المرحلة الثانوية فى الثى قطاع غزة ، رسالة ماجستير ، منشورة كلية التربية ،الجامعة

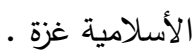

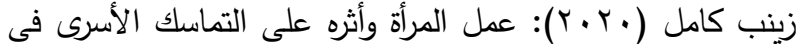
المجتمع الليبى "دراسة ميدانية فى مدينة ترهونة " ، رسالة

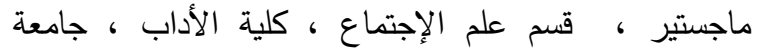

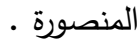

زينب محمد حقى ، نادية حسن أبو سكينة (991 ()): إدارة موارد

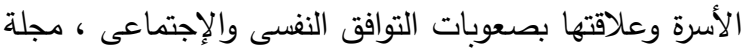
بحوث الاقتصاد المنزلى ، المجلد ^، العدد با، جامعة المنوفية

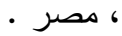

زينب محمد حسين حقى (1991)): أثر التخطيط الأسرى فى مواجهة صراع الدور لدى ربة الأسرة العاملة، مجلة بحوث الاقتصاد المنزلى، كلية الاقتصاد المنزلى، جامعة المنوفية،

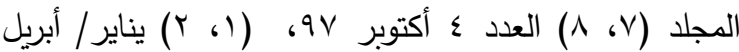
.1991 سالم الرحيمي وتوفيق المارديني (عابـ) : أثر إدارة الوقت في

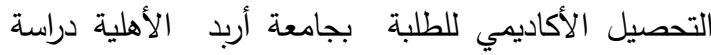

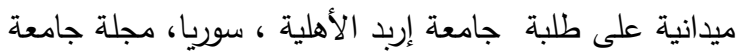

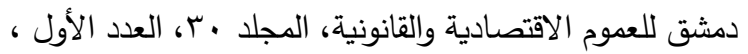

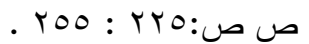

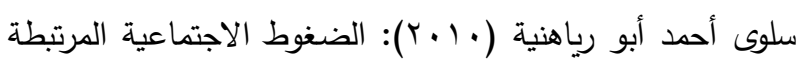
بصراع الأدوار لاى المرأة العاملة ، رسالة ماجستير غير الهاته

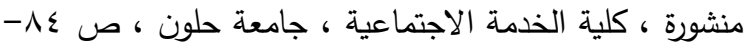
. 17

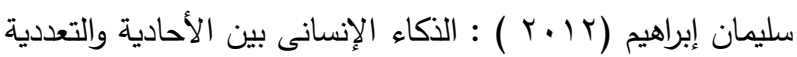
، الأسكندرية : دار الجامعة الجديدة .

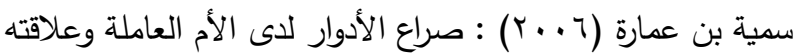
بتوافقها الزواجى ، ماجستير ، علم نفس الإجتماع ، جامعة قاصدى مرباح ورقلة ، كلية الاداب والعلوم الإنسانية ، قسم علم النفس وعلوم التربية .

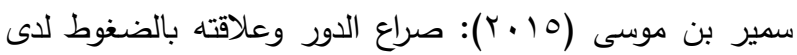
المرأة العاملة - دراسة تطبيقية بالقطاع الإستشفائى بن سينا بدائرة فرندة - ولاية تيارت ، مجلة العلوم الإنسانية العدد 


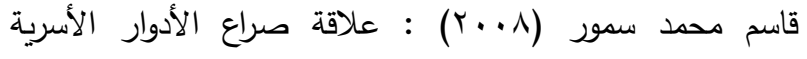

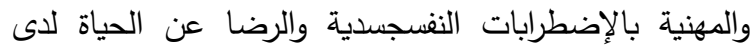

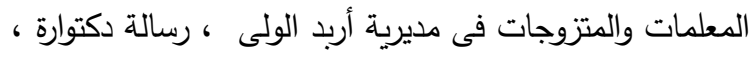

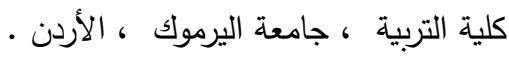

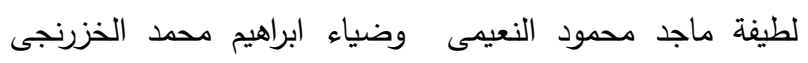

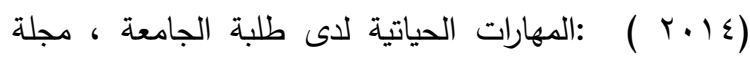

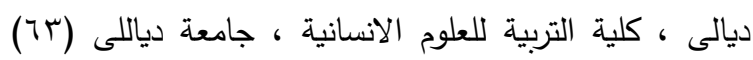
$.0 . r-\Sigma 74$

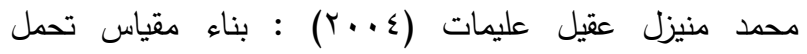

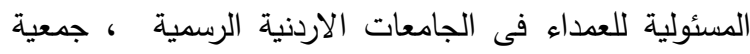

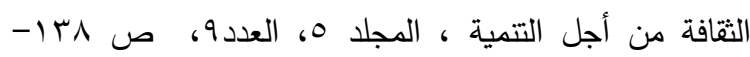
.174

محمد نبيل سعد ( ؟ . . †) : مؤشرات تخطيطية لتمية وعى المرأة

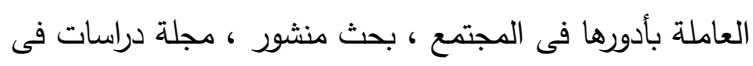

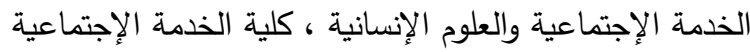
، جامعة حلون ، العدد (7 (1) .

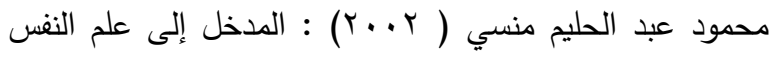
التعليمي الإسكندرية، مركز الإسكندرية للكتاب .

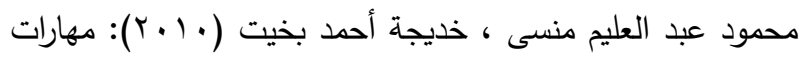

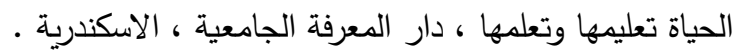
مصطفى عوفى (r...r) : خروج المرأة إلى ميدان العمل وأثره

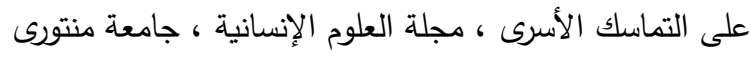
قسطنطينية ، العدد9 19.

معصومة خميس البلوشى (991 (99) : مقارنة الأنماط الاستهلاكية

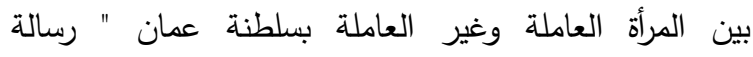

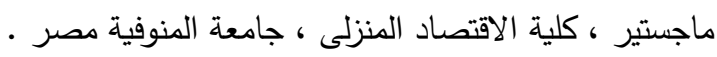

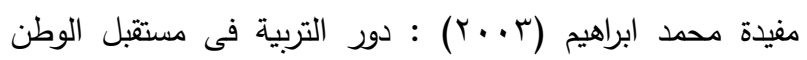

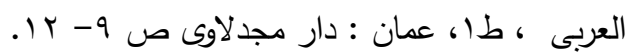

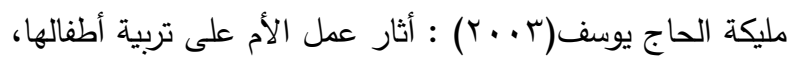

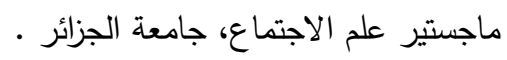

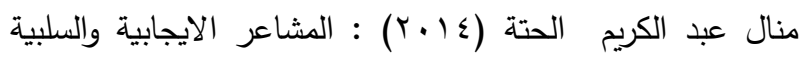

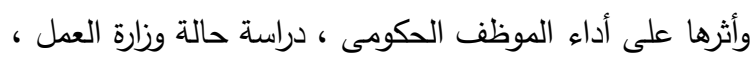

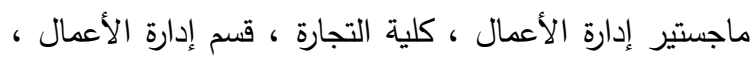

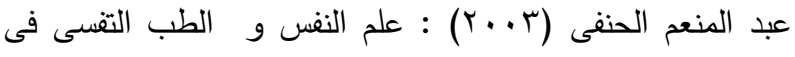
حياتتا اليومية المجلد الثاني ، مكتبة المدبولى القاهرة

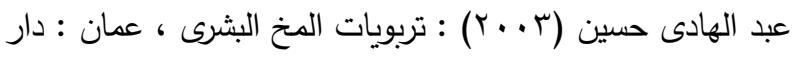

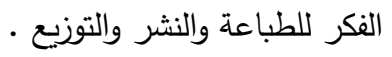

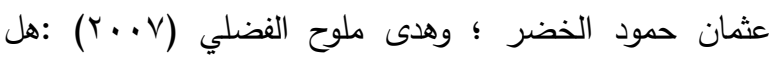
الأذكياء وجدانياً أكثر سعادة ؟مجلة العلوم الاجتماعية، الكويت، مجلس النشر العلمي، المجلد( ه广) ، العدد ( ب).

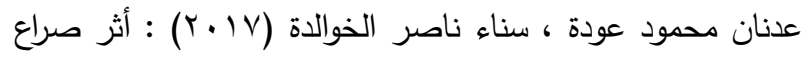
الأدوار فى التوافق الزواجى والرضا المهنى والضغوط النغاء ناهر النفية لدى الممرضات المتزوجات ، جمعية الاجتماعيين فى الثارقة

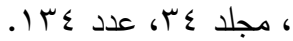
عصام عبد الرازق فتح الباب (r . . r) : تصميم مقياس المسئولية الاجتماعية لدى جماعات النشاط المدرسى اللاصفية , مجلة

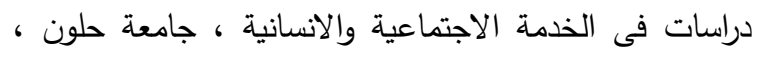

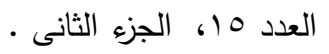

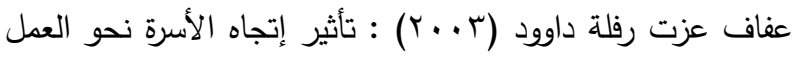
المنزلى على إدارة وقت ربة الأسرة ، رسالة ماجسيتر غير منشورة ، كلية التربية النوعية ، جامعة عين شمس .

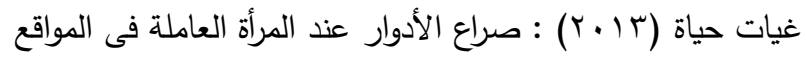

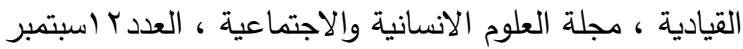

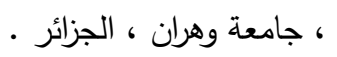

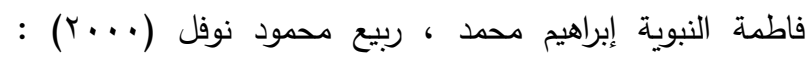

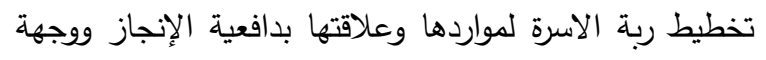

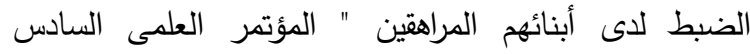

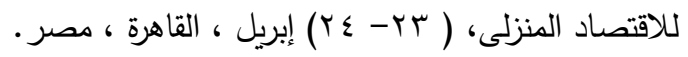

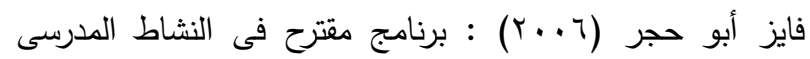

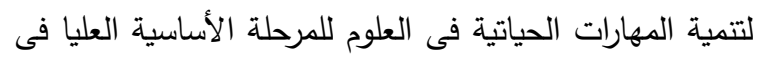
فلسطين ، رسالة دكتوارة غير منشورة ، كلية التربية برنامج

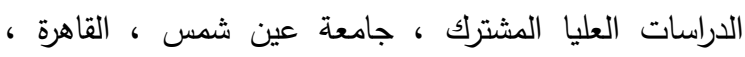

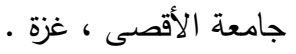

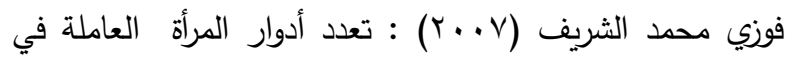
المجتم الليبي، وتأثير ذلك على الوظائف الأساسية للأسرة، رسالة ماجستير غير منشورة، كلية الآداب، جامعة الفاتح. 
وفاء شلبى، جيلان القبانى (994) : العلاقة بين إستخدام

الأدوات المنزلية الحديثة وبين كفاءة ربة الأسرة فى إدارة ،

$$
\text { مجلة الاقتصاد المنزلى ع (^) ، جامعة حلون. }
$$

Abdel Hadiel Gohary : Essays on Sociology and Social work, Cairo, Nahdhat

Elshark , 2003 , p 39 .

Aditi Aeran, Ravindra Kumar, Impact on life of women employees in education sector,

Indian Journal of Scientific Research, Global Academic Society, 6 (1), 2015.

Brown, S.C.(2004): Learning across campus: How college facilitates the development of wisdom, Journal of student development, 45, 134-148.

Christiana ( 2013). Work -Family role conflict among academic women in Nigerian Public Universities. The 2013 WE International Academic Conference proceedings, Orlando, USA

Cinamon ,R .(2004):Cender differencesnin the importance of work and Family roles: implications for work- family conflict. Sex Roles: Ajournal of Research.

Cinamon ,R.G.and Rich,Y.(2004):Conflict and Facilitation in Work - Family relations among teachers .Poster retrieved on May 7, 2007,from :

http //www. Tau.ac . /education/ahomepg/ Cinamon/ APA \%202006.ppt

Cynthia j Patel(2006):Working Mothers: Family- work Conflict,Job Performance And Family/Work Variables,SA Journal of Industustrial Psychology,32(2)39-45

Dombrowki,jhll.j,( 2000) The political economy of family : A study of household time decision Thesise, $\mathrm{Ph}, \mathrm{D}$, Unoversisty of Missouri, Columbia

Gray, M (1997): An Investigation of the job a Belated Stressors\& Department Chairpersons in A Selected Ceramicist college System (Doctoral Dissertations, Texas Southern University, Ordennr NO: Aac 98099908 pro Quest 3379- Dissertation A bstracts Interational, A58, 09

89- Grant, Louise( 2014): Hearts and Mind: Aspects of Empathy and Wellbeing in Social Work Educatioo, 33 (3) , 338-352

Hasegawa,Yuka,(2010): Adjustment of time allocatiom and daily emotiobal experience during the transition ti the role of working mother, Ph D Nagoya University ,Japan

Huang, Y.E.,Hammer,L.B., Neal,M.B.,\&Perrin,N.( 2004):The relationship between work- to- family and family- to work conflict :A longitudinal study. Journal of Family and Economic Lssues, 25,79-100

Kodagoda, Thila kshi (2010) family stress of women managers: Experience from banking sactor in Lanka, International Joumal of Management and Enterprise Deve Iopment, 9.

Kumari , V., Problems and Challenges Faced by Urban Working Women In India , Master
منال مرسى الشامى (0 . . †) : إدارة وقت ربة الأسرة العاملة وأثره على النمو الإجتماعى ، رسالة دكتوارة ، قسم إدارة المنزل والمؤسسات ، كلية الاقتصاد المنزلى ، جامعة المنوفية ،
منيرة بنت صالح الضحيان (T ( + ( ) : مجلة العلوم الزراعية ، كلية

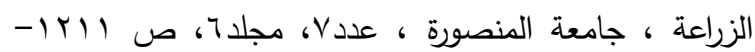

.1411

مهدية أحمد رمضان (Y. . . (Y) : المستوى المعرفى والمهارى للريفيات فى بعض مجالات الاقتصاد المنزلى بمركز كفر الثيخ، رسالة ماجستير فى العلوم الزراعية ، قسم الإرشاد الزراعى ، كلية الزراعة ، جامعة كفر الثيخ ، طنطا

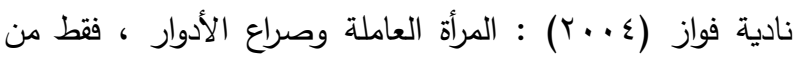
الرجال يقدمون المساعدة لزوجاتهم العاملات . 1\% أطلع عليه http//ww.alwatan.comr.. . $\varepsilon / / r / / 1$

نجيب نصر ( ؟ . . ץ): إدارة الوقت فى ضوء تطور علوم الإدارة الحديثة مجلة المهندين ، العدد OV9، نقابة المهندسين نجاه عبد الله مليبارى (999 (1)): إدارة المرأة العاملة وغير العاملة لمورد الوقت وأثر ذلك على تتشئة الاطفال فى مرحلة الطفولة المبكرة " رسالة ماجستير ، قسم السكن وإدارة المنزل ، كلية التربية للاقتصاد المنزلى والتربية الفنية ، جدة ، السعودية . هويدا حنفى (r ( ب) : مقياس إدارة الذات القاهرة ، مكتبة الانجلو

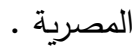

وجيدة محمد نصر حماد (991 (1) : دراسة مقارنة لتحليل وقت المرأة العاملة وغير العاملة بالمنوفية ، رسالة ماجستير ، قسم

إدارة المنزل والمؤسسات ، كلية الاقتصاد المنزلى ، جامعة المنوفية ، مصر

وجيدة محمد نصر حماد (11 • (Y) : أحداث الحياة الضاغطة لدى ربة الأسرة وعلاقتها ببعض الموارد الأسرية ، المؤتمر السنوى السادس عشر للارشاد النفسى ، الارشاد النفسى وإدارة التغيير ، مصر بعد ثورة Oب يناير، مركز الارشاد النفسى ،جامعة عين شمس.

وسام درويش بريك (ع ا . r) : تعدد الأدوار وعلاقته بصحة المرأة

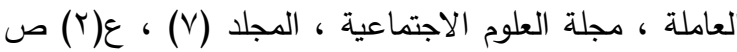


shallom , B (2013). Combiling Multiple Role among High Position W oman in Isreal, as Seen by the Woman Her Husband and a Child, Jornal Internarional Women Studies, Vol (14), No1.

Simon,M.,Kummerling,A.and Hasselhorn,H (2004): Work hom conflict in the European nursing profession. International Journal of Occapational and Environmental Health , 10(4),394-391.

Sponsil, Fallon ( 2008 ) :The Balance Between Paid Work and Home Responsibilities Personal Problem, Psychological Journal

Tierney, P., \& Farmer, S.M. (2002). Creative Self- Efficacy. Its potential antecedents and relationship to creative performance,Academy of management journal, 45 (6), 1137-1148

UNICEF (2006). for Every Child Health Education Quality Protection Advance Humanity, which skills are life skills? Module 7, Life Kills Retrieved, may 4-2013 from: http://www.unicef.org/lifeskills/undex_whichskills.html

World Health Organization, Life Skills Education in Schools, Division of Mental- Health Publication, 2007, p.6.
Thesis , National Institute of Technology Rourkela , Odisha , 2014.

Morett C.\& Rosenbaum E. (2007):" The Effect Of Shift Work On Parental InteractionWith Children, Marital Quality, And Depression. " Extended Abstract Submitted For Presentation At The2007Annual Department Of Sociology And Anthropology ,Fordham University441 E. Fordham Rd.

Narayanan\& Savarimuthu, ( 2013):Work Family conflict -An exploratory study of the of the dependents child age working Review of business \& economics research, vol (2) 1

Rasoala,C; Danienlssona, H\& Tomas, j(2012): Empathy among students in engineering programmes, European Journal of Engineering Education , 37(5),427-435

Robinson B.\&FlowersC\& Carroll J.(2001): "Work Stress Andmarriage:A Theoretical Model Examining The Relation shipbetween Work Holism And Marital Cohesion". International Of Stress Management .Voi.8.(No.2).

Sariati,A.and ,Martin,S.(2003):Work - family confict: a survey of Singaporean workers .Singapore Management Review 25(1),35- 53 


\title{
ABSTRACT \\ Life skills and their relationship with family roles conflict for a sample of working women
}

\author{
Doaa Awadeen Ibrahim , Abeer Moheb Abdel Moneim
}

The objective of the research is to know the relationship of life skills (Feeling control, time management, sympathy, taking over responsibility) the total with family roles conflict for a sample of working women (role conflict as a wife, role conflict as a mother, role conflict in doing household tasks.) and The total .The research tools -represented in the primary data form and the two questionnaires of life skills and family roles conflict- are applied on an intentional sample of 238 of working wives belonging to different social and economic levels. The research followed the descriptive and analytical method. The data was analyzed and the appropriate statistical treatment were performed using (Spss) program. The research has concluded that: there is a negative correlation of statistical significances of life skills (Feeling control, time management, sympathy, taking over responsibility) the total and family roles conflict for a sample of working women (role conflict as a wife, role conflict as a mother, role conflict in doing household tasks.). The research has also concluded that there are no differences in statistical significances between the average scores of the sample of the research in life skills (in terms of its axes and total) according to accommodation except for time management, it showed some higher levels in favor of urban inhabitants. As for sympathy results showed higher levels in favor of rural residents. There are differences in statistical significances between the average scores of the sample of the research in life skills (the axes and the total) in favor of older working woman, and also for long-duration marriages. There are no differences in statistical significances between the average scores of the sample of the research in life skills (in terms of its axes and total) according to the number of children, husband's level of education. There are differences in statistical significances between the average scores of the sample of the research in life skills (with regards to time management, holding responsibility and the total) in favor of wife's higher level of education; whereas, There are no differences in statistical significances between the average scores of the sample of the research in terms of sympathy and feelings control according to wife's education. There are no differences in statistical significances between the average scores of the sample of the research in working woman's life skills in terms of family income except for time management There are differences in statistical significances between the average scores of the sample of the research in favor of higher income. There are differences in statistical significances between the average scores of the sample of the research in conflict of family roles (in terms of the axes and the total) in favor of urban residents except for role conflict as a mother for which there are no difference with regards to place of accommodation. There are differences in statistical significances between the average scores of the sample of the research in conflict of family roles (in terms of the axes and the total) in favor of wife's younger age. There are no differences in statistical significances between the average scores of the sample of the research in conflict of family roles (in terms of the axes and the total) according to years of marriage. There are differences in statistical significances between the average scores of the sample of the research in conflict of family roles (in terms of the axes and the total) in favor of larger number of children and lower level of education of husband and wife, and family 's lower monthly income.

The research recommended the following: Providing the atmosphere and all necessary supplies that can reduce the burdens of wife's house chores and allocating more time for her duties through providing the package of community services such as nurseries, house services institutions, raising the awareness of working woman by planning guiding programs that can be provided by various social media, specially visual media which enables her to overcome the difficulties she faces to coordinate between her work outside the house and what she faces from roles conflict inside the house. 